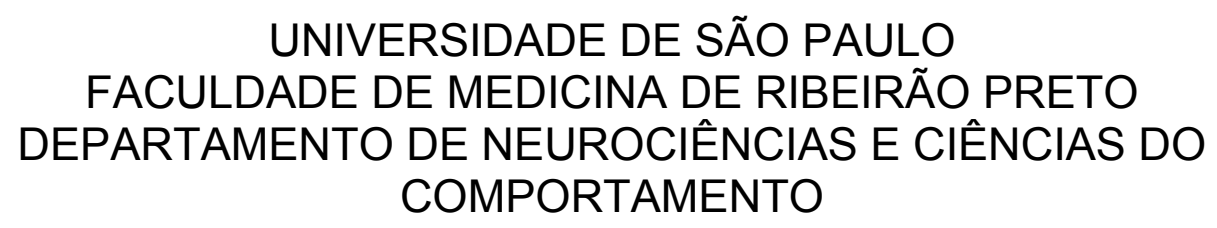

MARIANA RAQUEL MONTEIRO

PADRÕES DE EXPRESSÃO DE PROTEÍNAS ESTRUTURAIS E PLASTICIDADE NA EPILEPSIA DO LOBO TEMPORAL

RIBEIRÃO PRETO - SP

2011 


\title{
PADRÕES DE EXPRESSÃO DE PROTEÍNAS ESTRUTURAIS E PLASTICIDADE NA EPILEPSIA DO LOBO TEMPORAL
}

\author{
Dissertação apresentada ao Departamento de \\ Neurociências e Ciências do \\ Comportamento da Faculdade de Medicina de Ribeirão \\ Preto para obtenção do título de Mestre em Ciências - \\ modalidade \\ Neurociências.
}

Orientador: Prof. Dr. João Pereira Leite 
FICHA CATALOGRÁFICA

Monteiro, Mariana Raquel

Padrões de expressão de proteínas estruturais e plasticidade na epilepsia do lobo temporal.

Ribeirão Preto, 2011.

102 páginas

Dissertação de Mestrado, apresentada à Faculdade de Medicina de Ribeirão

Preto/USP. Área de concentração: Neurologia/Neurociências

Orientador: Leite, João Pereira.

1. Epilepsia do lobo temporal. 2. Modelo de lítio pilocarpina. 3. Proteínas estruturais. 4. Neobrotamento axonal das fibras musgosas. 


\title{
FOLHA DE APROVAÇÃO
}

Mariana Raquel Monteiro

\section{Padrões de expressão de proteínas estruturais e plasticidade na epilepsia do lobo temporal}

\begin{abstract}
Dissertação apresentada ao Departamento de Neurociências e Ciências do Comportamento da Faculdade de Medicina de Ribeirão Preto, como parte das exigências para a obtenção do título de Mestre em Ciências - modalidade

Neurociências.
\end{abstract}

Comissão Julgadora

Prof. Dr. Jorge Eduardo Moreira

Prof. Dra. Órfa Yineth Galvis Alonso

Prof. Dr. João Pereira Leite Orientador 


\section{DEDICATÓRIA}

Dedico este trabalho à minha família, meus pais Mauro e Fátima por todos os ensinamentos da vida, ao meu irmão Marcel por ser meu grande amigo e companheiro em todos os momentos e ao Tiago por me fazer uma pessoa

melhor a cada dia

Dedico ainda à minha grande amiga Ludmyla Kandratavicius por todos os ensinamentos em todas as esferas da minha vida... 


\section{AGRADECIMENTOS}

Agradeço:

Ao meu orientador, Prof. Dr. João Pereira Leite, por ter me dado esta oportunidade e ter confiado em mim para a realização deste trabalho

À técnica de nosso laboratório (Renata Scandiuzzi) pela grande amizade e disponibilidade para me ajudar sempre que precisei.

À todos os membros do Laboratório de Investigação em Epilepsia em especial meu amigo José Eduardo por todos os ensinamentos e pela disposição e atenção sempre que precisei.

À Raquel Araujo do Val da Silva pela colaboração com o material animal utilizado neste trabalho.

À secretária do programa de pós-graduação em Neurologia/Neurociências, Silvana Lo Turco, pela forma sempre prestativa em nos atender.

Ao doutor Alan Eckeli por me auxiliar em algumas etapas destes trabalho.

À minha amiga de infância, Lígia, que está sempre disposta a me ouvir e está comigo em todos os momentos da minha vida.

À todos os meus amigos, que fazem parte da minha vida e que de alguma forma participaram comigo deste trabalho.

À Fundação de Amparo à Pesquisa do Estado de São Paulo (FAPESP), Cooperação Interinstitucional de Apoio a Pesquisas sobre o Cérebro (CInAPCe) da FAPESP, Conselho Nacional de Desenvolvimento Científico e Tecnológico (CNPq), Coordenação de Aperfeiçoamento de Pessoal de Nível Superior (CAPES), Fundação de Apoio ao Ensino, Pesquisa e Assistência do Hospital das Clínicas da Faculdade de Medicina de Ribeirão Preto da Universidade de São Paulo (FAEPA), por financiar, direta ou indiretamente, o presente trabalho. 


\section{RESUMO}

Introdução: A epilepsia do lobo temporal mesial (ELTM) é a forma mais comum de epilepsia na população adulta, tendo a esclerose hipocampal como principal substrato neuropatológico. Uma elevada proporção dos pacientes com ELTM apresentam história familiar positiva para a epilepsia, sugerindo a participação de fatores genéticos nesta síndrome. O citoesqueleto neuronal é essencial para os processos fisiológicos das células nervosas e crises epilépticas parecem afetar esta estrutura. O citoesqueleto neuronal possui importantes componentes regulatórios, dentre eles as proteínas associadas aos microtúbulos do tipo 2 (MAP2) e tau. Objetivos: Avaliar a densidade neuronal (células imunomarcadas com NeuN), neobrotamento das fibras musgosas (por histoquímica de neo-Timm) e a expressão imunohistoquímica das proteínas MAP2 e tau no hipocampo de casos cirúrgicos de ELTM (subtipos familiar e esporádico) e controles. As mesmas análises foram conduzidas no modelo animal de lítiopilocarpina. Métodos: Casos ELTM $(n=38)$ foram divididos em ELTM familiar $(n=20)$ e ETLM esporádica $(n=18)$. Hipocampos controles $(n=10)$ foram provenientes de necrópsias de sujeitos sem histórico de problemas neurológicos. No modelo animal de lítio-pilocarpina, animais submetidos ao status epilepticus (SE) foram sacrificados nos seguintes tempos pós-SE: 1, 7, 15 e 60 dias e classificados como grupos SE1, SE7, SE15 e SE60. Animais controle foram injetados com salina. Resultados: O grupo ELTM apresentou menor densidade neuronal que o controle nas regiões da camada granular, hilo, CA4, CA3, CA1 e prosubículo. O grupo ELTM mostrou maior valor de cinza da histoquímica de neo-Timm na camada granular, molecular interna e molecular externa e maior espessura do neobrotamento axonal na camada molecular interna em relação ao grupo controle. O grupo ELTM esporádica teve maior valor de cinza da histoquímica de neo-Timm e tendência à maior espessura do neobrotamento que o grupo ELTM familiar na camada molecular interna. O grupo ELTM apresentou menor expressão de MAP2 que o grupo controle no hilo, CA4, CA3, CA1 e prosubículo e maior expressão que o controle na camada granular, CA2 e parasubículo. O grupo ELTM esporádica teve maior expressão de MAP2 que o grupo ELTM familiar em CA1 e córtex entorrinal. O grupo ELTM apresentou maior expressão de tau que o grupo controle nas regiões da camada granular, hilo, CA3, CA2 e córtex entorrinal. O grupo ELTM esporádica demonstrou menor imunorreatividade para tau que o grupo ELTM familiar no córtex entorrinal. No modelo de lítio-pilocarpina, os grupos submetidos ao SE apresentaram menor densidade neuronal e maior neobrotamento que o grupo salina. Quanto à expressão de MAP2, os grupos SE60 e SE15 apresentaram maiores valores de expressão que os demais grupos em todas as regiões analisadas. A expressão de tau em CA3 não foi diferente entre os grupos animais analisados. Conclusão: Nossos resultados existem perda neuronal, reorganização sináptica das fibras musgosas e alterações na expressão de proteínas MAP2 e tau no hipocampo de pacientes com ELTM. Dentre os casos ELTM, encontramos diferenças no neobrotamento de fibras musgosas e na expressão de MAP2 e tau entre os grupos ELTM familiar e esporádica, indicando que estes grupos se apresentam de forma distinta em relação à epilepsia. Encontramos resultados 
semelhantes em relação à densidade neuronal e o neobrotamento de fibras musgosas entre pacientes com ELTM e no modelo experimental. Porém, em relação à expressão das proteínas MAP2 e tau, encontramos algumas diferenças entre humanos e animais com ELTM. Nossos resultados sugerem que apesar do modelo de epilepsia induzida por lítio-pilocarpina ser relevante para o estudo da ELTM humana e mimetizar importantes aspectos neuropatológicos, a correspondência quanto à expressão de algumas proteínas estruturais não é completa. Estudos adicionais de expressão de proteínas do citoesqueleto em outros modelos animais de ELTM serão de grande importância para o melhor entendimento do processo epileptogênco. 


\section{ABSTRACT}

Introduction: Mesial temporal lobe epilepsy (MTLE) is the most common form of epilepsy in adults and has hippocampal sclerosis as the main pathological substrate. A high proportion of patients with MTLE have positive familial history for epilepsy, suggesting the involvement of genetic factors in this syndrome. Seizures may affect the neuronal cytoskeleton, an structure that is essential in the physiological processes of nerve cells. Components of the neuronal cytoskeleton include microtubule-associated protein type 2 (MAP2) and tau. Objectives: Our aim was to evaluate neuronal density, mossy fiber sprouting and immunohistochemical expression of MAP2 and tau in the hippocampus of surgical cases of MTLE (familial and sporadic subtypes) and controls. The same analysis were conducted in the MTLE lithiumpilocarpine animal model.Methods: MTLE cases $(n=38)$ were divided into familial MTLE $(n=$ $20)$ and sporadic MTLE $(n=18)$. Control hippocampi $(n=10)$ were obtained from autopsies of subjects without history of epilepsy. In the lithium-pilocarpine animal model, male Wistar rats were submitted to status epilepticus (SE) and were killed at the following post-SE days: 1, 7, 15 and 60, and were further classified SE1, SE7, SE15 and SE60. Control animals were injected with saline. Results: MTLE showed decreased neuronal density than controls in the granular layer, hilus, CA4, CA3, CA1 and prosubiculum. MTLE group showed increased neo-Timm gray value in the granular layer, inner and outer molecular layer, as well as increased mossy fiber length of mossy fiber in the inner molecular layer when compared to controls. Sporadic MTLE specimens exhibited increased inner molecular layer gray value than familial MTLE. MTLE hihppocampi showed decreased MAP2 expression in the hilus, CA4, CA3, CA1 and prosubiculum. In the granular layer, CA2 and parasubiculum, MAP2 expression was higher in MTLE specimens than in controls. CA1 and entorhinal cortex from sporadic MTLE hippocampi showed increased MAP2 expression than familial MTLE. Tau expression was increased in the granular layer, hilus, CA3, CA2 and entorhinal cortex of MTLE specimens. Sporadic MTLE exhibited lower tau immunoreactivity in the entorhinal cortex than familial MTLE. In the lithiumpilocarpine animal model, rats submitted to SE presented lower values of neuronal density and mossy fiber sprouting than controls. SE15 and SE60 showed increased MAP2 expression in all hippocampal subfields. Tau expression in CA3 was not different among the groups. Conclusion: Our results indicate that besides neuronal loss and axonal sprouting, MTLE specimens also exhibit dendritic abnormalities related to MAP2 expression. Increased tau immunoreactivity in epileptogenic hippocampi indicates possible abnormal expression related to mossy fiber sprouting in chronic MTLE. We found differential sprouting, MAP2 and tau expression between sporadic and familial MTLE. It is possible that different genetic background might result in somehow distinct neuropathological substrates between the two MTLE subtypes, although their clinical manifestation is quite similar. While neuronal loss and axonal sprouting profiles in human MTLE and chronic phase of the lithium-pilocarpine animal model are comparable, we could not find corresponding results regarding MAP2 and tau expression. 
Several studies have shown that chemo-convulsant as pilocarpine and kainic acid result in widespread brain epileptic discharges, which are different from the more focal hippocampal discharges seen in human MTLE. Despite its limitations, the lithium-pilocarpine model stands as an important and widely used animal model of epilepsy. Besides that, other animal models in which ictal discharges and lesions are more limited to the hippocampal formation might better mimic what we see in human MTLE. 


\section{ÍNDICE}

ABSTRACT

1. INTRODUÇÃO 17

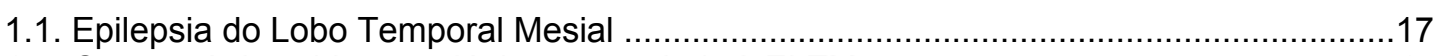

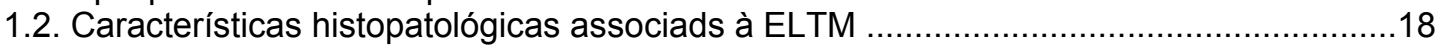

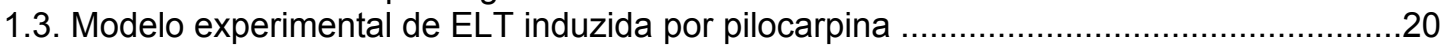

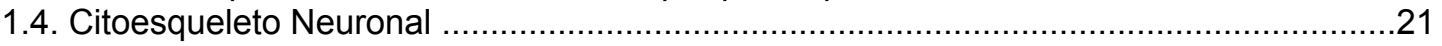

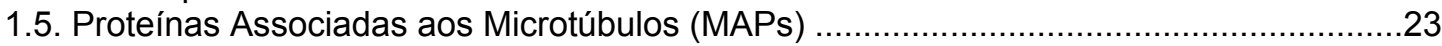

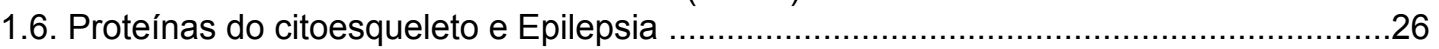

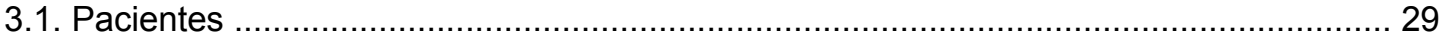

3.1.1. Processamento do tecido cerebral humano ................................................... 30

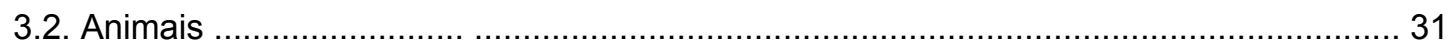

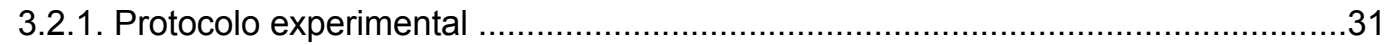

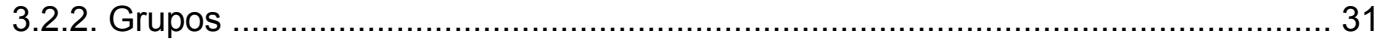

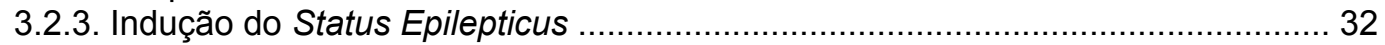

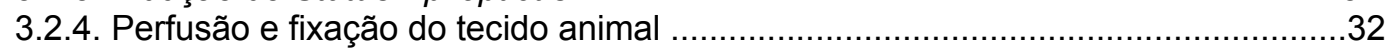

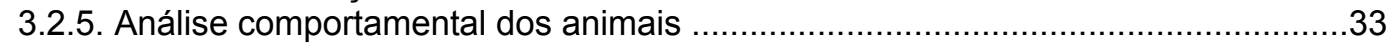

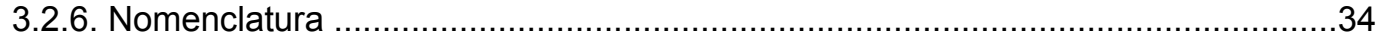

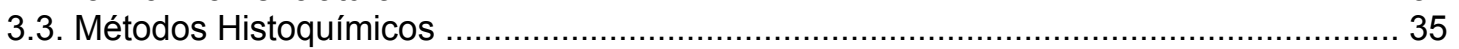

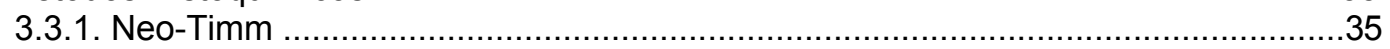

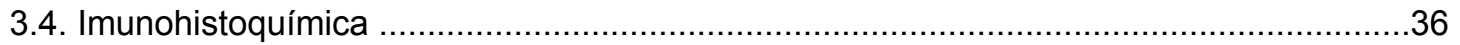

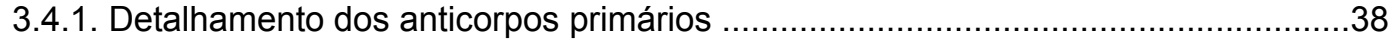

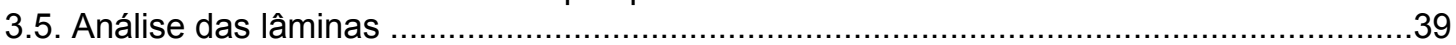

3.5.1. Análise da intensidade da marcação das imunohistoquímicas .............................39

3.5.2. Contagem Neuronal ........................................................................................ 40

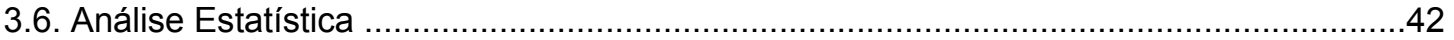

4. RESULTADOS

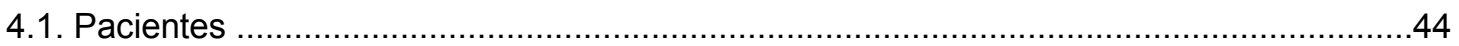

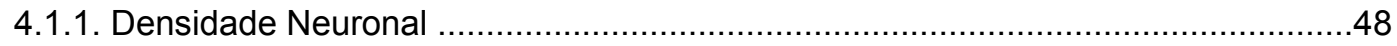

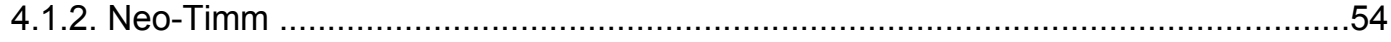

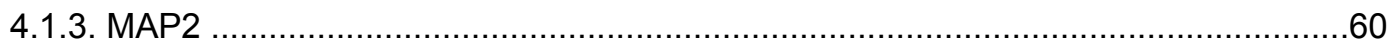

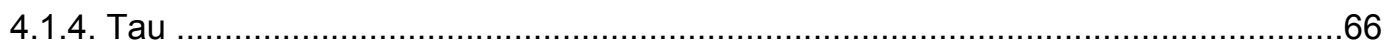

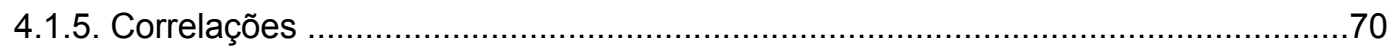

4.1.5.1. Variáveis Clínicas ........................................................................70

4.1.5.2. Expressão das proteínas do citoesqueleto, densidade neuronal e Timm .

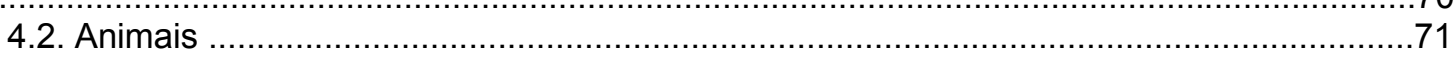

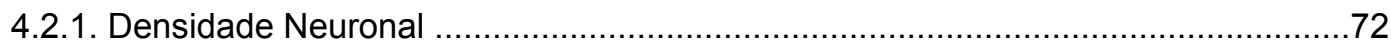

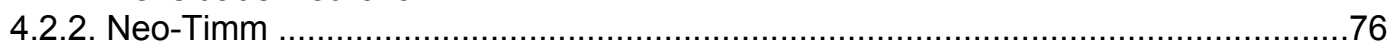

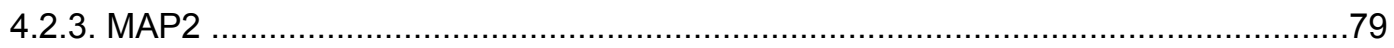




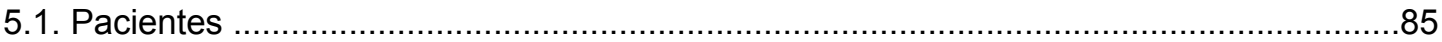

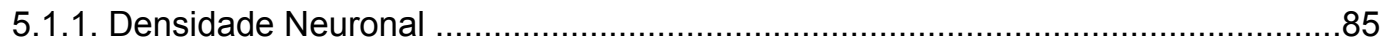

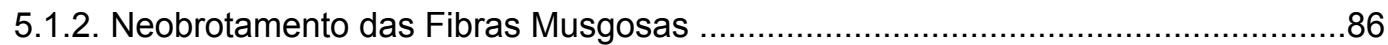

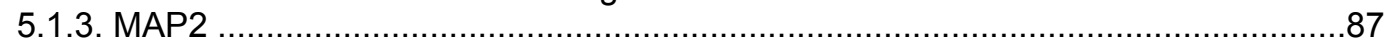

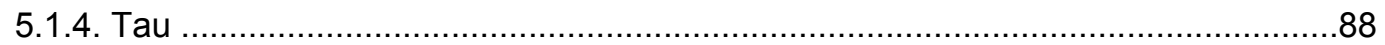

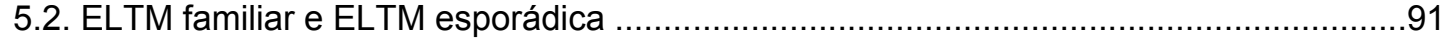

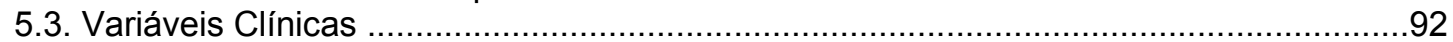

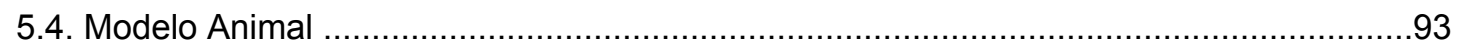

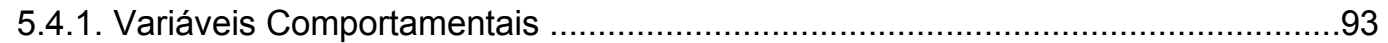

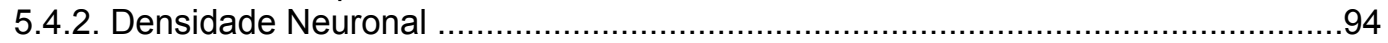

5.4.3. Neobrotamento das Fibras Musgosas ..............................................................94

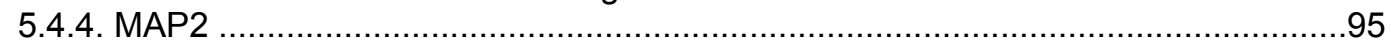

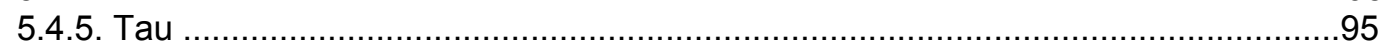

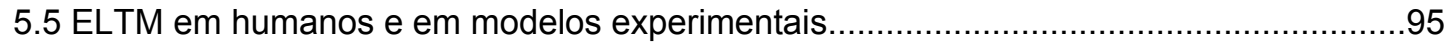

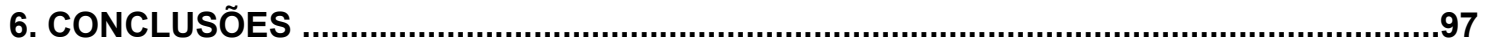

7. BIBLIOGRAFIA

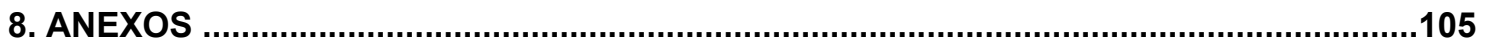

Comitê de Ética em Pesquisa do HCRP e da FMRP (USP)...........................................105

Comitê de Ética em Experimentação Animal ..............................................................106

Banco de Amostras de Tecido Cerebral ..................................................................107

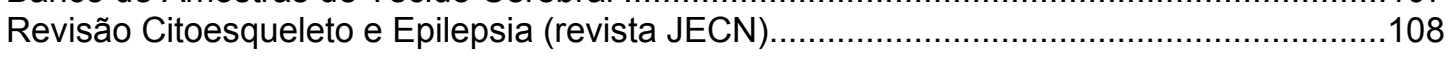




\section{LISTA DE ABREVIAÇÕES}

CA1: Corno de Ammon 1 (subregião do hipocampo)

CA2: Corno de Ammon 2 (subregião do hipocampo)

CA3: Corno de Ammon 3 (subregião do hipocampo)

CA4: Corno de Ammon 4 (subregião do hipocampo)

CERs: crises espontâneas e recorrentes

CG: camada granular

CMe: camada molecular externa

CMi: camada molecular interna

DAEs: drogas antiepilépticas

EEG: eletroencefalograna

EH: esclerose hipocampal

ELT: epilepsia do lobo temporal

ELTM: epilepsia do lobo temporal mesial

IOD: densidade óptica integrada

IPI: insulto precipitante inicial

MAPs: proteínas associadas aos microtúbulos

MAP2: proteína associada aos microtúbulos do tipo 2

NF: neurofilamento

NMDA N-metil-D-aspartato

QI: quociente de inteligência

RM: ressonância magnética

RNAm: ácido ribonucléico mensageiro

SE: status epilepticus

SNC: sistema nervoso central 


\section{LISTA DE TABELAS}

Tabela 1. Descrição das variáveis clínicas dos pacientes ELTM.

Tabela 2. Descrição dos valores das variáveis clínicas entre os grupos ELTM familiar e ELTM esporádica.

Tabela 3. Descrição das variáveis clínicas dos casos controle.

Tabela 4. Descrição dos valores de densidade neuronal entre os grupos ELTM e controle em todas as regiões do hipocampo.

Tabela 5. Descrição dos valores de densidade neuronal entre os grupos ELTM familiar e esporádica em toda formação hipocampal.

Tabela 6. Descrição dos valores de cinza da marcação de Neo-Timm dos grupos ELTM e controle.

Tabela 7. Descrição dos valores de espessura de camadas/ neobrotamento das fibras musgosas entre os grupos ELTM e controle.

Tabela 8. Descrição dos valores de cinza da marcação de neo-Timm entre os grupos ELTM familiar e esporádica.

Tabela 9. Descrição dos valores de espessura de camadas/ neobrotamento das fibras musgosas entre os grupos ELTM familiar e esporádica.

Tabela 10. Descrição dos valores da expressão de MAP2 entre os grupos ELTM e controle na formação hipocampal.

Tabela 11. Descrição dos valores de expressão de MAP2 entre os grupos ELTM familiar e esporádica.......

Tabela 12. Descrição dos valores de expressão de tau entre os grupos ELTM e controle. 68

Tabela 13. Descrição dos valores de expressão de tau entre os grupos ELTM familiar e esporádica.

Tabela 14. Comparação entre os resultados de correlação encontrados entre os pacientes ELTM e os casos controles.

Tabela 15. Descrição dos dados comportamentais de animais submetidos a SE (SE1, 7, 15 e 60 dias) e animais controle (salina).

Tabela 16. Descrição dos valores de densidade neuronal entre os grupos animais em todas as regiões do hipocampo.

Tabela 17. Descrição dos valores de cinza da marcação de Neo-Timm entre os grupos animais.

Tabela 18. Descrição dos valores de expressão de MAP2 entre os grupos animais nas regiões hipocampais.

Tabela 19. Descrição dos valores de expressão da proteína tau na região de CA3 de ratos. 


\section{LISTA DE FIGURAS}

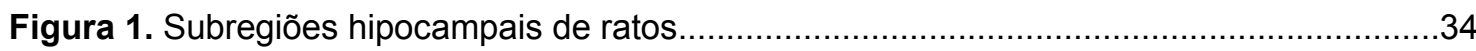

Figura 2. Subregiões hipocampais de ratos com nomenclatura modificada.............................35

Figura 3. Demarcação e quantificações realizadas com o auxílio do programa Image J..........40

Figura 4. Formação hipocampal humana imunomarcada com NeuN.

Figura 5. Imunorreatividade para NeuN nas diferentes subregiões do hipocampo nos grupos ELTM e controle.

Figura 6. Densidade neuronal nas diferentes subregiões do hipocampo de pacientes epilépticos (ELTM) e grupo controle.

Figura 7. Densidade neuronal nas subregiões do hipocampo em lâminas submetidas à imunohistoquímica para NeuN entre os grupos com ELTM familiar, esporádica e controles.....53

Figura 8. Secções hipocampais submetidas à histoquímica de Neo-Timm .54

Figura 9. Medidas de valor de cinza em lâminas submetidas à histoquímica de Neo-Timm em diferentes subregiões da Fascia Dentata dos grupos ELTM e controle.

Figura 10. Medidas de espessura em secções submetidas à histoquímica de Neo-Timm em subregiões da Fascia Dentata dos grupos ELTM e controle.

Figura 11. Medidas do valor de cinza nas subregiões da Fascia Dentata em lâminas submetidas à histoquímica de Neo-Timm

Figura 12. Medidas de espessura em diferentes subregiões da Fascia Dentata em lâminas submetidas à histoquímica de Neo-Timm

Figura 13. Imagem ilustrativa da expressão de MAP2 na formação hipocampal de pacientes com ELTM e controles.

Figura 14. Expressão de MAP2 na formação hipocampal de pacientes epilépticos (ELTM) comparados aos controles.

Figura 15. Expressão de MAP2 nas diferentes subregiões do hipocampo entre os grupos com

ELTM familiar, esporádica e controle.

Figura 16. Imagem ilustrativa da expressão da proteína tau em secções hipocampais provenientes de casos ELTM e controle.

Figura 17. Expressão de tau nas subregiões do hipocampo entre os grupos ELTM e controle.

Figura 18. Expressão de tau nas diferentes subregiões do hipocampo entre os casos de ELTM familiar, esporádica e controle.

Figura 19. Imagem ilustrativa da imunohistoquímica para NeuN em hipocampo de ratos........74

Figura 20. Densidade neuronal entre as diferentes regiões do hipocampo de ratos.................75

Figura 21. Imagens ilustrativas da histoquímica de neo-timm no tecido animal.......................77

Figura 22. Medidas de valor de cinza nas diferentes subregiões do hipocampo de ratos..........78 
Figura 23. Imunorreatividade para MAP2 na camada granular e CA2 de ratos.

Figura 24. Expressão de MAP2 nas subregiões do hipocampo de animais experimentais.......80

Figura 25. Figura ilustrativa da expressão de tau na região de CA3 do hipocampo animal......82

Figura 26. Expressão de tau na região de CA3 de animais. . .83 


\section{INTRODUÇÃO}

\subsection{Epilepsia do Lobo Temporal Mesial}

O termo epilepsia refere-se a um desequilíbrio da função cerebral caracterizada pela ocorrência de crises epilépticas espontâneas e recorrentes (McNamara 1994). $\mathrm{Na}$ epilepsia, as crises são consequência de descargas sincrônicas, rítmicas, excessivas e transitórias das células nervosas (Berg et al 2010; Guerreiro et al 2000; McNamara 1994). A síndrome epiléptica refere-se a um conjunto de sintomas que frequentemente ocorrem juntos e incluem os fatores: tipo, etiologia e idade de início das crises (Berg et al 2010).

A epilepsia do lobo temporal mesial (ELTM) é a forma mais comum de epilepsia focal na população adulta, compreendendo $40 \%$ dos casos. Na ELTM, as crises epilépticas são originadas no hipocampo, podendo também originar-se em estruturas extra-hipocampais e propagar-se para o hipocampo (Arzimanoglou et al 2002; Swanson 1995). Os pacientes com ELTM apresentam frequentemente um insulto precipitante inicial (IPI) nos primeiros anos de vida, podendo se apresentar como uma meningite, crise febril ou estado de mal epiléptico (Mathern et al 1995).

Além disso, uma elevada proporção de pacientes com ELTM e diminuição do volume hipocampal apresentam história familiar positiva para epilepsia, sugerindo a participação de fatores genéticos nesta síndrome (Andermann 1982; Andrade-Valenca et al 2008; Cendes et al 1998). A influência de fatores genéticos nas epilepsias sempre foi suspeitada, sendo que a ocorrência familiar foi inicialmente demonstrada nas epilepsias generalizadas (Berkovic et al 1998; Ottman et al 1996) e nas epilepsias parciais (Berkovic \& Scheffer 1999; Cendes et al 1998; Kinton et al 2002). Clinicamente, muitas destas síndromes se apresentam de forma heterogênea, o que pode dificultar o reconhecimento da recorrência familiar. 


\subsection{Características histopatológicas associadas à ELTM}

Características histopatológicas comuns na ELTM incluem a esclerose hipocampal (EH) associada a um neobrotamento anormal das fibras musgosas na camada molecular interna do giro denteado (Babb et al 1991; Houser 1990). Meyer et al. (1954) propuseram que a EH seria resultado de insultos cerebrais ocorridos na infância, como a convulsão febril. Porém, estudos epidemiológicos indicam que o risco de desenvolvimento de ELTM após convulsão febril é muito pequeno (Camfield et al 1994). Por outro lado, sabe-se que a EH está fortemente associada aos IPIs, reforçando o conceito de que a EH é uma condição patológica adquirida (Mathern et al 2002).

As fibras musgosas do giro denteado são constituídas por axônios das células granulares. Em condições fisiológicas, as fibras musgosas emitem prolongamentos para neurônios hilares e células piramidais de CA3 e CA4, bem como para as próprias células granulares (Amaral \& Insausti 1990). Porém, diante de uma perda celular intensa nessas regiões, como ocorre em pacientes com ELTM, as fibras musgosas sofrem alterações. Estas alterações incluem reorganização e neobrotamento para a camada molecular interna, formando novos terminais sinápticos com dendritos de interneurônios locais e também com dendritos das próprias células granulares. A autoinervação entre as células granulares pode gerar hiperexcitabilidade local, contribuindo para a patogênese da epilepsia (Cavazos \& Cross 2006).

O neobrotamento das fibras musgosas é um achado patológico típico na ELTM humana e em modelos experimentais de ELTM (Dudek et al 1994). O neobrotamento induzido por crise é dependente da síntese de proteínas estruturais associadas ao crescimento e/ou da reorganização de proteínas pré-existentes (Vaidya et al 2000).

Há inúmeras evidências da possibilidade do neobrotamento das fibras musgosas formar sinapses com células granulares e com interneurônios inibitórios. Com isso, três hipóteses são constantemente testadas, como revisto por Kandratavicius (2007): 1) Hipótese do neobrotamento induzido por perda celular, 2) Hipótese das células em cesto dormentes e 3) Hipótese da célula musgosa irritável. A hipótese do neobrotamento induzido por perda celular postula que a morte das células musgosas é o gatilho para o neobrotamento das fibras musgosas, cujos principais alvos eram as 
células musgosas agora inexistentes. Assim, as fibras musgosas emitiriam colaterais aberrantes formando sinapses excitatórias com os dendritos das próprias células granulares (Cavazos \& Cross 2006). A segunda hipótese sugere que a perda das células musgosas é importante por outra razão. A ausência delas removeria as sinapses excitatórias sobre interneurônios inibitórios, ou seja, as células em cesto inibiriam as células granulares, que assim se tornariam hipoativas ou dormentes (Sloviter et al 2003). A terceira hipótese enfatiza a sobrevivência das células musgosas e seu papel na amplificação dos padrões de atividades excitatórias das células granulares. Estudos eletrofisiológicos demonstraram aumento da excitabilidade das células musgosas seguido de trauma craniano (Santhakumar et al 2000) e crises induzidas por pilocarpina (Scharfman et al 2001). Porém, nenhuma das três teorias foi firmada até o presente como única verdadeira. É possível que tanto a perda quanto a sobrevivência de células hilares possam contribuir para a excitabilidade da circuitaria do giro denteado.

Segundo Ratzliff e colaboradores (2004) não se sabe se as alterações que ocorrem após as crises epilépticas são causadas pela perda das células hilares ou pelas mudanças que ocorrem subsequentes a essa perda. A perda de células hilares induzida experimentalmente, após trauma ou crises frequentes, ocorre junto de outras modificações. Essas modificações incluem mudanças na expressão gênica (BrooksKayal et al 2001; Kapur 2000) e alterações na conectividade causadas pelo neobrotamento anormal das fibras musgosas (Wuarin \& Dudek 2001).

Evidências da literatura sugerem que o neobrotamento das fibras musgosas possa ser um epifenômeno em relação à epilepsia. Estudos em modelo animal utilizando ciclohexamida, um inibidor de síntese protéica, que impede a formação do neobrotamento axonal, demonstraram que a presença ou ausência do brotamento não é indispensável para a ocorrência de crises (Longo \& Mello 1997; Longo et al 2002).

A hipótese de que o neobrotamento das fibras musgosas é um dos principais responsáveis por fornecer o substrato epileptogênico ao hipocampo é bastante conhecida na literatura. Esta hipótese é bastante consistente devido à coincidência temporal entre o surgimento do brotamento e o aparecimento das crises epiléticas. Este fenômeno pode ser observado na epilepsia humana (de Lanerolle et al 1989; Houser 
1990; 1999; Sutula et al 1989) e em modelos experimentais de ELT (Sutula et al 1989; Tauck \& Nadler 1985).

\subsection{Modelo experimental de ELT induzida por pilocarpina.}

Os modelos experimentais permitem um estudo controlado das diversas variáveis envolvidas no processo de epileptogênese, sendo importantes para a compreensão da ELT humana (Curia et al 2008; Guerreiro et al 2000; Leite et al 2002). Modelos animais de epilepsia podem ser induzidos por injeção local ou sistêmica de substâncias químicas convulsivantes, como o ácido caínico ou a pilocarpina. Segundo Harvey e Sloviter (2005), animais que sobrevivem a um episódio de SE e passam a ter crises recorrentes espontâneas (CERs) podem ser um modelo útil de ELT humana.

Um modelo experimental de ELT bastante utilizado baseia-se na injeção sistêmica ou intracerebral de pilocarpina. A pilocapina é um agonista de receptores colinérgicos muscarínicos, extraída de uma planta brasileira denominada Pilocarpus jaborandi (Clifford et al 1987). Experimentos com cultura de neurônios hipocampais demonstraram que a pilocarpina age através de receptores muscarínicos, causando um desequilíbrio entre as transmissões excitatórias e inibitórias, resultando na geração do SE (Priel \& Albuquerque 2002). No modelo da pilocarpina, alguns pesquisadores utilizam um pré-tratamento com cloreto de lítio, entre 19 e 24 horas antes da aplicação da pilocarpina. Isso potencializa a ação epileptogênica da pilocarpina, além de reduzir a quantidade de droga utilizada em até 10 vezes. Esta combinação de drogas diminui a mortalidade dos animais, produzindo o mesmo efeito patológico que altas doses da droga (Clifford et al 1987; Jope et al 1986).

O modelo clássico de epilepsia induzida por pilocarpina segue 3 fases após a injeção sistêmica de pilocarpina: 1) aguda, onde ocorre um status epilepticus (SE) duradouro; 2) latente, período em que o animal não apresenta manifestações comportamentais ou eletroencefálicas referentes as crises epilépticas; 3) crônica, é a fase que ocorre após a primeira crise espontânea, sendo caracterizada pelo surgimento das crises epilépticas espontâneas e recorrentes (CERs) (Leite et al 1990). 
O SE induzido por pilocarpina é caracterizado pelos comportamentos: salivação, piloereção, diurese, automatismos orofaciais, balanço da cabeça, clonia de patas, progredindo para convulsões mioclônicas recorrentes com elevação e queda. O tempo para iniciar o SE varia em média de 22 a 43 minutos em seguida da injeção da pilocarpina (Clifford et al 1987; Glien et al 2001). A maioria dos ratos que permanecem em SE por no mínimo 60 minutos, desenvolvem a fase crônica da epilepsia. A primeira CER acontece aproximadamente entre 5 e 40 dias após o SE (Cavalheiro 1995; Goffin et al 2007; Scorza et al 2009). Nestes modelos, a lesão neuronal produzida pelas crises epilépticas está localizada principalmente no hipocampo, córtex piriforme e entorrinal, septo, tálamo, amígdala e neocórtex. No hipocampo, o dano é maior na região ventral que dorsal, sendo os subcampos de CA3, CA1 e hilo os mais envolvidos (Clifford et al 1987).

Este modelo experimental é útil para o estudo dos processos epileptogênicos, do estado interictal e das consequências em longo prazo das CERs (Cavalheiro et al 1991; Cavalheiro et al 1996). Neste modelo, a gravidade das alterações neuropatológicas crônicas é proporcional à duração da fase aguda das crises epilépticas (Cavalheiro \& Sanabria 2000). O curso natural do desenvolvimento das características histopatológicas e comportamentais dos animais tratados com lítiopilocarpina é semelhante a dos pacientes com ELT que apresentam um IPI (Turski et al 1989). Estes animais sofrem uma lesão inicial pelo SE, passam por um período latente, sem crises, desenvolvendo, a seguir, as CERs, bem como as características histopatológicas associadas à ELTM (Curia et al 2008). Dessa forma, os modelos animais de epilepsia são de vital importância para o desenvolvimento de novos conhecimentos que permitirão o entendimento dos processos patológicos de humanos com ELTM.

\subsection{Citoesqueleto Neuronal}

O citoesqueleto é uma estrutura altamente dinâmica que participa dos processos de plasticidade, transporte e sinalização celular, além de ser o principal 
determinante da morfologia celular (Brady et al 2003; Bray \& Gilbert 1981). São componentes do citoesqueleto os microfilamentos, os filamentos intermediários e os microtúbulos. Os microfilamentos, também conhecidos como citoesqueleto de actina, formam uma estrutura complexa responsável pelo controle da forma celular, distribuição das proteínas de membrana e tráfego intracelular (Eitzen 2003). Os microfilamentos também participam da geração e motilidade dos cones de crescimento e de espinhos dendríticos (Brady et al 2003). Em neurônios, os filamentos de actina se acumulam nos espinhos dendríticos, que são especializações pós-sinápticas. O formato e a distribuição destes espinhos modificam a excitabilidade neuronal (Brusco et al 2010). Além disso, os filamentos de actina participam da morfogênese dos espinhos e da função sináptica (Meng et al 2003). Os filamentos intermediários, que estabilizam outros componentes do citoesqueleto, são constituídos principalmente por neurofilamentos (NF). Os NF são essenciais para a manutenção da forma neuronal, da arborização dendrítica e para o crescimento axonal e transporte de moléculas e organelas no sistema nervoso (Mikuni et al 1998).

Durante o estágio de morfogênese neuronal os componentes do citoesqueleto auxiliam nos processos de crescimento neurítico e estabilização de axônios e dendritos formados (Ludin \& Matus 1993). Embora todos os principais componentes do citoesqueleto estejam presentes em neurônios, as proteínas do citoesqueleto localizadas nos corpos celulares e dendritos são diferentes daquelas encontradas nos axônios (Mitchison \& Kirschner 1988). Além de participar do desenvolvimento do sistema nervoso, o citoesqueleto está envolvido em processos de plasticidade no cérebro adulto (Benitez-King et al 2004). Mutações em genes que codificam NF ou suas proteínas ligantes podem causar inibições no transporte axonal (Gama Sosa et al 2003). Adicionalmente, o acúmulo anormal de proteínas dos NF é uma característica de muitas doenças neurodegenerativas como a doença do neurônio motor humana (Gama Sosa et al 2003).

Os microtúbulos são compostos por heterodímeros de $\alpha$ e $\beta$-tubulina, que se formam por adição destas subunidades às suas extremidades "mais" (Gardiner \& Marc 2010). Tanto in vitro quanto in vivo, os microtúbulos oscilam entre as fases de 
crescimento (resgate) e encurtamento (catástrofe), um processo conhecido como instabilidade dinâmica (Drewes et al 1998). Os microtúbulos possuem funções essenciais nas células eucariotas, como segregação cromossômica, determinação do tamanho e da morfologia celular, transporte axonal, polaridade neuronal (Baas 2002) e distribuição de organelas (Hadfield et al 2003; Ludin \& Matus 1993). Porém, para o melhor desempenho destas funções é necessário que os microtúbulos oscilem entre as fases de crescimento e encurtamento. Esta instabilidade dinâmica é regulada por fatores celulares, incluindo as proteínas associadas aos microtúbulos (MAPs) (Drewes et al 1998).

O sistema microtubular é provavelmente o mais interessante em termos de desenvolvimento e função dendrítica, já que são elementos essenciais para a elaboração das ramificações dendríticas (Poulain \& Sobel 2010). Bensimon e Chermat (1991) sugeriram que a desagregação microtubular poderia estar diretamente relacionada aos danos cognitivos vistos em doenças neurodegenerativas. Isso porque a administração crônica de colchicina em ratos causa uma desestabilização dos microtúbulos. Como resultado, observa-se um deficit de aprendizagem similar ao que ocorre na doença de Alzheimer. Além disso, alterações na memória de longo prazo e diminuição das espículas dendríticas foram encontradas no hipocampo de ratos tratados com colchicina (Avila-Costa et al 1999). Tais modificações estruturais são moduladas pelas MAPs (Tucker 1990).

\subsection{Proteínas Associadas aos Microtubúlos (MAPs)}

As MAPs são divididas em dois grupos principais: as estruturais, envolvidas nos processos de polimerização, agregação e estabilidade dos microtúbulos; e as motoras, envolvidas no transporte de vesículas ou proteínas ao longo dos microtúbulos (Tucker 1990). Além disso, as MAPs são classificadas em dois grupos de acordo com seus pesos moleculares, as de alto peso molecular $(>200 \mathrm{kD})$ e as de baixo peso molecular (30 a 50kD) (Lewis et al 1988). 
As MAPs também podem ser divididas em três famílias distintas: MAP1, MAP2 e tau. A família MAP1 apresenta três isoformas, presentes na maioria dos vertebrados, MAP1A, MAP1B (também conhecida como MAP5 ou MAP1X) e MAP1S. Os integrantes da família MAP1 são codificados por genes diferentes, regulam a estabilização e a formação de fascículos microtubulares pela formação de pontes cruzadas entre eles (Poulain \& Sobel 2010; Tucker 1990). Apesar da grande variedade de MAPs existentes, concentraremo-nos nas proteínas MAP2 e tau.

$\mathrm{Na}$ família MAP2 existem as isoformas de alto peso molecular, MAP2A e MAP2B, expressas exclusivamente em neurônios e as de baixo peso molecular, MAP2C e MA2D, presentes em neurônios e células gliais. As MAP2 de alto peso molecular são restritas ao corpo celular e dendritos, não sendo encontradas em axônios. Já as MAP2 de baixo peso molecular estão distribuídas em todos os compartimentos neuronais (Bernhardt \& Matus 1984; Poulain \& Sobel 2010).

As múltiplas isoformas de MAP2 são codificadas por um único gene que sofre um processamento alternativo durante o desenvolvimento (Quinlan \& Halpain 1996). A isoforma MAP2A é a mais abundante no cérebro adulto (Chung et al 1996; Sanchez et al 2000; Tucker 1990) embora também esteja presente em estágios iniciais do desenvolvimento, como observado no estudo de Kalcheva e colaboradores (1997). Os autores observaram a expressão de MAP2A na medula espinhal de fetos humanos provenientes de abortos com aproximadamente 24 semanas de gestação. Além disso, experimentos com cultura de neurônios hipocampais demonstraram que a expressão de MAP2 aparece distribuída por toda célula neuronal, inclusive em axônios, em estágios iniciais do desenvolvimento. Porém, com o avanço do desenvolvimento, os níveis de MAP2 nos axônios diminuem tornando-se quase nulos em neurônios adultos (Caceres et al 1986).

O estado de fosforilação da MAP2 é essencial para a regulação de suas funções. Estudos in vitro indicaram que a MAP2 fosforilada diminui sua habilidade de promover a estabilidade dos microtúbulos e atenua sua atividade de ligação à actina (Quinlan \& Halpain 1996). Assim, a inibição da expressão de MAP2 em neurônios hipocampais e cerebelares previne o crescimento neurítico (Caceres et al 1992). Da 
mesma forma, a inibição desta proteína após a formação de neuritos resulta em microtubúlos desorganizados e reduz o número de processos neuríticos (Sharma et al 1994)

Além de atuar nos processos de morfogênese neuronal, a MAP2 é conhecida como um marcador sensível para isquemia. Estudos de imunohistoquímica revelaram que a perda da imunorreatividade desta proteína precede mudanças morfológicas que ocorrem nos neurônios hipocampais (Kitagawa et al 1992; Kitamura et al 2005; Yanagihara et al 1990). Assim, anormalidades no citoesqueleto e/ou em suas proteínas associadas parecem estar envolvidas não só em doenças neurodegenerativas, mas também em outras disfunções do sistema nervoso central (SNC) como na isquemia cerebral (Kitamura et al 2005; Matesic \& Lin 1994).

A terceira família das MAPs é representada pela proteína tau. Existem seis isoformas de tau identificadas em neurônios de mamíferos, cuja função principal é se ligar, estabilizar e promover a associação dos microtúbulos (Poulain \& Sobel 2010). As isoformas de tau estão presentes nos axônios das células neuronais maduras (Kosik 1990), mas também são encontradas em corpos celulares e dendritos de neurônios hipocampais em desenvolvimento (Bulinski et al 1998; Ferreira et al 1987).

As isoformas de tau do cérebro humano adulto são geradas por processamento alternativo. Este mecanismo é regulado pelo desenvolvimento, assim como seu estado de fosforilação (Johnson \& Stoothoff 2004). No feto, somente as isoformas menores estão presentes (Kosik et al 1989) e a tau dos fetos apresenta mais sítios de fosforilação que a de adultos (Watanabe et al 1993). Assim, a forma fetal promove de forma menos eficiente a agregação dos microtúbulos que a forma adulta (Yoshida \& Ihara 1993).

A inibição da expressão de tau antes do início dos mecanismos de polaridade neuronal previne a formação de axônios. Da mesma forma, a inibição de tau após o início deste mecanismo induz a perda dos axônios, indicando o papel essencial da proteína tau na iniciação e manutenção da axogênese (Caceres et al 1991). Entretanto, outro estudo sugeriu que a tau não é indispensável para o crescimento axonal in vivo. Neste estudo, ratos transgênicos com deficiência de proteína tau não apresentavam 
qualquer efeito deletério nos mecanismos de axogênese (Harada et al 1994). Assim, a fosforilação da tau em seus sítios específicos de ligação é o que garante seu funcionamento normal. Por outro lado, sua fosforilação inapropriada resulta em disfunção e menor viabilidade celular. De fato, todas as doenças neurodegenerativas, envolvidas com a proteína tau, apresentam esta proteína anormalmente fosforilada (Gartner et al 1998; Kosik 1990; Lee et al 2001; Moreno et al 2011).

\subsection{Proteínas do Citoesqueleto e Epilepsia}

O funcionamento apropriado do sistema nervoso depende da complexidade das redes neuronais elaboradas durante o desenvolvimento, quando os neurônios adquirem suas formas e funções específicas. Por esta razão, os mecanismos de neuritogênese, axogênese e dendritogênese são essenciais para os neurônios adquirirem suas características morfológicas funcionais. Estes mecanismos dependem da dinâmica específica e coordenada do citoesqueleto de actina e dos microtúbulos (Poulain \& Sobel 2010).

Crises epilépticas podem modificar a expressão das proteínas do citoesqueleto, como recentemente revisado por nosso grupo (Monteiro et al 2011). Há evidências de que a maioria das anormalidades morfológicas observadas na ELT estão localizadas no hipocampo. Kato e colaboradores (2001), através da análise de microscopia eletrônica no hipocampo de camundongos submetidos às crises por abrasamento, encontraram um aumento no número de microtúbulos polimerizados nas células granulares do giro denteado. Para os autores, estes resultados sugerem que o crescimento de dendritos com microtúbulos estáveis faz parte de um processo de plasticidade estrutural em resposta à atividade de crises em áreas específicas do cérebro adulto. Em modelo de ácido caínico, Pollard e colaboradores (1994) detectaram aumento na expressão de $\alpha$ tubulina e tau, e diminuição na expressão de MAP2 na fase latente. O aumento na expressão de tau foi verificado particularmente nos corpos celulares e axônios das células granulares. Como tau tem um papel importante nos processos de iniciação, elongação e estabilização de neuritos, os autores sugeriram que tau possa estar 
envolvida no processo de formação do neobrotamento axonal aberrante em animais epilépticos.

Evidências experimentais indicam que o remodelamento sináptico que ocorre na ELT é um componente importante do processo epileptogênico. Há significativa participação de proteínas do citoesqueleto nos processos de geração e manutenção de circuitos anormais (Mizoguchi et al 1998; Palmini et al 1994). O remodelamento sináptico das fibras musgosas é uma característica comum entre pacientes com ELTM e no modelo animal de lítio-pilocarpina. Não existem trabalhos na literatura que analisaram, em um único trabalho, a expressão das proteínas estruturais MAP2 e tau no hipocampo de pacientes com ELTM e em modelos animais de ELT induzida por lítiopilocarpina. Nosso estudo concentrou-se na análise da expressão das proteínas MAP2 e tau no hipocampo de pacientes com ELTM e em modelo animal de epilepsia induzida por lítio-pilocarpina. Além disso, analisamos a expressão imunohistoquímica destas proteínas entre casos de ELTM familiar e esporádica. Além da análise de expressão das proteínas do citoesqueleto, verificamos se existiam correlações entre as alterações de expressão destas proteínas e o crescimento anormal das fibras musgosas. 


\section{OBJETIVOS}

- Analisar a densidade neuronal, formação do neobrotamento anormal das fibras musgosas e a expressão das proteínas MAP2 e tau no hipocampo de pacientes com ELTM e no de controles sem histórico de problemas neurológicos;

- Analisar a densidade neuronal, formação do neobrotamento anormal das fibras musgosas e a expressão das proteínas MAP2 e tau no hipocampo de pacientes com ELTM familiar e ELTM esporádica;

- Analisar a densidade neuronal, formação do neobrotamento anormal das fibras musgosas e a expressão das proteínas MAP2 e tau no hipocampo do modelo animal de ELTM induzida por lítio-pilocarpina;

- Correlacionar as alterações de expressão destas proteínas estruturais (MAP2 e tau) com a reorganização anormal das fibras musgosas 


\section{MATERIAIS E MÉTODOS}

\subsection{Pacientes}

Os critérios de inclusão dos pacientes foram: 1) semiologia ictal consistente com ELT, usualmente com aura epigástrica, autonômica ou psíquica, seguida por parada comportamental, perda progressiva da consciência, automatismos oroalimentares e manuais e fenômenos autonômicos; 2) registro eletroencefalográfico interictal com paroxismos epileptiformes localizados nas regiões temporais anteriores e mesiais; 3) nenhuma outra lesão além de atrofia e/ou aumento de sinal do hipocampo e de estruturas mesiais, identificada na ressonância nuclear magnética; 4) exame histopatológico compatível com $\mathrm{EH} ; 5)$ investigação pré-cirúrgica compatível com início de crises unilateral; 6) ausência de patologia dual que pudesse ser identificada pelos métodos de avaliação (clínica, eletrofisiológica, histopatológica e de neuroimagem). Os critérios de exclusão dos pacientes da amostra foram: 1) anormalidades neurológicas focais no exame físico; 2) Eletroencefalograma (EEG) com paroxismos epileptiformes extratemporais ou generalizados; 3) acentuado prejuízo cognitivo nos testes neuropsicológicos.

O trabalho fez parte do projeto aprovado (n\# HC 8730/2010) pelo comitê de ética em pesquisa do Hospital das Clínicas de Ribeirão Preto (HCRP), e o consentimento por escrito foi obtido de todos os pacientes ou seus responsáveis legais. Uma parcela das biópsias selecionadas para o estudo foi proveniente do banco de amostras de tecido cerebral (n\# HC 9370/2003), aprovado pelo comitê de ética do HCRP e que tem como responsável o Professor João Pereira Leite.

Os hipocampos controles foram provenientes de necrópsias realizadas pelo Departamento de Patologia da Faculdade de Medicina de Ribeirão Preto (FMRP), sendo que estes pacientes não apresentavam nenhum histórico de doença neurológica.

$\mathrm{Na}$ separação dos grupos também foram consideradas as características clínicas sexo, escolaridade, idade, drogas antiepilépticas (DAEs) e benzodiazepínicos, idade de início da epilepsia (crises recorrentes), duração da epilepsia, história positiva 
de IPI, história positiva de epilepsia na família (pais, irmãos ou tios), crises parciais complexas com frequência mensal prejudicando a consciência no ano anterior à cirurgia e lado da cirurgia. Apenas pacientes com parentes em primeiro grau com história positiva de epilepsia na família foram considerados como ELTM familiar. Para o grupo ELTM esporádica foram considerados apenas aqueles pacientes que não apresentavam familiares de primeiro ou segundo graus positivo para epilepsia. Todas estas informações foram obtidas retrospectivamente através de consultas a prontuários médicos.

A avaliação pré-cirúrgica foi realizada por uma equipe multidisciplinar experiente e incluiu história clínica e exame neurológico detalhados, análise do vídeo-EEG ictal e interictal, neuroimagem estrutural e funcional, avaliações psiquiátrica, neuropsicológica e social. Desta forma, obtivemos os seguintes grupos: grupo ELTM familiar $(n=20)$, grupo ELTM esporádica $(n=18)$ e grupo controle $(n=10)$.

\subsubsection{Processamento do tecido cerebral humano}

O tecido hipocampal foi obtido a partir da peça cirúrgica intra-operatória (grupo ELTM) e material necroscópico (grupo controle). Os hipocampos do grupo controle foram selecionado de necrópsias de indivíduos sem história de epilepsia ou outra doença neurológica, coletados entre 6 e 12 horas após a morte, e sem história de ventilação mecânica ou estado de choque grave e prolongado.

Os blocos contendo tecido hipocampal inicialmente foram imersos em uma solução de formaldeído tamponado. O hipocampo foi seccionado em fragmentos de 7 a 10 milímetros, obtendo-se cinco a seis fragmentos. Os fragmentos contendo tecido hipocampal foram incluídos de forma alternada em solução de glutaraldeído em tampão Millionig e formaldeído tamponado. Os fragmentos incluídos em formaldeído (dois) eram encaminhados ao serviço de patologia do HCFMRP-USP para processamento de rotina e diagnóstico etiológico. O material foi processado e analisado no Laboratório de Investigação de Epilepsia no HCFMRP-USP. Este material permaneceu por quatro ou cinco dias na geladeira para fixação. 
Posteriormente os blocos foram transferidos para uma solução de sacarose a $10 \%$ por 24 horas, congelados com gelo seco e seccionados em criostato, em cortes de 10 e $30 \mu \mathrm{m}$ de espessura, e montados em lâminas gelatinizadas, contendo dois a quatro cortes por lâmina. O material foi processado para a histoquímica de Neo-Timm. Lâminas obtidas de blocos de parafina foram cortadas em $8 \mu \mathrm{m}$ de espessura e processadas para as imunohistoquímicas.

\subsection{Animais}

Foram utilizados ratos Wistar, machos, com idade de 2 meses, pesando entre 200-250g no início dos experimentos. Estes animais foram provenientes do Biotério Central da FMRP-USP, tiveram livre acesso à água e comida, e foram mantidos em ciclo claro-escuro de 12 horas, com temperatura ambiente constante. Todos os procedimentos foram realizados de acordo com as normas da Sociedade Brasileira de Neurociências e Comportamento (SBNeC) para o uso ético de animais de investigação.

O trabalho foi submetido à Comissão de Ética em Experimentação Animal da FMRP-USP (CETEA), processo $n^{\circ}$ 093/2008. O modelo animal utilizado em nosso estudo foi obtido em colaboração com a doutoranda Raquel Araújo do Val da Silva.

\subsubsection{Protocolo Experimental}

Em nosso trabalho utilizamos o modelo de lítio-pilocarpina, com administração intraperitoneal, para a indução do SE. Após o episódio de SE, ocorreram as CERs. Com isso, nosso intuito foi observar a evolução dos mecanismos epileptogênicos e a expressão das proteínas estruturais MAP2 e tau em diferentes tempos pós-SE.

\subsubsection{Grupos}

Os animais foram divididos em grupo epiléptico e grupo controle, de forma que ambos foram submetidos aos procedimentos de injeção intraperitoneal. Porém, o grupo 
epiléptico recebeu pilocarpina enquanto que o grupo controle recebeu apenas salina $(0,9 \% \mathrm{p} / \mathrm{v})$. Os animais que desenvolveram SE e CERs foram sacrificados nos seguintes intervalos pós-SE: 1, 7, 15 e 60 dias, possibilitando assim o acompanhamento temporal dos mecanismos epileptogênicos.

\subsubsection{Indução do Status Epilepticus}

Os animais passaram por um pré-tratamento com cloreto de lítio $(127,17 \mathrm{mg} / \mathrm{Kg}$, Sigma, L4408), injetado intraperitonealmente e após 20 horas foram submetidos à injeção intraperitoneal de Pilocarpina (30 mg/Kg, Sigma, P6503) para a indução do SE. Durante as crises, assim que se iniciaram as clonias dos membros superiores, acompanhadas por elevação do tronco, correspondente ao estágio 4 da escala de Racine Modificada (Racine 1972), os animais receberam uma injeção de metilescopolamina por via subcutânea (1 $\mathrm{mg} / \mathrm{Kg}$, Sigma, S2250). A metil-escopolamina é um antagonista muscarínico utilizado para amenizar os efeitos colinérgicos periféricos que ocorrem após a administração da pilocarpina.

Os animais permaneceram em SE por 4 horas (Cavalheiro et al 1991; Leite et al 1990) e após este período receberam uma injeção de Tiopental Sódico (20 mg/Kg, Abbot, 6431) para a interrupção do SE. Os animais foram observados e alimentados cuidadosamente (solução isotônica e banana amassada) logo após a recuperação e até 7 dias pós SE, afim de melhorar a taxa de sobrevivência destes animais. No grupo de 2 meses, após 7 dias do SE, os animais foram filmados por 6 horas diárias para propósito de análise comportamental.

\subsubsection{Perfusão e fixação do tecido animal}

A perfusão ocorreu nos dias 1, 7, 15 e 60 após o episódio de SE de acordo com os diferentes tempos pós SE do grupo de animais epilépticos. Os animais foram anestesiados com injeção intraperitoneal de Tiopental Sódico (80mg/Kg ip); a perfusão foi realizada por via intracardíaca. Com o auxílio de uma agulha foi puncionado o 
ventrículo esquerdo do animal, em seguida foi realizada uma incisão no átrio direito para permitir a saída de líquidos. Logo após a incisão no átrio direito foi infundida uma solução de salina tamponada $0,9 \%(\mathrm{p} / \mathrm{v})$ em tampão Millonig $\mathrm{CaCl}_{2}$ em um volume de $100 \mathrm{ml}$. A seguir, uma solução de sulfeto de sódio $0,1 \%(\mathrm{p} / \mathrm{v})(150$ a $200 \mathrm{ml})$ em salina tamponada e por último, paraformaldeído tamponado a 4\% (150 a 200 ml).

Após a perfusão, a cabeça foi separada do restante do corpo do animal com auxílio de uma tesoura através de um corte transversal entre o osso occipital e a coluna vertebral. O cérebro era removido da caixa óssea, com o auxílio de uma goiva, e mergulhado em solução de paraformaldeído tamponado $4 \%$ por 4 horas. A seguir os cérebros foram desidratados, gradualmente em soluções com concentrações crescentes de álcool, iniciando com álcool 50\% (v/v) e terminando com álcool absoluto (100\%). Após essa etapa o tecido foi diafanizado em xilol e incluído em parafina.

Os blocos em parafina foram cortados em secções de $8 \mu \mathrm{m}$ de espessura, no mínimo após dois dias do emblocamento, utilizando o micrótomo. As secções foram montadas em lâminas gelatinizadas de forma sequencial (25 lâminas). As secções foram coletadas entre $-3,30$ a $-3,60 \mathrm{~mm}$ em relação ao bregma de acordo com o Atlas de Paxinos e Watson (1986).

Após a secagem, as lâminas foram colocadas na estufa histológica a $58^{\circ} \mathrm{C}$ por 2 horas e armazenadas para posterior realização da coloração de Neo-Timm e imunohistoquímicas.

\subsubsection{Análise comportamental dos animais}

Em todos os grupos experimentais submetidos ao SE, os animais foram avaliados quanto à latência e severidade das crises epilépticas. Os animais do grupo de 2 meses foram monitorados para registrar as CERs, sendo avaliados o tempo de intervalo para início das crises, o tipo, a severidade, a duração, a frequência e o número total das CERs. Para a classificação das crises epilépticas utilizamos a escala de Racine, onde o desenvolvimento das crises motoras divide-se em cinco estágios: (1) 
movimentos faciais e orais; (2) balanço da cabeça; (3) clonia de patas; (4) elevação; (5) elevação e queda (Racine, 1972).

\subsubsection{Nomenclatura}

As subregiões hipocampais de ratos são normalmente subdivididas em fascia dentata, que compreende as camadas granulares superior e inferior e hilo, CA3a, b e c, CA2 e CA1 (figura 1). Em nosso estudo, modificamos esta nomenclatura (figura 2) afim de aproximar, ao máximo, as característica do tecido animal do tecido humano para traçarmos paralelos entre eles.

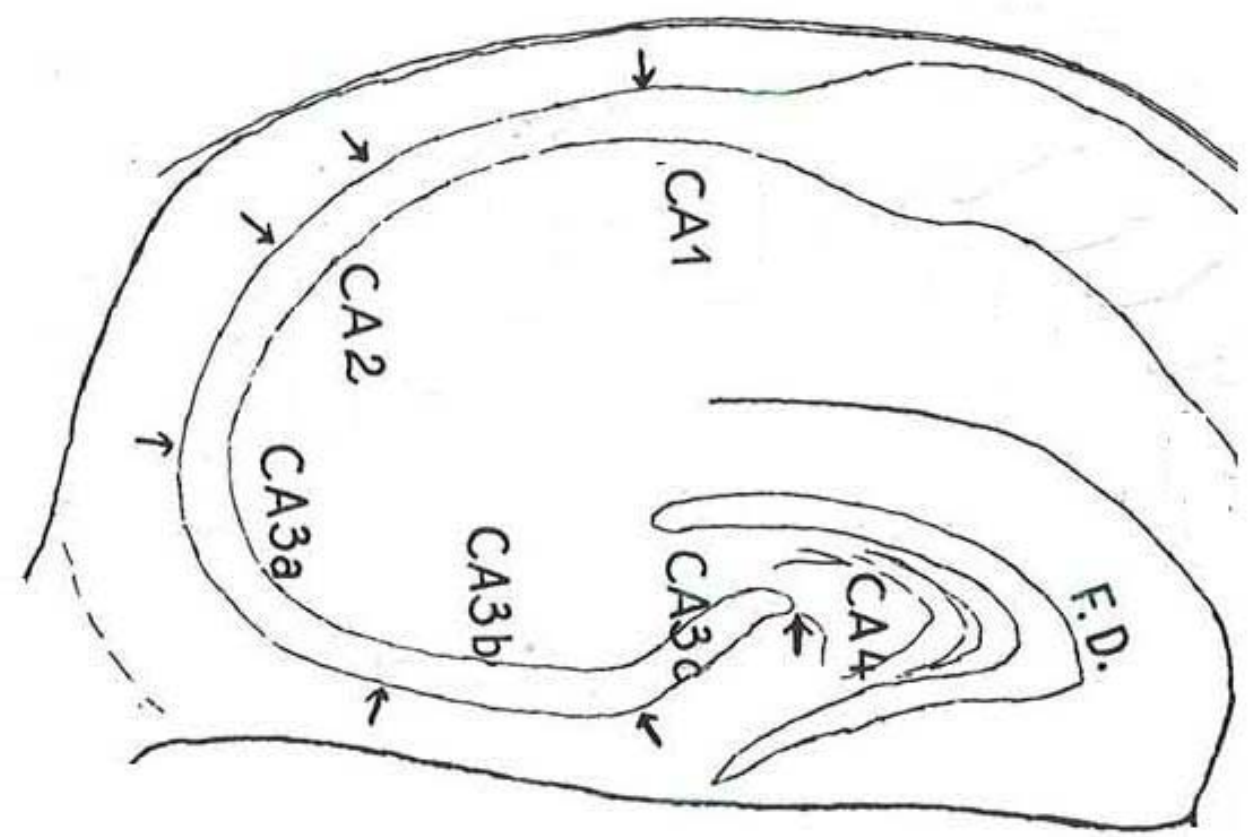

Figura 1: Subregiões hipocampais de ratos: Nomenclatura original. Adaptado de Lorente de Nó, 1934. FD: Fascia Dentata (camada granular superior e inferior+hilo). 


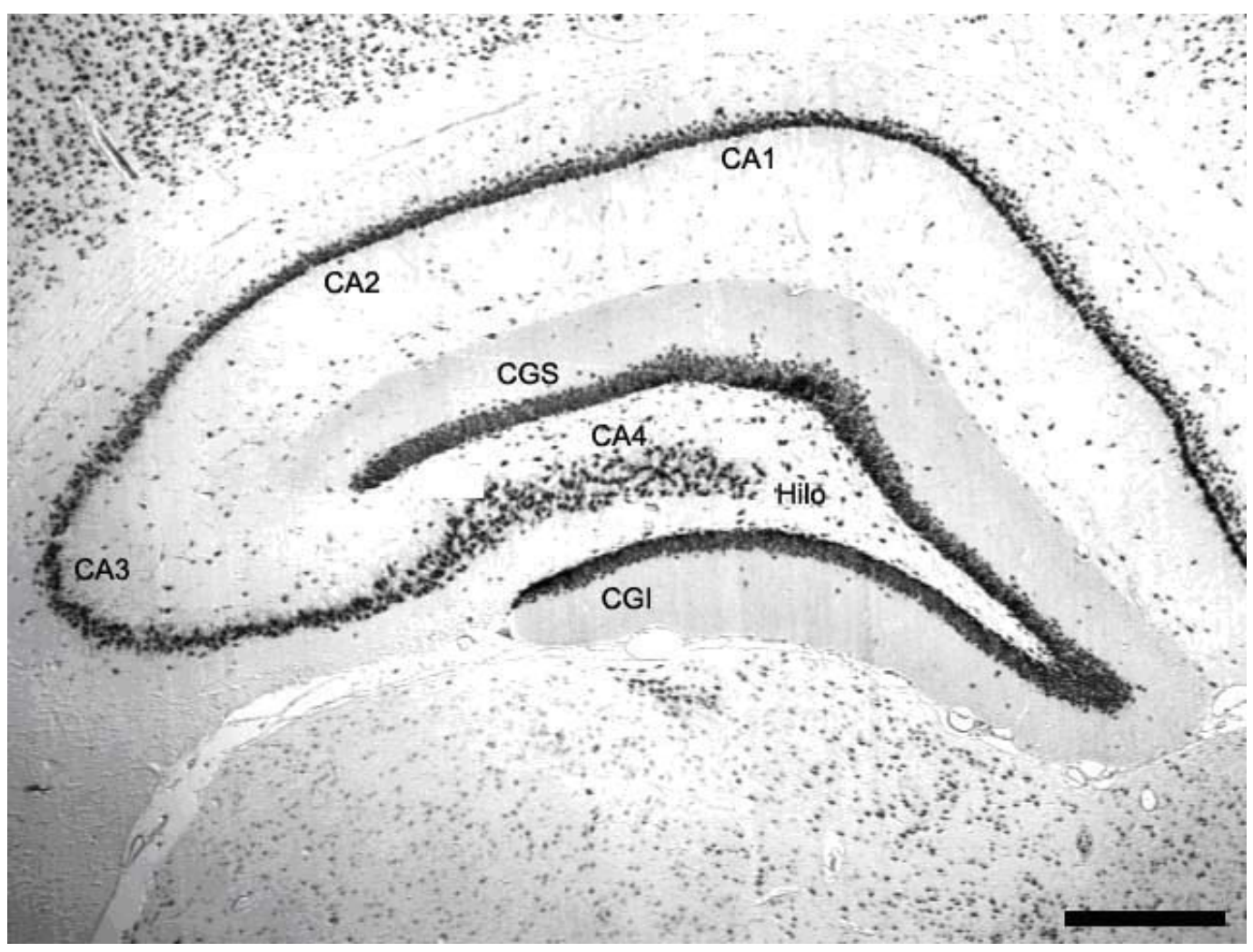

Figura 2: Subregiões hipocampais de ratos com nomenclatura modificada. Imagem do tecido de um dos nossos animais injetados com salina, submetido à imunohistoquímica para NeuN. CGI: camada granular inferior; CGS: camada granular superior. Barra canto inferior direito equivale a $400 \mu \mathrm{m}$.

\subsection{Métodos Histoquímicos}

\subsubsection{Neo-Timm}

Na década de 50, Timm (1958) descreveu a histoquímica para metais pesados, sendo também conhecida como método do sulfeto de prata. Nesta técnica o reagente de Timm (sulfeto de sódio) se liga a metais pesados, dentre estes o zinco que se encontra nos terminais sinápticos (glutamatérgicos) das fibras musgosas. Através de uma reação química por pontes dissulfeto há a produção de sulfeto de zinco.

Foram utilizadas apenas as secções cerebrais sem pré-fixação em formalina para o processamento pelo método do Neo-Timm. Os blocos contendo material 
hipocampal foram colocados numa solução composta de tampão Millonig ${ }^{1}$ contendo 84 $\mathrm{mL}$ de solução de $5 \mathrm{mM} \mathrm{Na} \mathrm{Na}_{2}$ (Sigma) e $16 \mathrm{~mL}$ de glutaraldeído (Vetec) a 25\% (v/v), sendo então conservados na geladeira por três a quatro dias. Os tecidos fixados pela solução de Timm (sulfeto de sódio) foram transferidos para uma solução de sacarose (Vetec) a 10\% (p/v) em tampão Millonig por 12 horas e então congelados e cortados no criostato, com $30 \mu \mathrm{m}$ de espessura.

As secções removidas do criostato foram montadas em lâminas previamente banhadas com gelatina e deixadas para secar em temperatura ambiente. Posteriormente foram imersas numa solução reveladora mantida a $36^{\circ} \mathrm{C}$ em sala escura.

A solução reveladora era constituída de $180 \mathrm{~mL}$ de uma solução de goma arábica (Sigma) a 50\% (p/v), adicionada de $30 \mathrm{~mL}$ de $0,12 \mathrm{M}$ de ácido cítrico, $22 \mathrm{~mL}$ de $80 \mathrm{mM}$ de citrato de sódio e $90 \mathrm{~mL}$ de $0,16 \mathrm{M}$ de hidroquinona (Vetec). À mistura destas soluções mantidas em banho úmido de $36^{\circ} \mathrm{C}$ foi acrescentado, em ambiente protegido de luz, $1,5 \mathrm{~mL}$ de $2,17 \mathrm{M}$ de $\mathrm{AgNO}_{3}$ (Cennabras). $\mathrm{O}$ sulfeto de zinco acumulado nas fibras musgosas reage com a hidroquinona, substância que reduz os sais de prata, evidenciando-os por precipitação. A cuba com as lâminas foi deixada dentro do banhomaria aquecido conforme o tempo ideal, que varia entre 40 e 50 minutos para hipocampo humano e 30 e 40 minutos para hipocampo de rato.

\subsection{Imunohistoquímica}

A primeira etapa da imunohistoquímica foi a desparafinização, que visa a passagem dos cortes histológicos de uma situação hidrofóbica para hidrofílica. As lâminas foram incubadas em estufa histológica a $58^{\circ} \mathrm{C}$ por 10 minutos em jarro coplin. Essa temperatura corresponde ao ponto de fusão da maioria das parafinas comerciais. Adicionamos xilol $^{2}$ imediatamente após a retirada do coplin da estufa, mantendo-nas à

\footnotetext{
${ }^{1}$ Tampão Millonig: 0,13 mM CaCl 2 (Quimex), 0,12 $\mathrm{M} \mathrm{NaH}_{2} \mathrm{PO}_{4}$ (Vetec), $97 \mathrm{mM} \mathrm{NaOH}$ (Quimex) $\mathrm{pH}$ 7,3

${ }^{2}$ Todos os solventes utilizados são da marca Synth
} 
temperatura ambiente por 5 minutos. Continuando a desparafinização, colocamos as lâminas numa segunda solução de xilol e em seguida numa de xilol-álcool absoluto.

Como o álcool é um solvente miscível em água, passamos às etapas de hidratação, utilizando soluções com concentrações decrescentes de álcoois, sendo elas de $95 \%, 90 \%, 80 \%, 70 \%$ e $50 \%$ (v/v) por 2 minutos em cada, seguida de vários banhos em água destilada. $\mathrm{O}$ passo seguinte foi o bloqueio da peroxidase endógena, com incubação das secções em 4,5\% (v/v) de peróxido de hidrogênio $\left(\mathrm{H}_{2} \mathrm{O}_{2}\right)$ em $\mathrm{PBS}^{3}$ por 20 minutos. Depois iniciamos a recuperação antigênica, que resultou na exposição de epitopos protéicos do tecido. Incubamos as secções em coplin plástico com tampão 50mM Tris- $\mathrm{HCl} \mathrm{pH}$ 9,6 ou 10 mM citrato de sódio pH 6,0, dependendo do anticorpo, no micro-ondas Brastemp DES modelo BMU27ABHNA, sendo dois "tiros" de 5 minutos, com intervalo de 1 minuto entre eles, em potência nominal máxima.

A próxima etapa foi o bloqueio dos grupamentos aldeídos livres, que tem por objetivo impedir a formação de compostos instáveis e irreversíveis pela ligação desses grupamentos com grupos aminos livres, o que impediria a ligação dos anticorpos primários aos sítios específicos. Incubamos as secções em Tris-Glicina ${ }^{4}$ por 40 minutos à temperatura ambiente. Depois realizamos o bloqueio dos sítios protéicos inespecíficos incubando as lâminas em tampão de bloqueio [tampão $\mathrm{B}^{5}$ contendo $5 \%(\mathrm{p} / \mathrm{v})$ de leite em pó desnatado Molico e 10\% (v/v) de soro de cabra (Vector)] por 4-5 horas em temperatura ambiente.

Em seguida realizamos a incubação com o anticorpo primário por aproximadamente 16 horas, sendo que em lâminas controle este é omitido. Após este período, as lâminas foram lavadas com tampão B para a retirada do excesso de anticorpo, por quatro vezes de 5 minutos.

A incubação com o anticorpo secundário (anti-mouse ${ }^{6}$ ou anti-rabbit ${ }^{7}$ ) deu-se por 1 hora, à temperatura ambiente. As secções passaram por outra lavagem com

\footnotetext{
${ }^{3}$ PBS: tampão fosfato salina $=50 \mathrm{mM} \mathrm{Na}_{2} \mathrm{HPO}_{4}$ (Vetec) $\mathrm{pH} 7,4$ contendo $0,9 \%(\mathrm{p} / \mathrm{v}) \mathrm{NaCl}$ (Quimex).

${ }^{4}$ Tris-Glicina: 0,1 M Glicina (Fluka) pH 7,4 ajustado com 0,1 M Tris (Vetec) básico.

${ }^{5}$ Tampão B: Preparado a partir do tampão A $\left(20 \mathrm{mM} \mathrm{Na}_{2} \mathrm{HPO}_{4}, 450 \mathrm{mM} \mathrm{NaCL} \mathrm{pH} \mathrm{7,4)} \mathrm{por}\right.$ adição de $0,3 \%$ (v/v) de Triton X-100 (Vetec).

${ }^{6}$ Biotinylated swine anti-mouse IgG (Dako E0354), diluído a 1:200 com tampão de bloqueio.

${ }^{7}$ Biotinylated swine anti-rabbit IgG (Dako E0353), diluído a 1:100 com tampão de bloqueio.
} 
tampão B, para retirar o excesso de anticorpo secundário que não se ligou ao tecido, e com tampão PBS duas vezes de 5 minutos.

Depois, foi realizada a incubação com kit Elite $A B C$ (Vector), onde misturamos $10 \mu \mathrm{L}$ de reagente $\mathrm{A}$ (solução rica em avidina) com $10 \mu \mathrm{L}$ de reagente $\mathrm{B}$ (solução rica em biotina complexada com peroxidase) para cada $500 \mu \mathrm{L}$ de PBS. As secções ficaram incubadas nessa solução por 1 hora à temperatura ambiente. Como o anticorpo secundário é biotinilado, a avidina do kit se liga a ele, e a biotina do kit se liga a esta avidina. A biotina do kit é acoplada com peroxidase, molécula que ficará exposta à revelação a seguir.

Para a revelação descongelamos um eppendorf de $1 \mathrm{~mL}$ de solução estoque (10 mg/mL) de diaminobenzidina (DAB, Sigma), mantida à $-20^{\circ} \mathrm{C}$, sendo descongelada apenas no momento do uso. Misturamos a esta solução $24 \mathrm{~mL}$ de tampão Tris- $\mathrm{HCl}$ pH 7,6 e $8 \mu \mathrm{L}$ de $\mathrm{H}_{2} \mathrm{O}_{2}$ a $30 \%$ (v/v). O peróxido de hidrogênio é catalisador da reação de polimerização do DAB pela peroxidase, que resulta em um precipitado de cor marrom escuro.

Acompanhamos o progresso da reação visualizando o escurecimento das secções em uma cuba acrílica. O tempo de reação não excedeu 12 minutos, a fim de evitar a saturação. Após a revelação as lâminas foram desidratadas em soluções com concentrações crescentes de álcool, e posteriormente xilol e montagem com lamínula e Kristalon (Harleco). Aguardamos a secagem das lâminas por 24 horas antes do início das análises microscópicas.

\subsubsection{Detalhamento dos anticorpos primários}

- Anti-MAP2 (H-300) (Santa Cruz, sc-20172), diluído a 1:200 em tampão de bloqueio. Este anticorpo é produzido em coelhos, reconhece a sequência de aminoácidos 1-300 da porção N-terminal da proteína MAP2 de humanos, tanto formas fosforiladas quanto desfosforiladas. Fonte: http://www.scbt.com/datasheet-20172-map-2-h-300-antibody.html. 
- Anti-Tau (H-150) (Santa Cruz, sc-5587), diluído a 1:100 em tampão de bloqueio. Anticorpo policlonal gerado em coelhos, reconhece a sequência corresponde aos aminoácidos de 1 a 150 da porção N-terminal da proteína Tau-1 de humanos. Reconhece tanto as formas fosforiladas como as não-fosforiladas, já que o sítio de fosforilação desta proteína está localizado na porção C-terminal. Fonte: http://www.scbt.com/datasheet-5587-tau-h-150-antibody.html.

- Anti-NeuN (Chemicon, MAB377), diluído a 1:500 em tampão de bloqueio. Este anticorpo monoclonal purificado de núcleos de neurônios de camundongo reconhece uma proteína nuclear específica de neurônios denominada NeuN, também encontrada no pericário e prolongamentos proximais de neurônios de vertebrados.

Fonte: http://www.chemicon.com/browse/productdetail.asp?ProductID=MAB377.

\subsection{Análise das Lâminas}

Todos os procedimentos histológicos foram realizados no Laboratório de Investigação em Epilepsia. As análises histológicas (Neo-Timm), contagem neuronal e de expressão de proteínas (quantidade de puncta positivos detectáveis, área marcada A-IR) foram realizadas de forma cega em relação a quais pacientes ou animais pertenciam a cada grupo.

\subsubsection{Análise da intensidade da marcação das} imunohistoquímicas.

As imagens digitais das secções foram feitas no microscópio Olympus BX60 acoplado a uma câmera monocromática Hamamatsu CCD, modelo C2400-75H, que transforma a imagem visualizada em imagem digital. Imagens digitais dos cortes coronais do hipocampo, relativos à região do corpo foram adquiridas com um aumento de 200 vezes nas imunohistoquímicas, e em 40 vezes na histoquímica de Neo-Timm. Com o objetivo de garantir a uniformidade do sinal das imagens digitais calibramos 
sempre a luminosidade do sistema óptico. Para este fim utilizamos uma régua de escalas de cinza padronizada (KodaK photographic step tablet $n^{\circ} 2,21$ steps density range aproximately 0.05 to 3.05 ), e mantemos constante a luminosidade do sistema com um valor intermediário na escala de 0 a 255 , com o objetivo de evitar a saturação do sistema por excesso ou falta de luminosidade. Estas imagens digitais foram salvas em formato TIF para análise em um computador Windows com o software ImageJ 1.42q. Estas análises incluíram contagem neuronal, valores de cinza e espessura e área marcada ou IOD das lâminas submetidas à imunohistoquímica.

Este programa nos permite selecionar, de forma padronizada, um limiar específico para a marcação da expressão de cada proteína analisada. A região selecionada em vermelho foi a analisada para o valor de área marcada, sendo desprezadas as marcações de fundo, como pode ser visto na figura 3 .
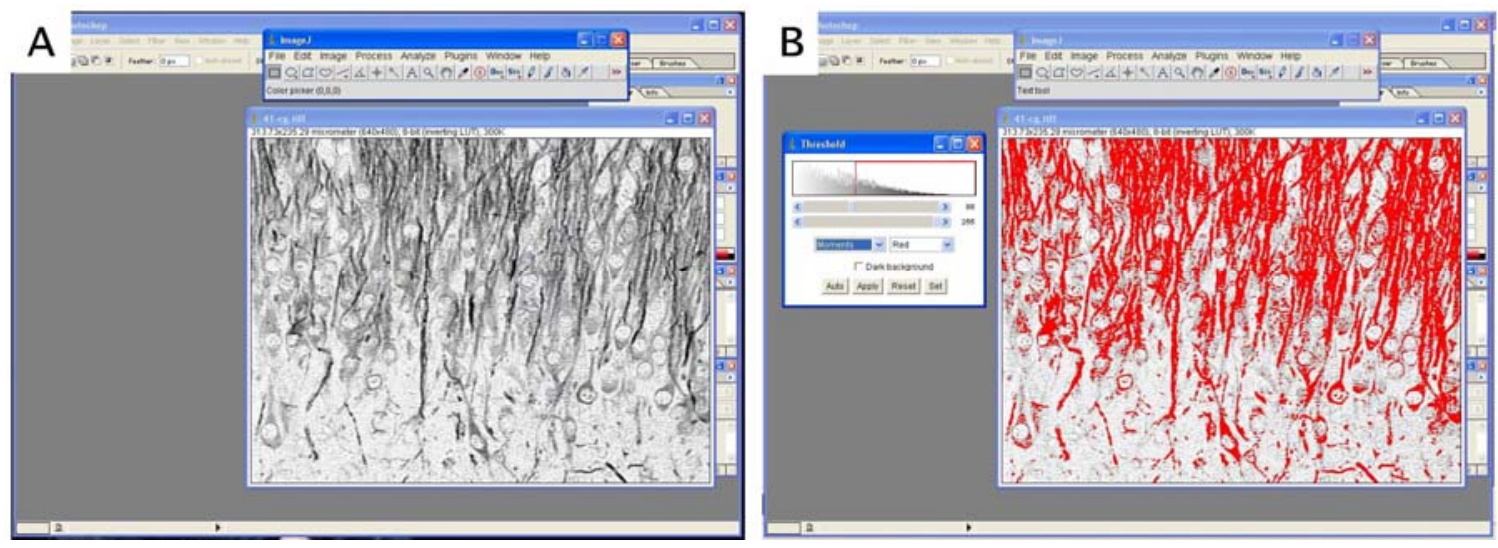

Figura 3: Demarcação e quantificações realizadas com o auxílio do programa Image J. A) Figura original da região da camada granular de um paciente submetido à hipocampectomia, imunomarcada para MAP2. B) A mesma imagem, após seleção (em vermelho) das regiões imunorreativas para MAP2.

\subsubsection{Contagem Neuronal}

A contagem neuronal para cada região hipocampal foi realizada em seções de 8 $\mu \mathrm{m}$ de espessura em lâminas submetidas à imunohistoquímica para NeuN. As regiões 
foram definidas de acordo com a classificação de Lorente de Nó (1934), como ilustrado na figura 4.

A contagem foi realizada através do programa Image J versão $1.42 q$, seguindo o seguinte procedimento: foram feitos 5 quadrados de $50 \times 50 \mu \mathrm{m}$ para cada região, sendo os quadrados distribuídos pela foto nas porções mais representativas de cada região. Foi aplicado o fator de correção de Abercrombie (1946) para espessura do corte, permitindo-se definir a densidade neuronal, com os valores apresentados em milhares de células por milímetro cúbico.

O fator de correção de Abercrombie inclui a seguinte fórmula:

(contagem celular) $\mathrm{X}$ (fator de Abercrombie)

$\mathrm{N}^{0}$ de células $/ \mathrm{mm}^{3}=$

(área total) $\mathrm{X}$ (espessura do corte)

O item "contagem celular" corresponde ao número absoluto de células contadas em cada região; "área total" ao número de quadrados contados e a espessura do corte foi de $8 \mu \mathrm{m}$. Já para a obtenção do fator de Abercrombie é considerado o diâmetro da célula e a espessura do corte, sendo que as células granulares apresentam um diâmetro de $\pm 8 \mu \mathrm{m}$ para os casos de tecido humano e $\pm 7 \mu \mathrm{m}$ para ratos e $\pm 14,3 \mu \mathrm{m}$ para as células do hilo e piramidais do tecido humano e $\pm 14 \mu \mathrm{m}$ para ratos. 


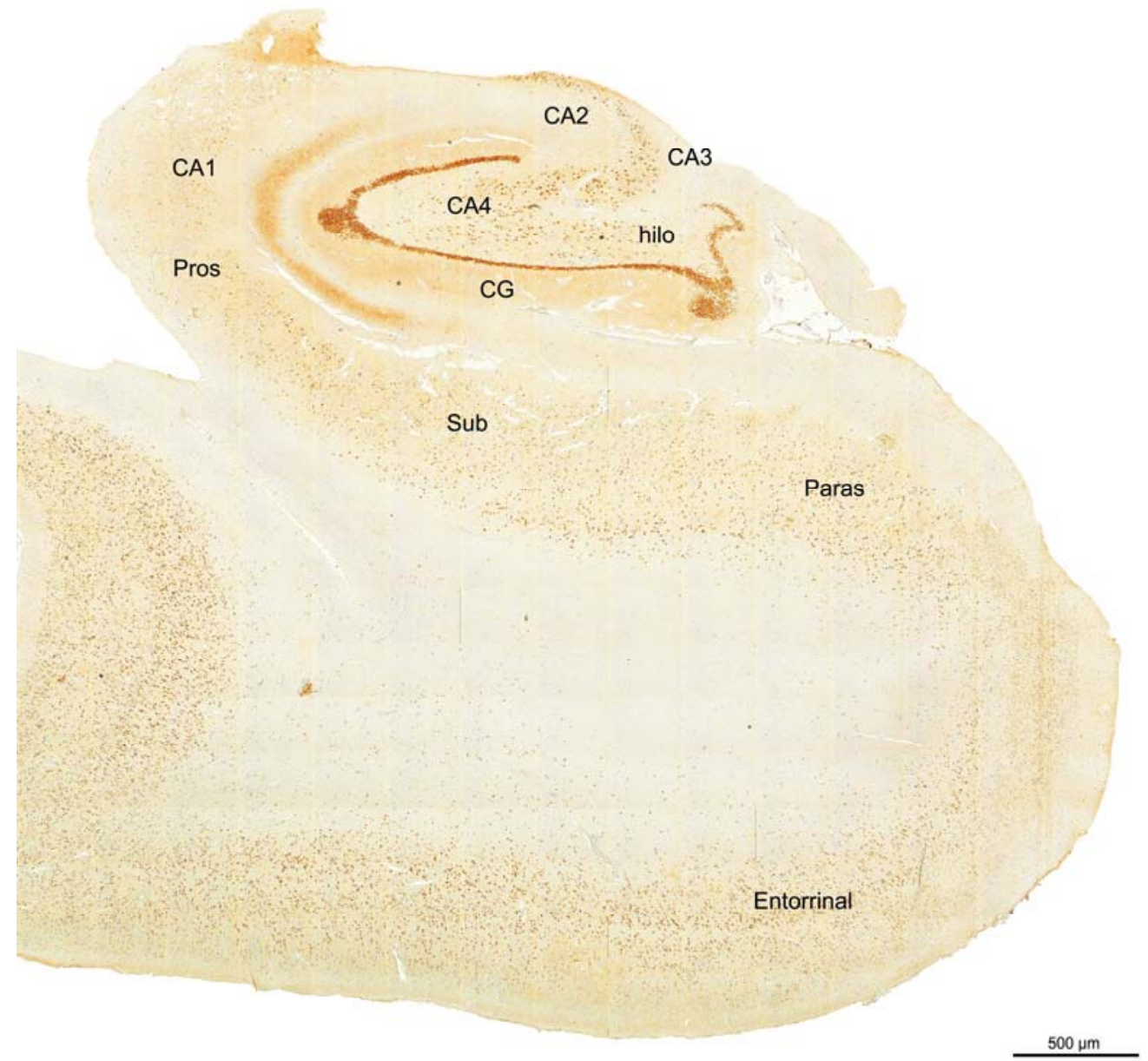

Figura 4: Formação hipocampal humana imunomarcada com Neu-N: Subregiões hipocampais de um dos casos controle analisados em nosso estudo. CG: camada granular, Pro: prosubículo, Sub: subículo, Paras: Parasubíclo, Entorrinal: córtex entorrinal.

\subsection{Análise Estatística}

Foi aplicado o teste de Kolmogorov-Smirnov para determinar o tipo de distribuição das variáveis a serem estudadas. Quando as variáveis apresentaram uma distribuição normal utilizamos os testes paramétricos: teste $t$ de Student ou ANOVA seguido do pós-teste de Bonferroni. No caso das variáveis que não apresentaram uma distribuição normal utilizamos testes não-paramétricos: Mann Whitney ou Kruskal-Wallis e quando o teste de Kruskall-Wallis indicou significância, o teste de Dunn foi utilizado. $\mathrm{Na}$ análise das variáveis categóricas aplicamos o qui-quadrado $\left(x^{2}\right)$ ou teste exato de 
Fischer, conforme a frequência esperada nas células. O programa estatístico utilizado foi o SigmaPlot (versão 11.0) e foram consideradas diferenças significativas apenas valores de alfa menores que 0,05 . Os resultados foram apresentados no formato média \pm desvio padrão (DP). 


\section{RESULTADOS}

\subsection{Pacientes}

A tabela a seguir contém o detalhamento das variáveis clínicas dos pacientes epilépticos, divididos em dois grupos: familiar e esporádico. As variáveis clínicas analisadas foram: gênero, IPI, idade na primeira crise (anos), idade de início das crises recorrentes (anos), frequência de crises (mês), domínio manual, desempenho de memória verbal, Quociente de Inteligência (QI), escolaridade (anos), idade na cirurgia (anos), duração da epilepsia (anos), lado operado (tabela 1).

Apenas a variável frequência de crises teve distribuição diferente entre os grupos, sendo que o grupo com ELTM esporádica apresentou maior frequência de crises por mês que o grupo com ELTM familiar $(p=0,049$, teste $t)$, como observado na tabela 2.

Utilizamos dez casos controles cujas características clínicas sexo, idade, causa mortis e tempo pós-mortem estão descritas na tabela 3. As variáveis gênero (ELTM = 44,74 \% M: 55,26\% F; Controle $=40 \%$ M: $60 \%$ F; $p=1$, teste Exato de Fisher) e idade $($ ELTM $=38,71 \pm 7,09 ;$ Controle $=48,7 \pm 22,54 ; p=0,098$, teste $\mathrm{t})$ tiveram igual distribuição ao compararmos os grupos ELTM e controle. 

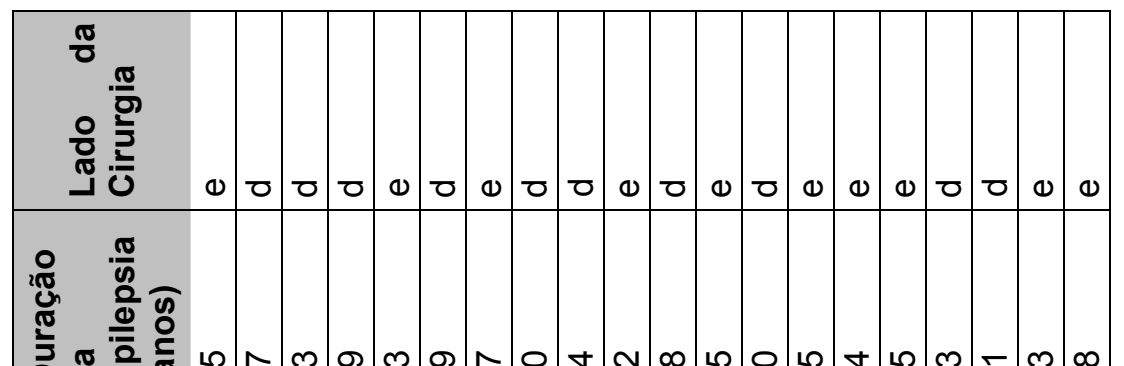

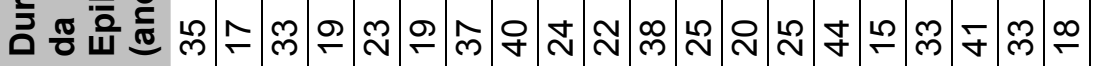
ㄸ.

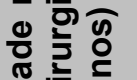

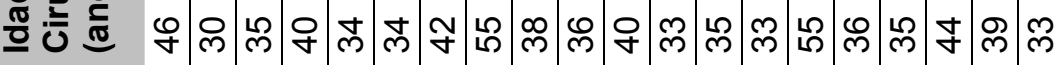

$\frac{0}{0}$

$\frac{\pi}{2}$

응

出

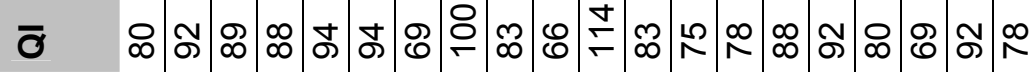

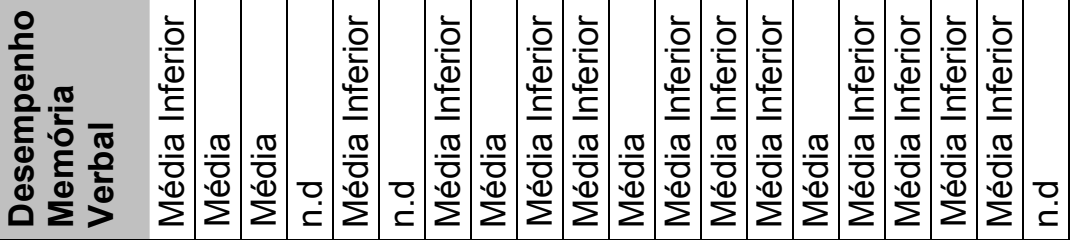

$\frac{ㅇ ㅡ ㄹ ~}{\frac{1}{5}} \frac{\pi}{2}$

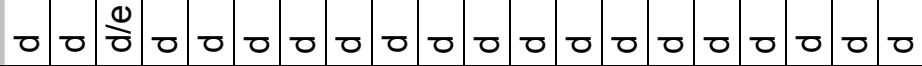

赵

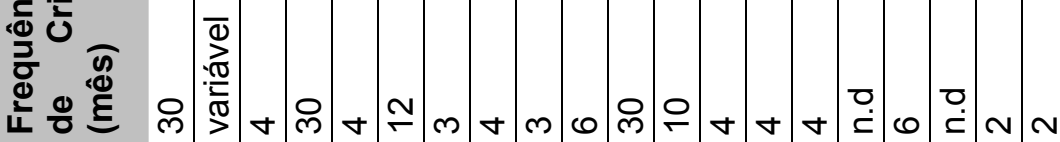

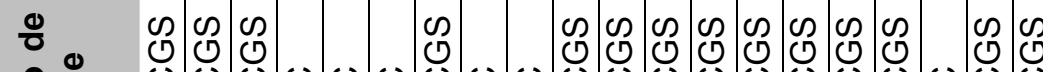
ஃ. 年它 응 \&

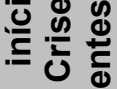

응

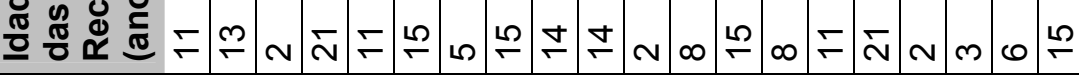
윰

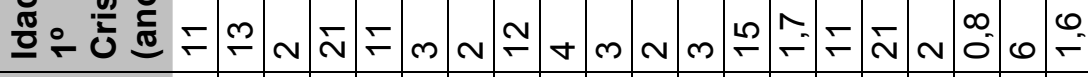

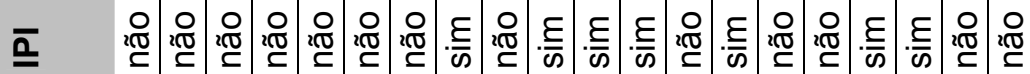

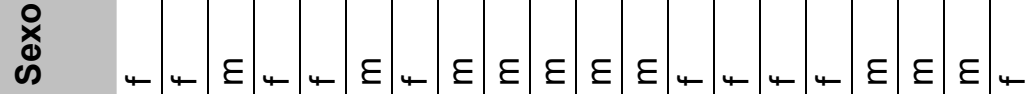

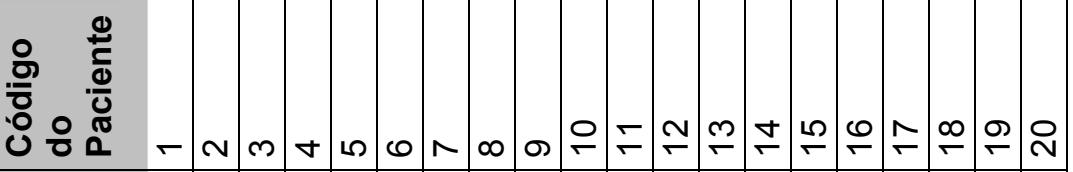
总 

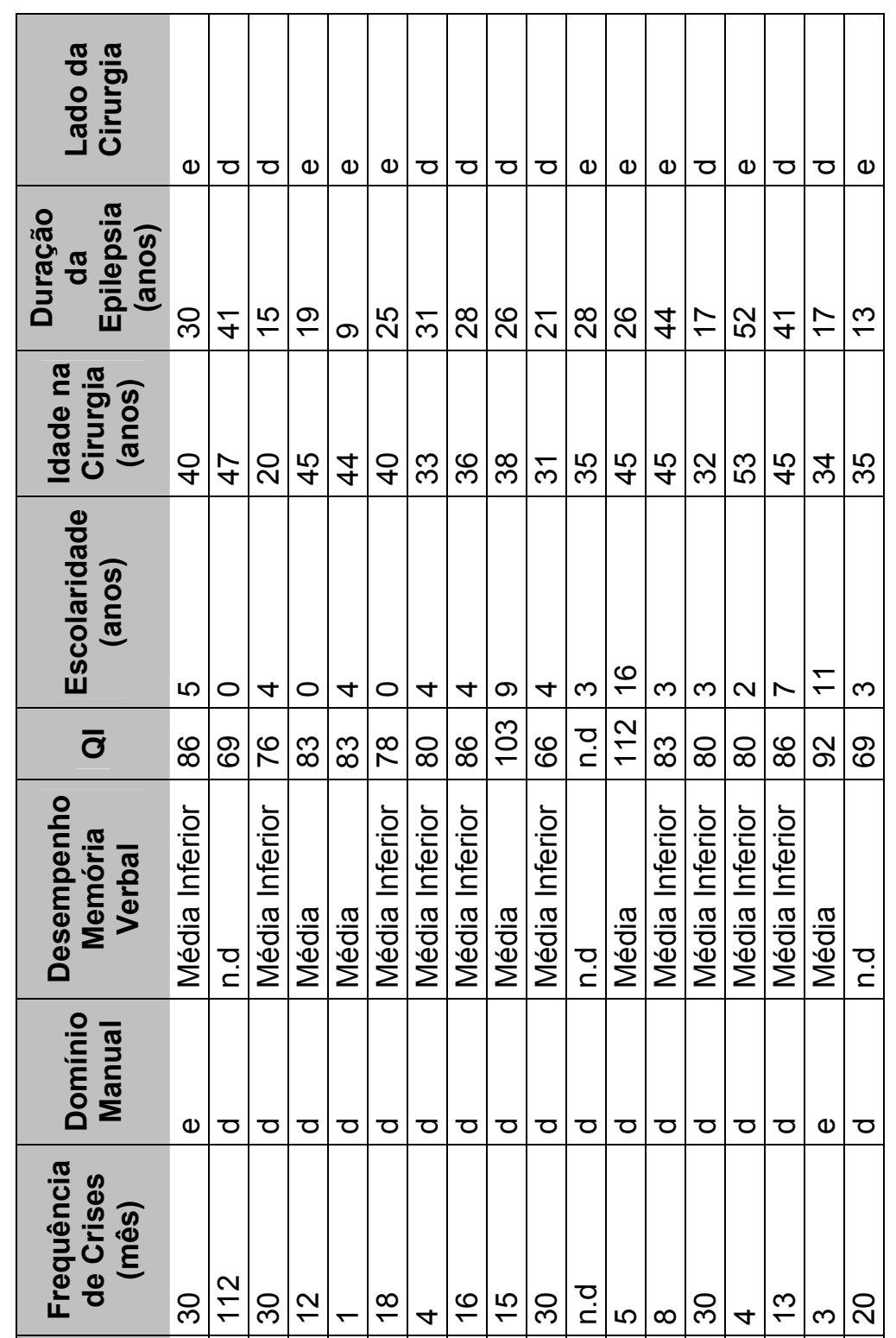

:

些等
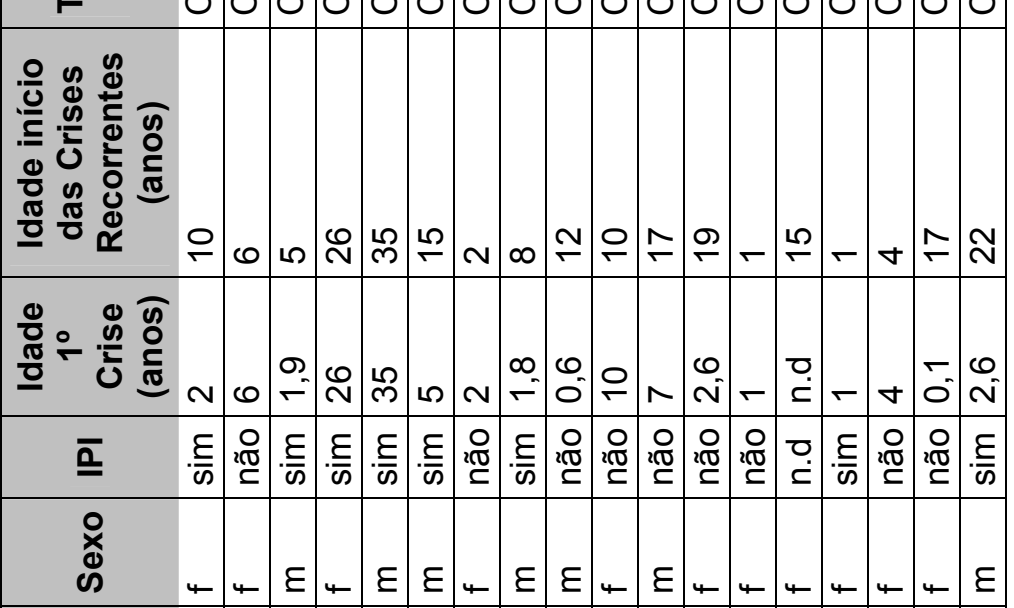

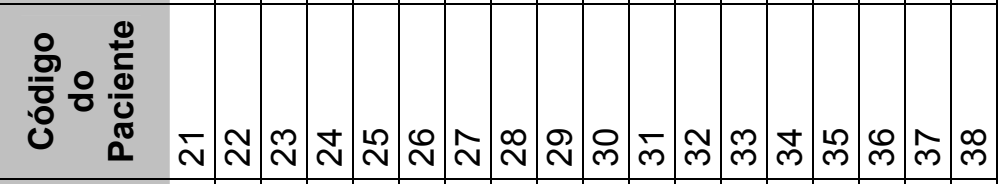

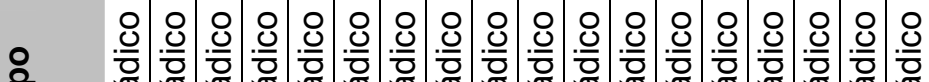

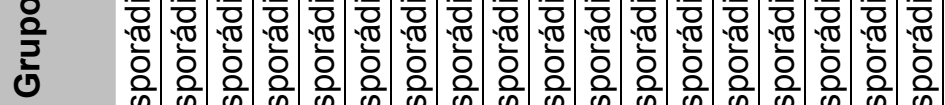
w 
ร

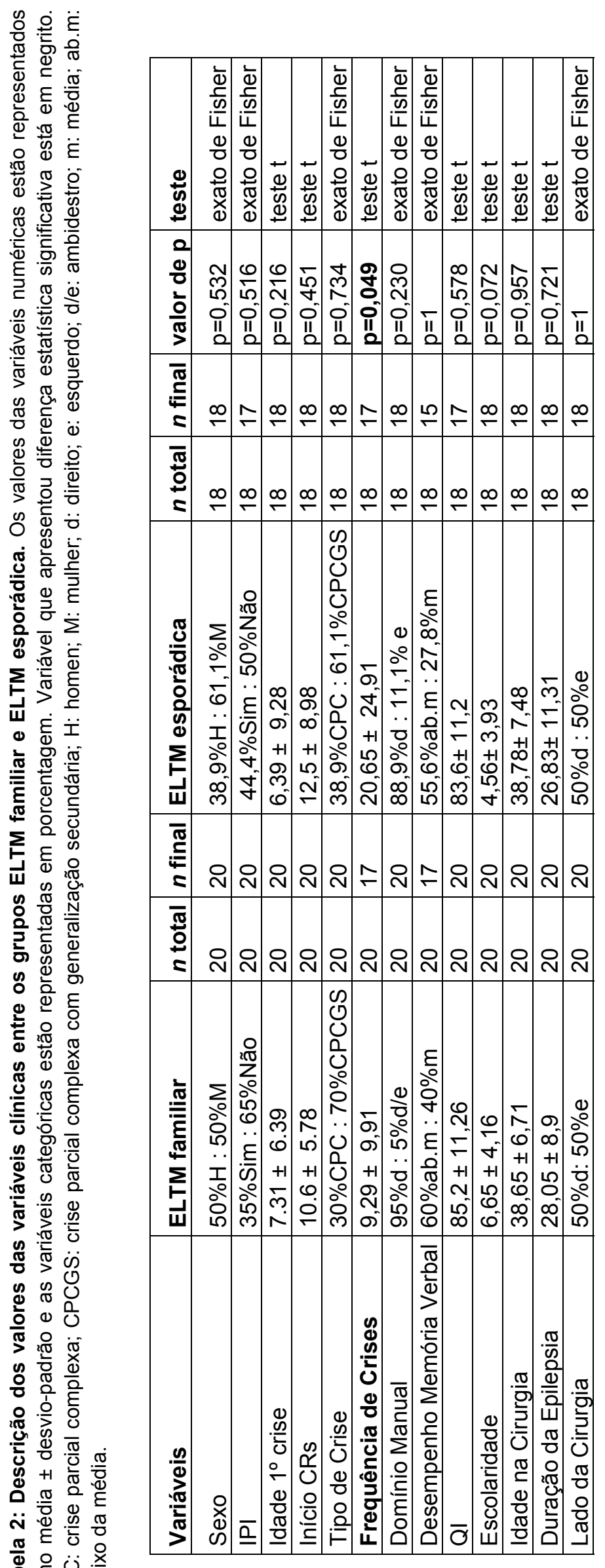


Tabela 3: Descrição das variáveis clínicas dos casos controle.

\begin{tabular}{|l|l|l|l|l|l|}
\hline Grupo & $\begin{array}{l}\text { Código } \\
\text { do } \\
\text { Paciente }\end{array}$ & Sexo & Idade & \multicolumn{1}{|c|}{$\begin{array}{c}\text { Causa } \\
\text { Mortis }\end{array}$} & $\begin{array}{c}\text { Tempo } \\
\text { pós- } \\
\text { mortem } \\
\text { (horas) }\end{array}$ \\
\hline Controle & 1 & $\mathrm{f}$ & 14 & Pneumonia & 4 \\
\hline Controle & 2 & $\mathrm{~m}$ & 66 & Insuficiência respiratória & 2 \\
\hline Controle & 3 & $\mathrm{~m}$ & 34 & Cardiopatia & 6,7 \\
\hline Controle & 4 & $\mathrm{~m}$ & 60 & Choque cardiogênico & 6 \\
\hline Controle & 5 & $\mathrm{~m}$ & 86 & Choque cardiogênico, nefro-esclerose & 6,3 \\
\hline Controle & 6 & $\mathrm{f}$ & 39 & Hipertensão arterial & 6 \\
\hline Controle & 7 & $\mathrm{f}$ & 65 & $\begin{array}{l}\text { Choque cardiocirculatório, insuficiência } \\
\text { cardiaca }\end{array}$ & 6 \\
\hline Controle & 8 & $\mathrm{f}$ & 13 & Infarto pulmonar múltiplo, tetralgia de Fallot & 3,3 \\
\hline Controle & 9 & $\mathrm{f}$ & 63 & Hemorragia pulmonar & 4,5 \\
\hline Controle & 10 & $\mathrm{f}$ & 47 & Hepatopatia & 4,5 \\
\hline
\end{tabular}

\subsubsection{Densidade Neuronal}

A figura 5 é uma imagem ilustrativa das subregiões da formação hipocampal de pacientes epilépticos e controles, imunorreativas para NeuN, um antígeno presente em células neuronais maduras. O hipocampo de pacientes epilépticos apresenta significativa perda de células neuronais em todas subregiões quando comparado ao hipocampo de pacientes controle, exceto em CA2, subículo, parasubículo e córtex entorrinal.

Nesta figura, podemos observar algumas características clássicas que existem na formação hipocampal de pacientes epilépticos, como a dispersão e perda de células granulares. No grupo controle, as células granulares se apresentam mais densamente agrupadas. Além disso, no grupo ELTM existe uma grande perda de células neuronais no setor de Sommer, representado pelas subregiões de CA1 e prosubículo. 


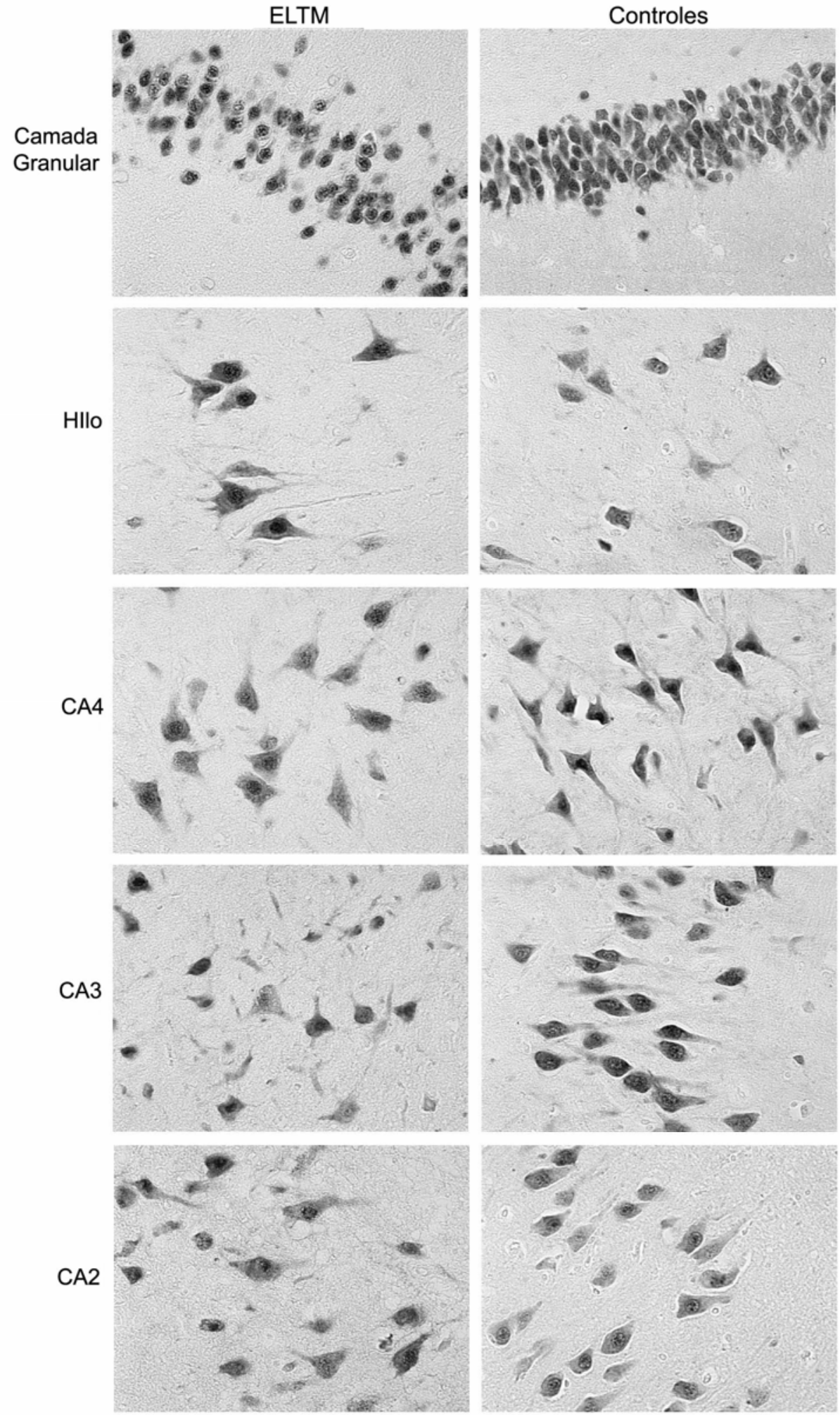




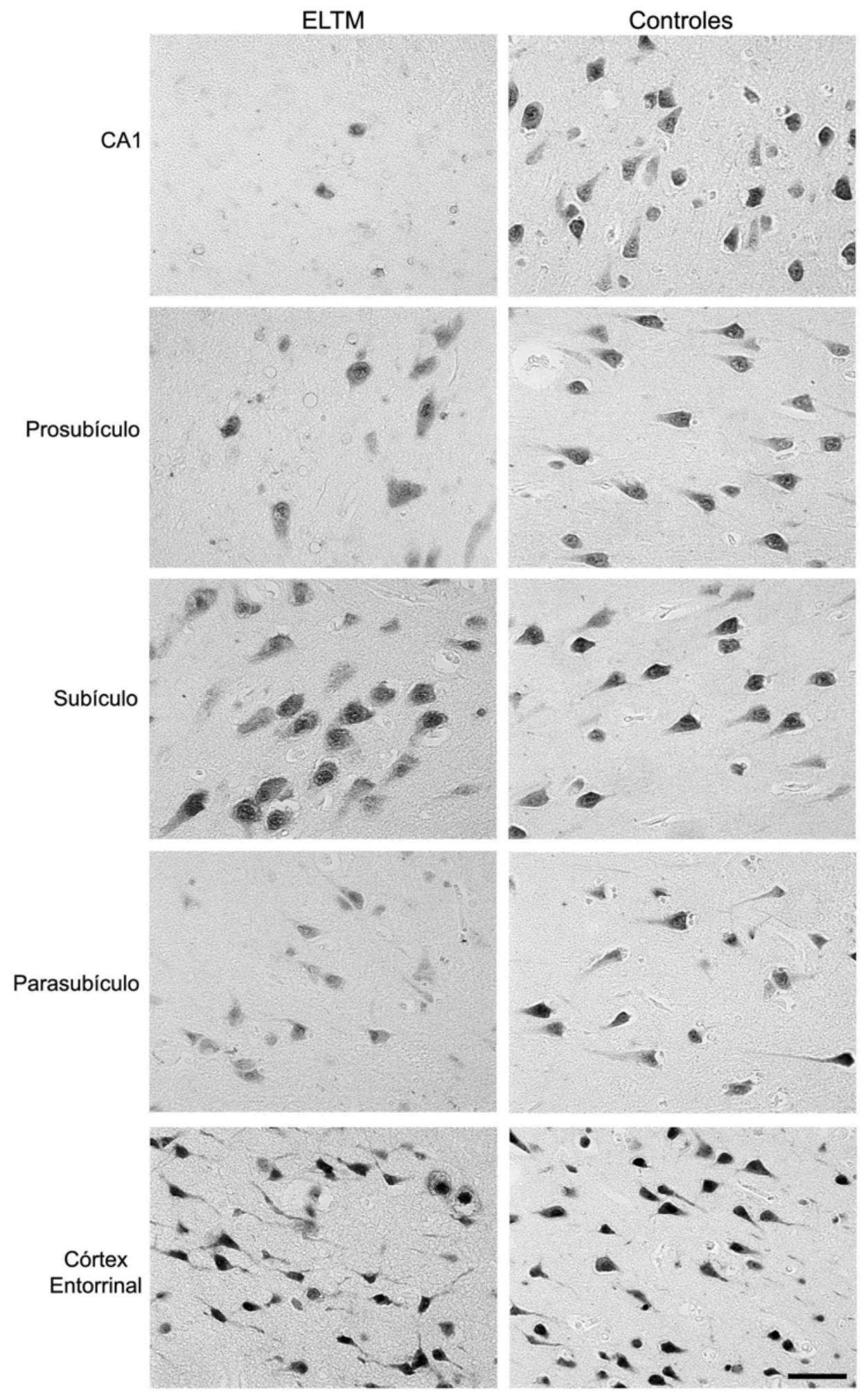

Figura 5: Imunorreatividade para NeuN nas diferentes subregiões do hipocampo nos grupos ELTM e controle. Hipocampos epilépticos apresentam menor densidade neuronal que hipocampos controle na maioria das subregiões da formação hipocampal. A barra no canto inferior direito equivale a $50 \mu \mathrm{m}$. 
Em relação aos resultados de contagem neuronal, observamos diferenças estatisticamente significativas na densidade neuronal entre os grupos ELTM e controle. Como esperado, o grupo ELTM apresentou menor número de células positivas para NeuN que o grupo controle nas regiões da camada granular ( $p<0,001$, teste $t)$, hilo $(p=0,001$, teste $t)$, CA4 $(p=0<001$, teste $t)$, CA3 $(p=0,009$, teste $t)$, CA1 $(p<0,001$, teste $t)$ e prosubículo $(p=0,002$, teste t), como indicado pelos asteriscos na figura 6 .
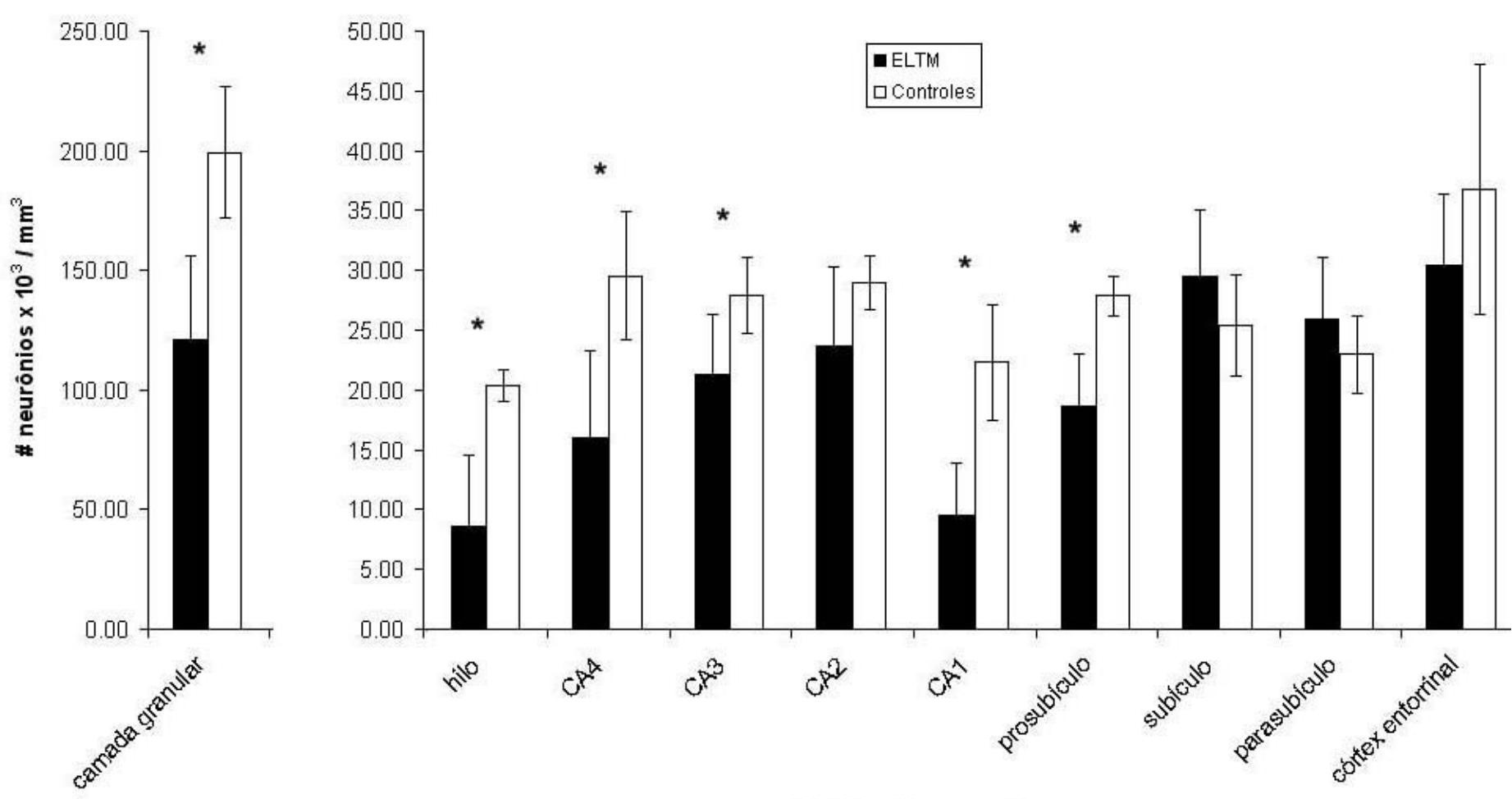

Regiões Hipocampais

Figura 6: Densidade neuronal nas diferentes subregiões do hipocampo de pacientes epilépticos (ELTM) e grupo controle. O grupo ELTM apresentou menor número de células neuronais que o grupo controle nas regiões da camada granular $(p<0,001$, teste $t)$, hilo $(p=0,001$, teste $t)$, CA4 ( $p<0,001$, teste $t)$, CA3 $(p=0,009$, teste $t)$, CA1 $(p<0,001$, teste $t)$ e prosubículo $(p=0,002$, teste $t)$, como indicado pelos asteriscos. Valores apresentados como média \pm DP. 
Tabela 4: Descrição dos valores de densidade neuronal entre os grupos ELTM e controle em todas as regiões do hipocampo. Os valores estão representados como média \pm DP. Regiões que apresentaram diferença estatística significativa estão em negrito.

\begin{tabular}{|l|l|l|l|}
\hline Regiões & ELTM & Controles & valor de $\mathbf{p}$ \\
\hline CG & $120,80 \times 10^{3} / \mathrm{mm}^{3}( \pm 35,54)$ & $199,33 \times 10^{3} / \mathrm{mm}^{3}( \pm 27,25)$ & $\mathbf{p}<\mathbf{0 , 0 0 1}$ \\
\hline Hilo & $8,63 \times 10^{3} / \mathrm{mm}^{3}( \pm 5,86)$ & $\left.20,37 \times 10^{3} / \mathrm{mm}^{3} \pm \pm 1,30\right)$ & $\mathbf{p}=\mathbf{0 , 0 0 1}$ \\
\hline CA4 & $16,02 \times 10^{3} / \mathrm{mm}^{3}( \pm 7,26)$ & $\left.29,52 \times 10^{3} / \mathrm{mm}^{3} \pm \pm 5,36\right)$ & $\mathbf{p}<\mathbf{0 , 0 0 1}$ \\
\hline CA3 & $21,32 \times 10^{3} / \mathrm{mm}^{3}( \pm 5,04)$ & $\left.27,88 \times 10^{3} / \mathrm{mm}^{3} \pm \pm 3,14\right)$ & $\mathbf{p}=\mathbf{0 , 0 0 9}$ \\
\hline CA2 & $23,74 \times 10^{3} / \mathrm{mm}^{3}( \pm 6,55)$ & $\left.28,97 \times 10^{3} / \mathrm{mm}^{3} \pm \pm 2,25\right)$ & $\mathrm{p}=0,076$ \\
\hline CA1 & $9,50 \times 10^{3} / \mathrm{mm}^{3}( \pm 4,34)$ & $22,30 \times 10^{3} / \mathrm{mm}^{3}( \pm 4,82)$ & $\mathbf{p}<\mathbf{0 , 0 0 1}$ \\
\hline Prosubículo & $18,65 \times 10^{3} / \mathrm{mm}^{3}( \pm 4,32)$ & $27,88 \times 10^{3} / \mathrm{mm}^{3}( \pm 1,64)$ & $\mathbf{p}=\mathbf{0 , 0 0 2}$ \\
\hline Subículo & $29,52 \times 10^{3} / \mathrm{mm}^{3}( \pm 5,54)$ & $25,42 \times 10^{3} / \mathrm{mm}^{3}( \pm 4,26)$ & $\mathrm{p}=0,173$ \\
\hline Parasubículo & $25,99 \times 10^{3} / \mathrm{mm}^{3}( \pm 5,06)$ & $22,96 \times 10^{3} / \mathrm{mm}^{3}( \pm 3,28)$ & $\mathrm{p}=0,303$ \\
\hline $\begin{array}{l}\text { Córtex } \\
\text { entorrinal }\end{array}$ & $30,44 \times 10^{3} / \mathrm{mm}^{3}( \pm 5,99)$ & $\left.36,74 \times 10^{3} / \mathrm{mm}^{3} \pm \pm 10,45\right)$ & $\mathrm{p}=0,251$ \\
\hline
\end{tabular}

Quando comparamos os grupos ELTM familiar, esporádica e controle, observamos que os grupos familiar e esporádico apresentaram menor densidade neuronal que o grupo controle nas regiões da camada granular ( $p<0,001$, ANOVA), hilo $(p=0,004$, ANOVA), CA4 $(p=0,001$, ANOVA), CA1 ( $p=0,002$, ANOVA) e prosubículo ( $p<0,001$, ANOVA), figura 7.

O grupo ELTM familiar apresentou menor número de células positivas para NeuN que o grupo controle na região de CA3 ( $p=0,037$, ANOVA), figura 7.

Entre os grupos ELTM familiar e esporádica encontramos apenas uma tendência à diferença na região do parasubículo $(p=0,054$, teste $t)$, indicado pelo sinal cardinal na figura 7 , sendo a maior densidade neuronal do grupo familiar. 


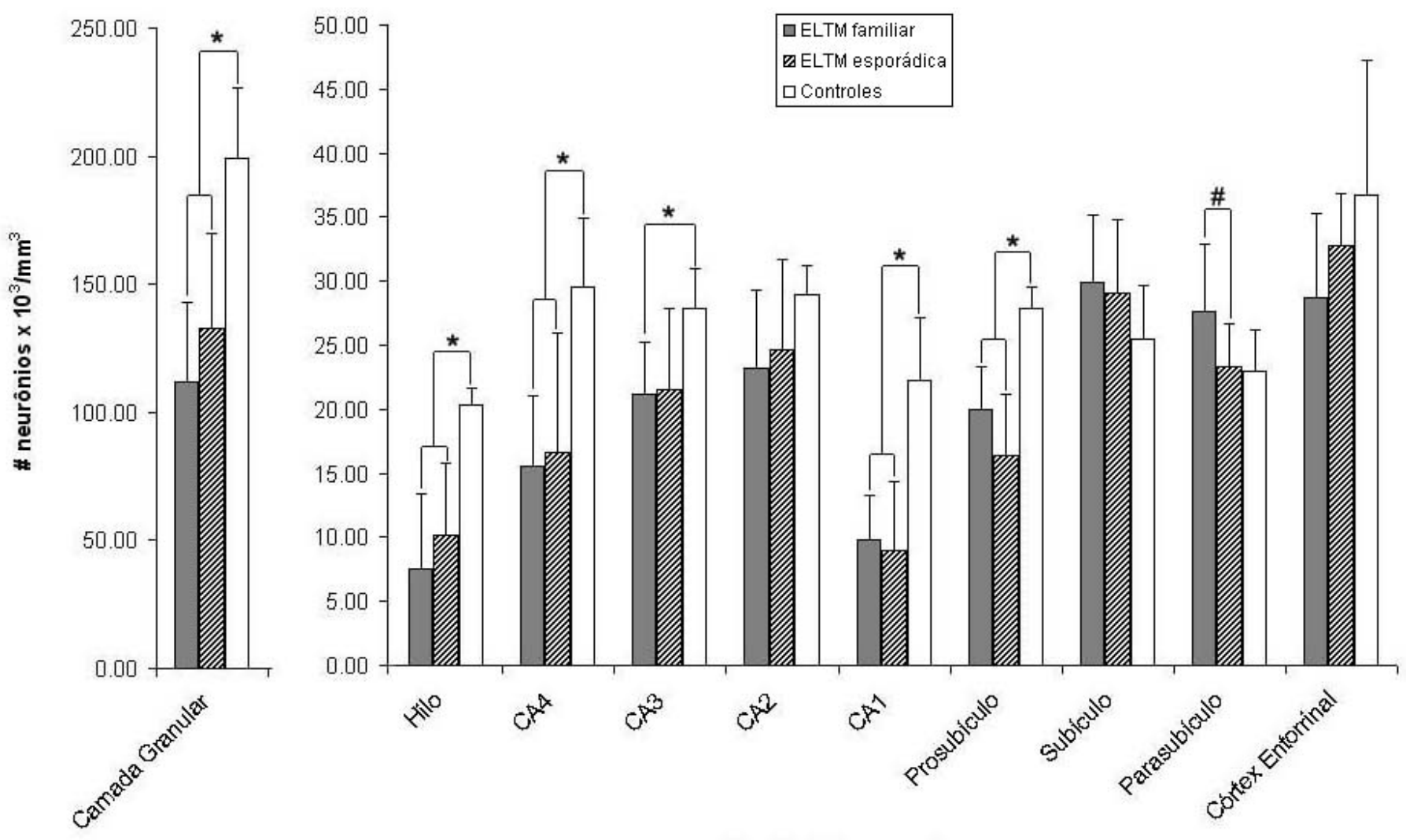

Regiõs Hipocampais

Figura 7: Densidade neuronal nas subregiões do hipocampo em lâminas submetidas à imunohistoquímica para NeuN entre os grupos com ELTM familiar, esporádica e controles.

Os grupos familiar e esporádico apresentaram menor número de células neuronais que o grupo controle nas regiões da camada granular (*, ANOVA, $p<0,001)$, hilo (*, ANOVA, $p=0,004)$, CA4 (*, ANOVA, $p=0,001)$, CA1 ( ${ }^{*}$, ANOVA, $\left.p=0,002\right)$ e prosubículo $\left({ }^{*}\right.$, ANOVA, $\left.p<0,001\right)$. O grupo com ELTM familiar apresentou menor densidade neuronal que o grupo controle na região de CA3 ( ${ }^{*}$, ANOVA, $\left.p=0,037\right)$. $O$ grupo ELTM familiar apresentou tendência à maior densidade neuronal que o grupo esporádico na região do parasubículo (\#, $p=0,054$, teste $t$ ). Valores apresentados como média $\pm D P$. 
Tabela 5: Descrição dos valores de densidade neuronal entre os grupos ELTM familiar e esporádica em toda formação hipocampal. Os valores estão representados como média $\pm \mathrm{DP}$. Região que apresentou tendência à diferença está em negrito.

\begin{tabular}{|l|l|l|l|}
\hline Regiões & ELTM familiar & ELTM esporádica & valor de $p$ \\
\hline CG & $111,86 \times 10^{3} / \mathrm{mm}^{3}( \pm 31,07)$ & $132,49 \times 10^{3} / \mathrm{mm}^{3}( \pm 37,58)$ & $\mathrm{p}=0,123$ \\
\hline Hilo & $7,59 \times 10^{3} / \mathrm{mm}^{3}( \pm 5,77)$ & $10,14 \times 10^{3} / \mathrm{mm}^{3}( \pm 5,67)$ & $\mathrm{p}=0,252$ \\
\hline CA4 & $15,58 \times 10^{3} / \mathrm{mm}^{3}( \pm 5,47)$ & $16,67 \times 10^{3} / \mathrm{mm}^{3}( \pm 9,29)$ & $\mathrm{p}=0,728$ \\
\hline CA3 & $21,17 \times 10^{3} / \mathrm{mm}^{3}( \pm 4,04)$ & $21,55 \times 10^{3} / \mathrm{mm}^{3}( \pm 6,29)$ & $\mathrm{p}=0,884$ \\
\hline CA2 & $23,21 \times 10^{3} / \mathrm{mm}^{3}( \pm 6,10)$ & $\left.24,60 \times 10^{3} / \mathrm{mm}^{3} \pm \pm 7,15\right)$ & $\mathrm{p}=0,657$ \\
\hline CA1 & $9,84 \times 10^{3} / \mathrm{mm}^{3}( \pm 3,46)$ & $8,95 \times 10^{3} / \mathrm{mm}^{3}( \pm 5,43)$ & $\mathrm{p}=0,472$ \\
\hline Prosubículo & $19,95 \times 10^{3} / \mathrm{mm}^{3}( \pm 3,40)$ & $\left.16,40 \times 10^{3} / \mathrm{mm}^{3} \pm 4,80\right)$ & $\mathrm{p}=0,167$ \\
\hline Subículo & $29,87 \times 10^{3} / \mathrm{mm}^{3}( \pm 5,21)$ & $29,05 \times 10^{3} / \mathrm{mm}^{3}( \pm 5,80)$ & $\mathrm{p}=0,688$ \\
\hline Parasubículo & $27,68 \times 10^{3} / \mathrm{mm}^{3}( \pm 5,18)$ & $23,29 \times 10^{3} / \mathrm{mm}^{3}( \pm 3,42)$ & $\mathrm{p}=\mathbf{0 , 0 5 4}$ \\
\hline $\begin{array}{l}\text { Córtex } \\
\text { entorrinal }\end{array}$ & $28,69 \times 10^{3} / \mathrm{mm}^{3}( \pm 6,56)$ & $\left.32,78 \times 10^{3} / \mathrm{mm}^{3} \pm \pm 4,09\right)$ & $\mathrm{p}=0,134$ \\
\hline
\end{tabular}

\subsubsection{Neo-Timm}

Na análise do neobrotamento anormal das fibras musgosas feita em lâminas submetidas à histoquímica de Neo-Timm, podemos observar a intensa marcação dos terminais ricos em zinco na camada molecular do giro denteado do hipocampo epiléptico em relação ao hipocampo controle (figura 8).
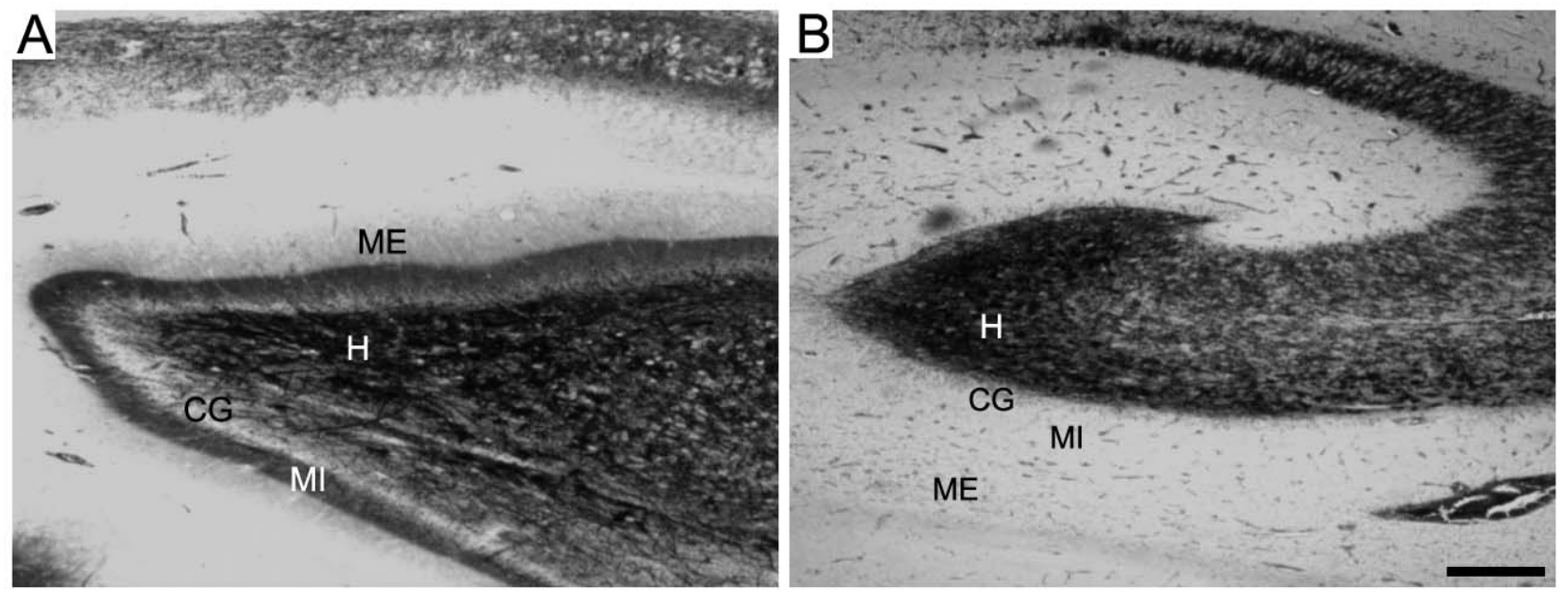

Figura 8: Secções hipocampais submetidas à histoquímica de Neo-Timm. Imagens representativas da marcação das colaterais axônicas ricas em zinco em paciente do grupo ELTM (A) e Controle (B). CG: camada granular; $\mathrm{H}$ : hilo; $\mathrm{Ml}$ : camada molecular interna e ME: camada molecular externa. A barra no canto inferior direito equivale a $200 \mu \mathrm{m}$. 
A partir de lâminas submetidas à histoquímica de Neo-Timm, como as exemplificadas acima, estabelecemos medidas comparativas entre os grupos para estimar a quantidade (valor de cinza) e a magnitude do neobrotamento das fibras musgosas (espessura).

Quando comparamos o grupo ELTM com o grupo controle, observamos que o grupo ELTM possui maior valor de cinza em relação ao grupo controle nas regiões da camada granular $(p<0,001$, teste $t)$, molecular interna $(p<0,001$, teste $t)$ e molecular externa $(p<0,001$, teste $t)$, como ilustrado na figura 9 .

O grupo ELTM também apresentou maior valor de espessura na camada molecular interna $(p<0,001$, teste $t)$, figura 10 .

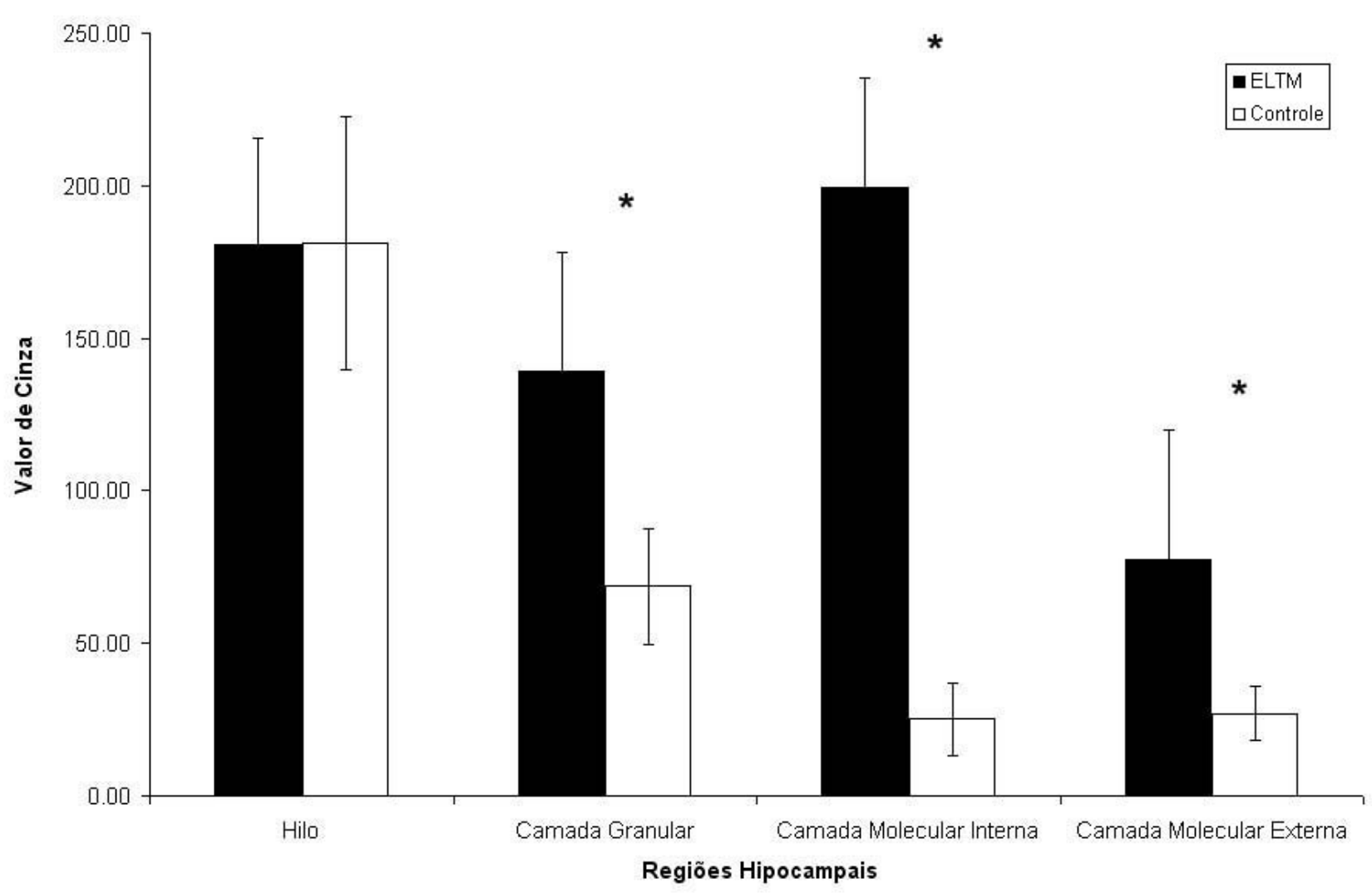

Figura 9: Medidas de valor de cinza em lâminas submetidas à histoquímica de Neo-Timm em diferentes subregiões da Fascia Dentata dos grupos ELTM e controle. O grupo ELTM apresentou maior valor de cinza em relação ao grupo controle nas regiões da camada granular $(p<0,001$, teste $t$ ), molecular interna $(p<0,001$, teste $t)$ e molecular externa $(p<0,001$, teste $t)$, como indicado pelos asteriscos. Valores apresentados como média \pm DP. 
Tabela 6: Descrição dos valores de cinza da marcação de Neo-Timm dos grupos ELTM e controle. Os valores estão representados como média \pm DP. Regiões que apresentaram diferença estatística significativa estão em negrito.

\begin{tabular}{|l|l|l|l|}
\hline Regiões & ELTM & Controle & valor de $\mathbf{p}$ \\
\hline CG & $131,31( \pm 41,10)$ & $68,63( \pm 19,17)$ & $\mathbf{p}<\mathbf{0 , 0 0 1}$ \\
\hline Hilo & $181,32( \pm 40,78)$ & $181,07( \pm 41,37)$ & $\mathbf{p}=0,988$ \\
\hline Camada molecular interna & $184,64( \pm 42,75)$ & $25,17( \pm 11,09)$ & $\mathbf{p}<\mathbf{0 , 0 0 1}$ \\
\hline Camada molecular externa & $79,40( \pm 43,08)$ & $27,00( \pm 8,98)$ & $\mathbf{p}<\mathbf{0 , 0 0 1}$ \\
\hline
\end{tabular}

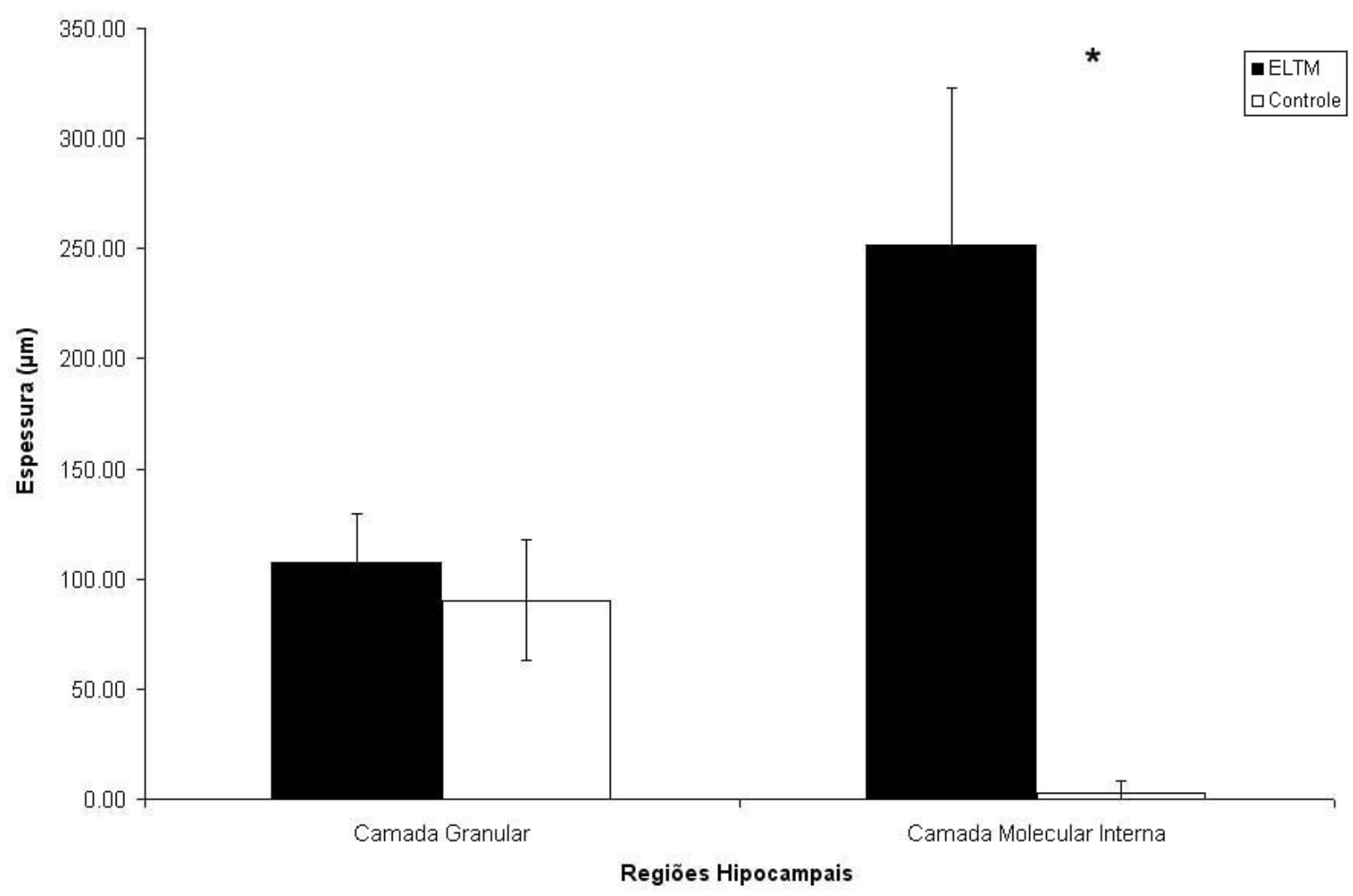

Figura 10: Medidas de espessura em secções submetidas à histoquímica de Neo-Timm em subregiões da Fascia Dentata dos grupos ELTM e controle. O grupo ELTM apresentou maior valor de espessura em relação ao controle na camada molecular interna $(p<0,001$, teste $t$ ), como indicado pelo asterisco. Valores apresentados como média \pm DP. 
Tabela 7: Descrição dos valores de espessura de camadas/ neobrotamento das fibras musgosas entre os grupos ELTM e controle. Os valores estão representados como média \pm desvio padrão. Região que apresentou diferença estatística significativa está em negrito.

\begin{tabular}{|c|c|c|c|}
\hline Regiões & ELTM & Controles & valor de $p$ \\
\hline CG & $97,33 \mu \mathrm{m}( \pm 32,90)$ & $90,33 \mu \mathrm{m}( \pm 27,45)$ & $p=0,580$ \\
\hline $\begin{array}{ll}\text { Camada molecular } \\
\text { interna }\end{array}$ & $222,02 \mu \mathrm{m}( \pm 76,58)$ & $2,77 \mu \mathrm{m}( \pm 5,79)$ & $p<0,001$ \\
\hline
\end{tabular}

Comparamos a formação do neobrotamento das fibras musgosas entre os grupos com ELTM familiar, esporádica e controle. Observamos que os grupos familiar e esporádico demonstraram maior valor de cinza em relação ao grupo controle nas regiões da camada granular ( $p<0,001, A N O V A)$, camada molecular interna $(p<0,001$, ANOVA) e molecular externa ( $p=0,002$, ANOVA), como indicado pelos asteriscos na figura 11.

Entre os grupos familiar e esporádico encontramos que o grupo com ELTM esporádica apresentou maior valor de cinza na camada molecular interna $(p=0,023$, teste $t)$, como indicado pelo asterisco na figura 11. 


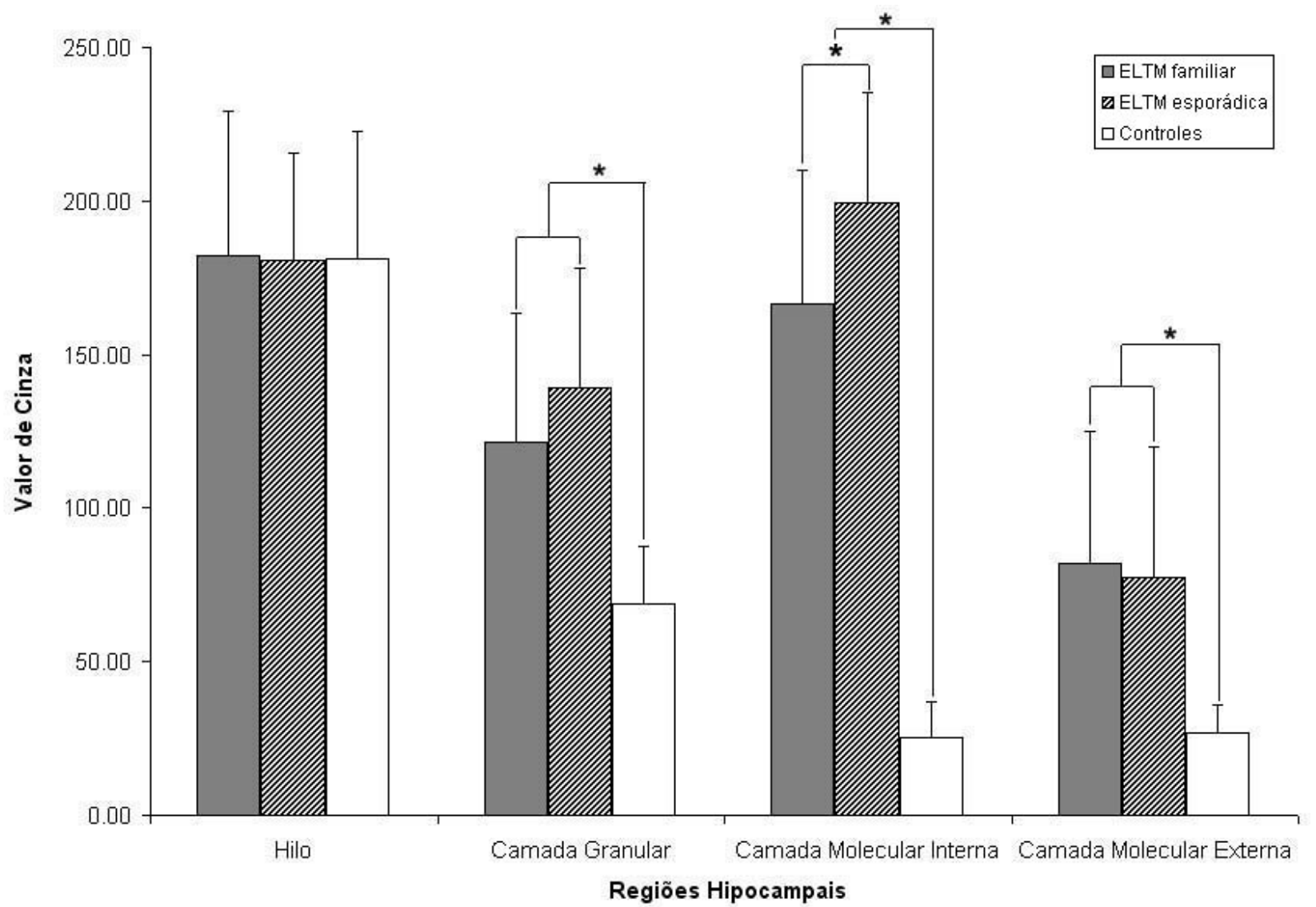

Figura 11: Medidas do valor de cinza nas subregiões da Fascia Dentata em lâminas submetidas à histoquímica de Neo-Timm. Os grupos familiar e esporádico apresentaram maior valor de cinza que o grupo controle nas regiões da camada granular ( ${ }^{*}$, ANOVA, p<0,001), camada molecular interna $\left(^{*}\right.$, ANOVA, $p<0,001)$ e camada molecular externa ( ${ }^{*}$, ANOVA, $\left.p=0,002\right)$, como indicado pelos asteriscos. $O$ grupo com ELTM esporádica apresentou maior valor de cinza que o grupo ELTM familiar na camada molecular interna $\left({ }^{*}, p=0,023\right.$, teste $\left.t\right)$, como indicado pelo sustenido. Valores apresentados como média \pm DP.

Tabela 8: Descrição dos valores de cinza da marcação de neo-Timm entre os grupos ELTM familiar e esporádica. Os valores estão representados como média \pm DP. Região que apresentou diferença estatística significativa está em negrito.

\begin{tabular}{|c|c|c|c|}
\hline Regiões & ELTM familiar & ELTM esporádica & valor de $p$ \\
\hline CG & $\begin{array}{l}121,42 \text { valor de cinza }( \pm \\
41,99)\end{array}$ & $\begin{array}{lllll}139,39 & \text { valor de cinza } & ( \pm \\
38,52) & & & & \\
\end{array}$ & $p=0,357$ \\
\hline Hilo & \begin{tabular}{|l}
182,07 \\
$47,06)$
\end{tabular} valor de cinza $( \pm$ & $\begin{array}{llll}180,71 \\
34,79)\end{array}$ valor de cinza $( \pm$ & 5 \\
\hline lecula & $\begin{array}{ll}162,44 \\
40,03)\end{array}$ valor de cinza $( \pm$ & $\begin{array}{lllll}204,08 & \text { valor de cinza } & ( \pm \\
31,68)\end{array}$ & $p=$ \\
\hline Camad & $\begin{array}{l}82,09 \\
43,13)\end{array}$ valor de cinza $\quad( \pm$ & $\begin{array}{l}77,20 \text { valor de cinza }( \pm \\
42,90)\end{array}$ & $p=0,813$ \\
\hline
\end{tabular}


O mesmo ocorreu com os valores de espessura do neobrotamento das fibras musgosas entre os três grupos, ou seja, os grupos ELTM familiar e esporádica apresentaram maior valor de espessura que o grupo controle na camada molecular interna ( $p<0,001$, ANOVA), como indicado pelo asterisco (Figura 12).

Encontramos uma tendência à diferença entre os grupos ELTM familiar e esporádica na espessura da camada molecular interna $(p=0,058$, teste $t)$, como indicado pelo sinal cardinal (figura 12). Sendo o maior valor de espessura do grupo ELTM esporádica.

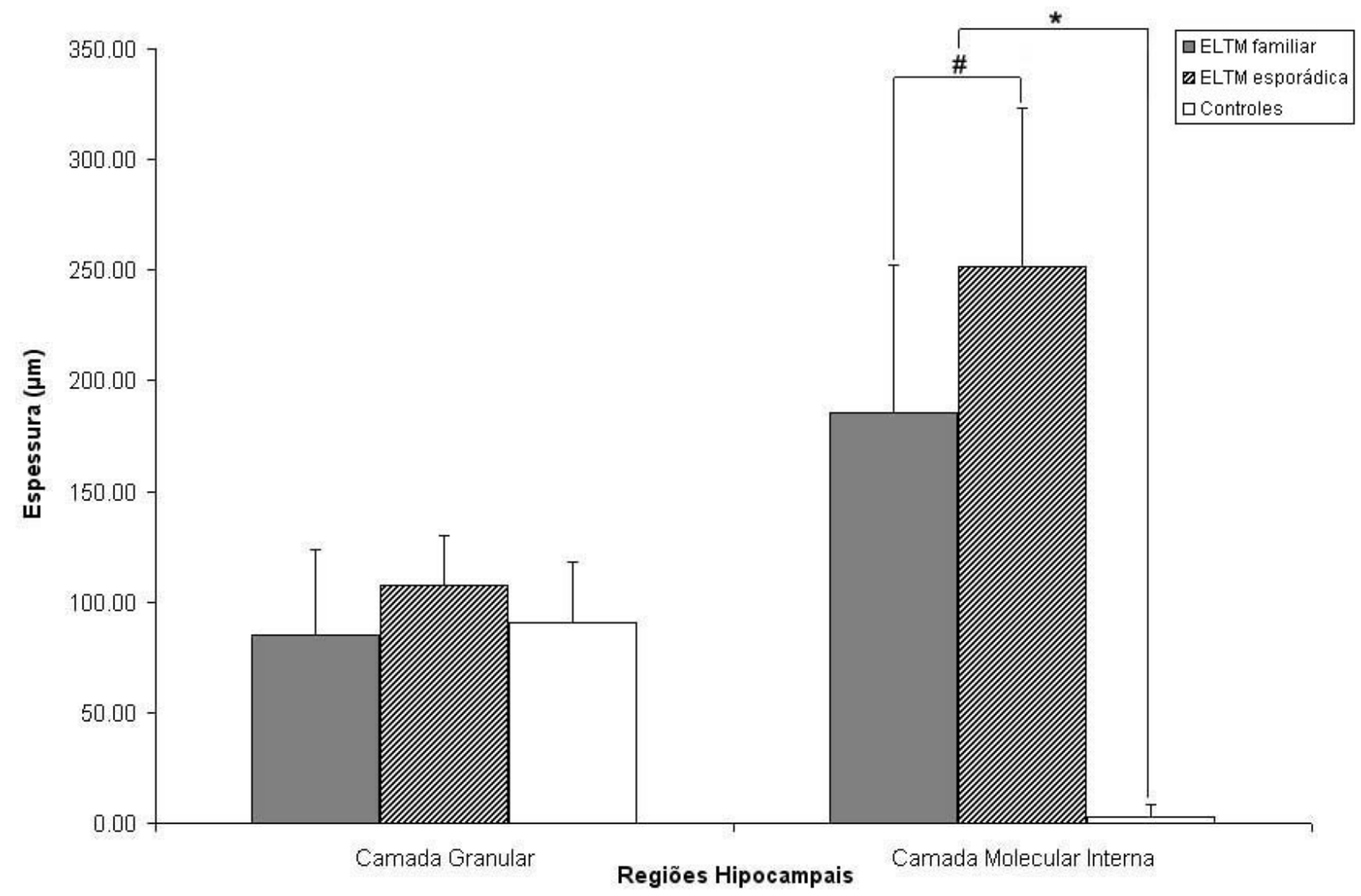

Figura 12: Medidas de espessura em diferentes subregiões da Fascia Dentata em lâminas submetidas à histoquímica de Neo-Timm. Os grupos ELTM familiar e esporádica apresentaram maior valor de espessura que o grupo controle na camada molecular interna ( ${ }^{*}$, ANOVA, $p<0,001$ ), indicado pelo asterisco. Os grupos ELTM familiar e esporádica apresentaram uma tendência à diferença na espessura da camada molecular interna (\#, teste $t, p=0,058)$. Valores apresentados como média \pm DP. 
Tabela 9: Descrição dos valores de espessura de camadas/ neobrotamento das fibras musgosas entre os grupos ELTM familiar e esporádica. Os valores estão representados como média \pm DP. Nenhuma região apresentou diferença estatística significativa. A região da camada molecular interna apresentou apenas uma tendência à diferença entre os grupos (em negrito).

\begin{tabular}{|l|l|l|l|}
\hline Regiões & ELTM familiar & ELTM esporádica & valor de $\mathbf{p}$ \\
\hline CG & $84,94 \mu \mathrm{m}( \pm 39,02)$ & $107,46 \mu \mathrm{m}( \pm 22,22)$ & $\mathrm{p}=0,129$ \\
\hline $\begin{array}{l}\text { Camada molecular } \\
\text { interna }\end{array}$ & $185,62 \mu \mathrm{m}( \pm 66,38)$ & $251,81 \mu \mathrm{m}( \pm 71,32)$ & $\mathbf{p}=\mathbf{0 , 0 5 8}$ \\
\hline
\end{tabular}

\subsubsection{MAP2}

A formação do neobrotamento anormal das fibras musgosas é uma característica histopatológica bem conhecida na ELTM. Além das alterações axonais, existem alterações na estrutura dendrítica da formação hipocampal de pacientes epilépticos. Dessa forma, estudamos o padrão de expressão da proteína MAP2, que é expressa de forma predominante em dendritos. Na figura 13, exemplificamos a expressão desta proteína nas diferentes regiões do hipocampo de pacientes epilépticos em comparação à expressão de MAP2 em hipocampos controle. 


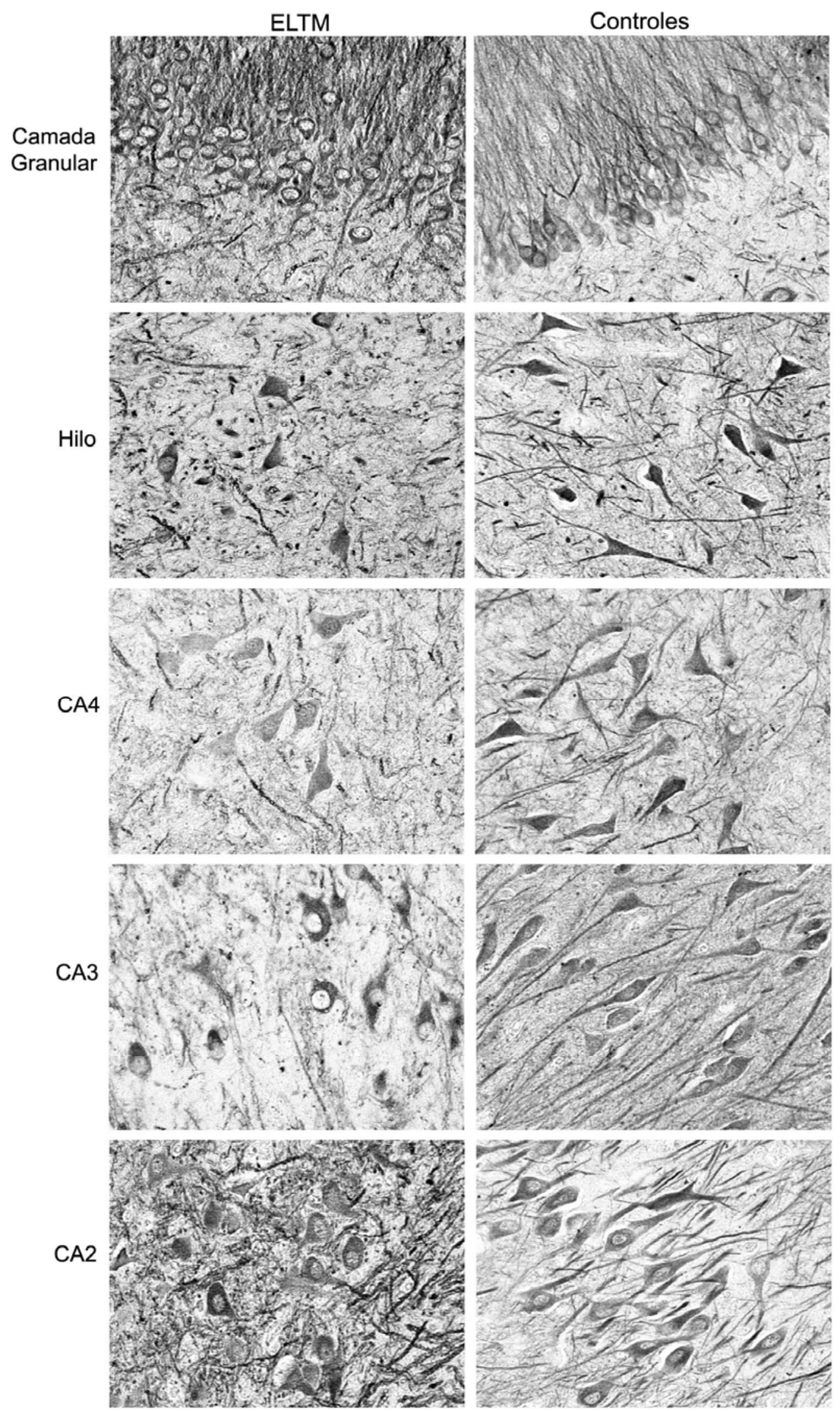




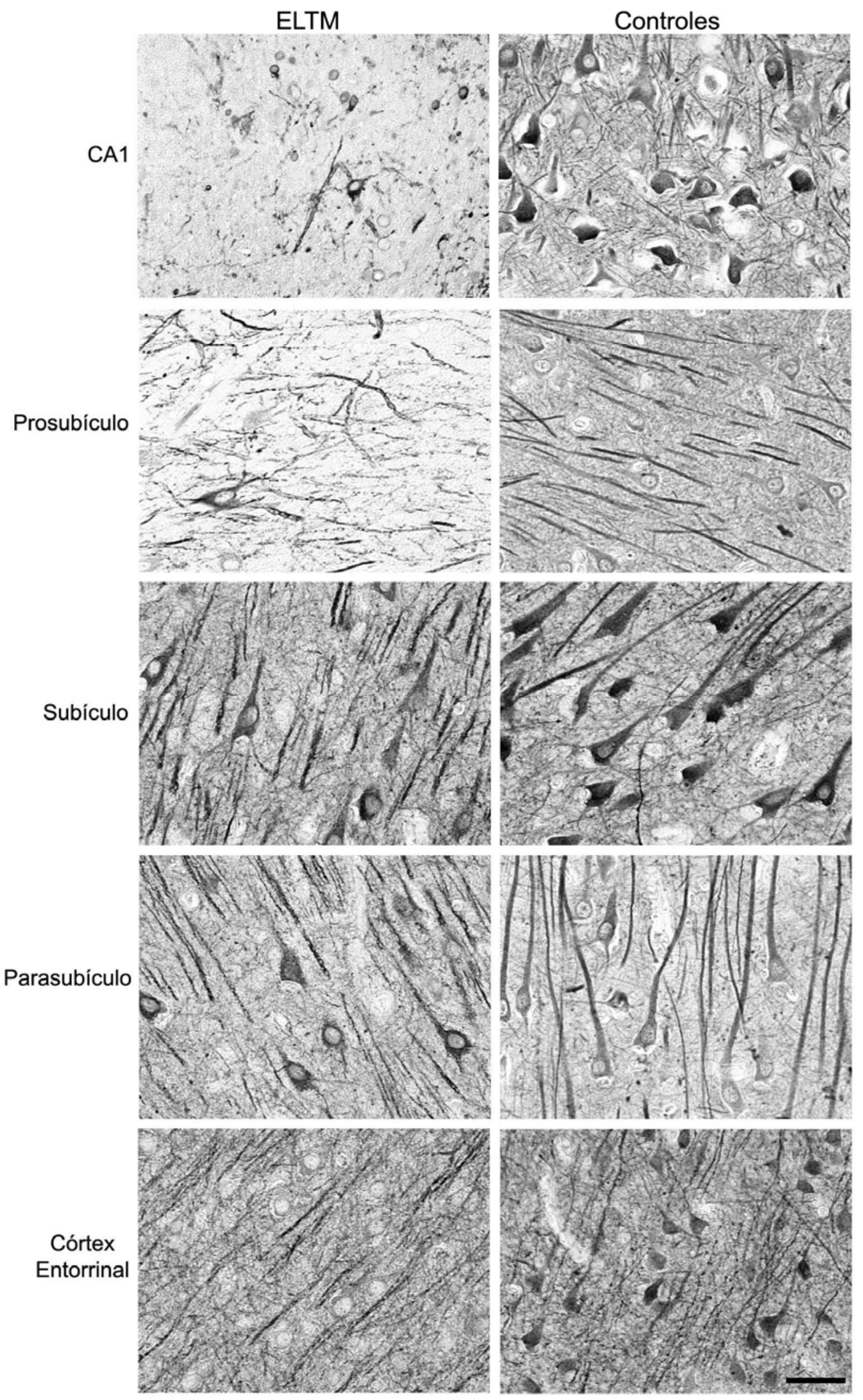

Figura 13: Imagem ilustrativa da expressão de MAP2 na formação hipocampal de pacientes com ELTM e controles. Hipocampos ELTM têm menor expressão de MAP2 que hipocampos controles em 
várias regiões do hipocampo, exceto na camada granular, CA2 e parasubículo. Barra no canto inferior direito equivale a $50 \mu \mathrm{m}$.

Quando quantificamos a expressão de MAP2 nos grupos ELTM e controle, encontramos que o grupo ELTM apresentou maiores valores de expressão de MAP2 em relação ao grupo controle nas regiões da camada granular ( $p<0,001$, teste t), CA2 ( $p=0,001$, teste $t)$ e parasubículo $(p=0,017$, teste $t)$, figura 14 .

O grupo ELTM apresentou menores valores de expressão de MAP2 em relação ao grupo controle nas regiões do hilo $(p=0,003$, teste $t)$, CA4 $(p<0,001$, teste $t)$, CA3 $(p=0,003$, teste $t)$, CA1 $(p<0,001$, teste $t)$ e prosubículo $(p<0,001$, teste $t)$, figura 14 .

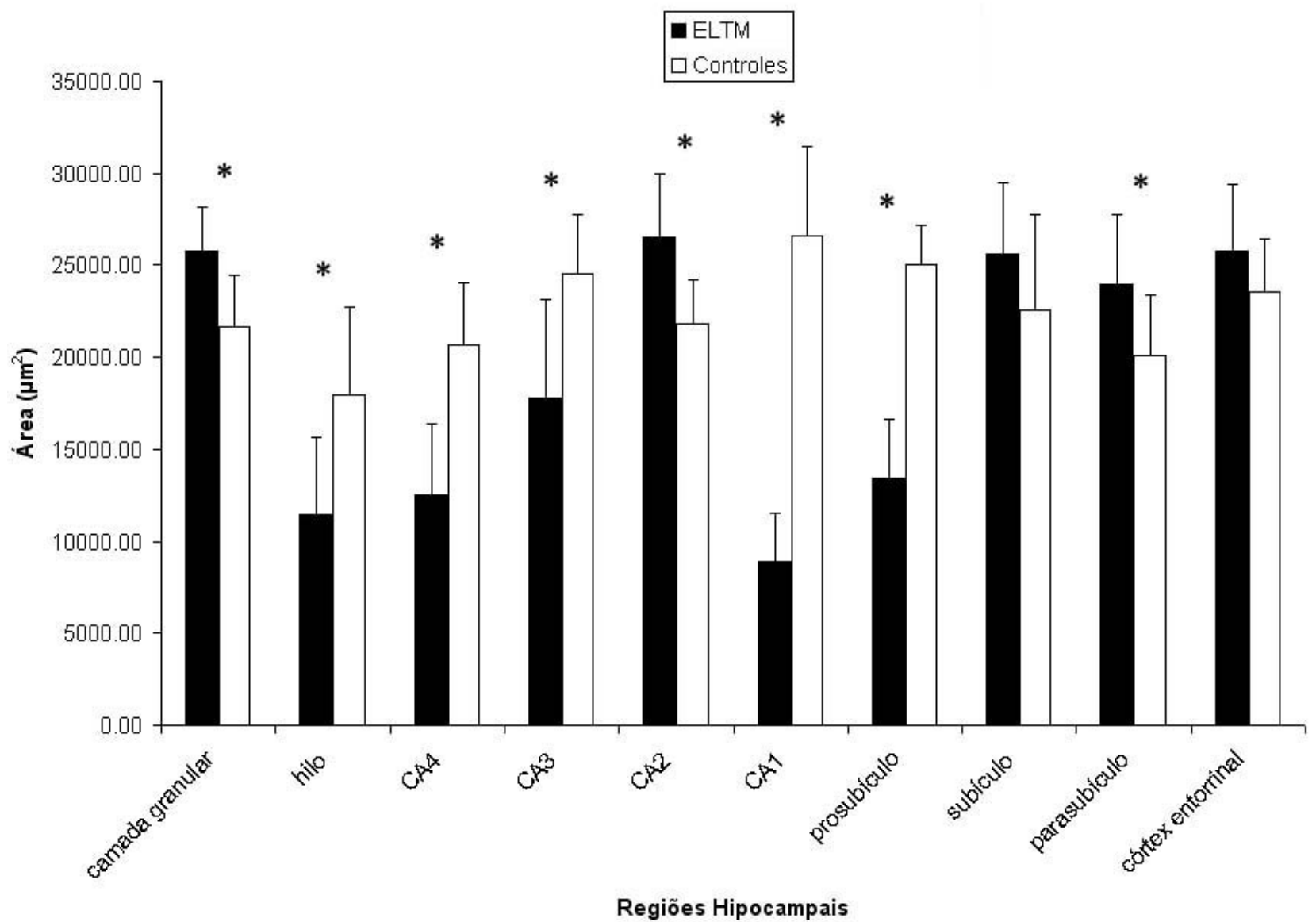

Figura 14: Expressão de MAP2 na formação hipocampal de pacientes epilépticos (ELTM) comparados aos controles. O grupo ELTM apresentou maiores valores de expressão de MAP2 em relação ao grupo controle nas regiões da camada granular $(p<0,001$, teste $t)$, CA2 $(p=0,001$, teste $t)$ e 
parasubículo ( $p=0,017$, teste $t)$. O grupo controle apresentou maiores valores de expressão de MAP2 em relação aos epilépticos nas regiões do hilo $(p=0,003$, teste $t), C A 4(p<0,001$, teste $t), C A 3(p=0,003$, teste $t)$, CA1 $(p<0,001$, teste $t)$ e prosubículo $(p<0,001$, teste $t)$, como indicado pelos asteriscos. Valores apresentados como média \pm DP.

Tabela 10: Descrição dos valores da expressão de MAP2 entre os grupos ELTM e controle na formação hipocampal. Os valores estão representados como média \pm DP. Regiões que apresentaram diferença estatística significativa estão em negrito.

\begin{tabular}{|l|l|l|l|}
\hline Regiões & ELTM & Controles & valor de $\mathbf{p}$ \\
\hline CG & $25754,43 \mu \mathrm{m}^{2}( \pm 2403,54)$ & $21620,15 \mu \mathrm{m}^{2}( \pm 2804,41)$ & $\mathbf{p}<\mathbf{0 , 0 0 1}$ \\
\hline Hilo & $11411,28 \mu \mathrm{m}^{2}( \pm 4243,14)$ & $17927,82 \mu \mathrm{m}^{2}( \pm 4791,22)$ & $\mathbf{p = 0 , 0 0 3}$ \\
\hline CA4 & $12514,22 \mu \mathrm{m}^{2}( \pm 3881,04)$ & $20691,71 \mu \mathrm{m}^{2}( \pm 3330,44)$ & $\mathbf{p}<\mathbf{0 , 0 0 1}$ \\
\hline CA3 & $17817,39 \mu \mathrm{m}^{2}( \pm 5310,85)$ & $24579,46 \mu \mathrm{m}^{2}( \pm 3160,36)$ & $\mathbf{p}=\mathbf{0 , 0 0 3}$ \\
\hline CA2 & $26503,71 \mu \mathrm{m}^{2}( \pm 3481,21)$ & $21823,08 \mu \mathrm{m}^{2}( \pm 2377,20)$ & $\mathbf{p}=\mathbf{0 , 0 0 1}$ \\
\hline CA1 & $8874,54 \mu \mathrm{m}^{2}( \pm 2692)$ & $26626,56 \mu \mathrm{m}^{2}( \pm 4830,86)$ & $\mathbf{p}<\mathbf{0 , 0 0 1}$ \\
\hline Prosubículo & $13435,30 \mu \mathrm{m}^{2}( \pm 3159,78)$ & $25007,77 \mu \mathrm{m}^{2}( \pm 2143,16)$ & $\mathbf{p}<\mathbf{0 , 0 0 1}$ \\
\hline Subículo & $25631,01 \mu \mathrm{m}^{2}( \pm 3886,31)$ & $22583,65 \mu \mathrm{m}^{2}( \pm 5153,88)$ & $\mathbf{p}=0,080$ \\
\hline Parasubículo & $23963,01 \mu \mathrm{m}^{2}( \pm 3801,11)$ & $20107,38 \mu \mathrm{m}^{2}( \pm 3295,01)$ & $\mathbf{p = 0 , 0 1 7}$ \\
\hline $\begin{array}{l}\text { Córtex } \\
\text { entorrinal }\end{array}$ & $25779,08 \mu \mathrm{m}^{2}( \pm 3613,56)$ & $23587,36 \mu \mathrm{m}^{2}( \pm 2869,97)$ & $\mathbf{p}=0,114$ \\
\hline
\end{tabular}

Quando comparamos os grupos ELTM familiar, ELTM esporádica e controle, encontramos que os grupos familiar e esporádico apresentaram maior valor de expressão de MAP2 que o grupo controle nas regiões da camada granular ( $p<0,001$, ANOVA) e CA2 $(p=0,005$, ANOVA), figura 15 .

Em contrapartida, os grupos familiar e esporádico apresentaram menor expressão de MAP2 em relação ao grupo controle nas regiões do hilo $(p=0,011$, ANOVA), CA4 $(p<0,001$, ANOVA), CA3 ( $p=0,008$, ANOVA), CA1 ( $p<0,001$, ANOVA) e prosubículo $(p<0,001$, ANOVA), como indicado pelos asteriscos (figura 15).

O grupo ELTM esporádica apresentou maior expressão de MAP2 que o grupo controle na região do parasubículo ( $p=0,042$, ANOVA), como indicado pelo asterisco (figura 15).

Quando comparamos apenas os grupos ELTM familiar e esporádica, encontramos que o grupo ELTM esporádica apresentou maior expressão de MAP2 que o grupo ELTM familiar nas 
regiões de CA1 $(p=0,002$, teste t) e córtex entorrinal $(p=0,042$, teste $t)$, como indicado pelos asteriscos (figura 15).

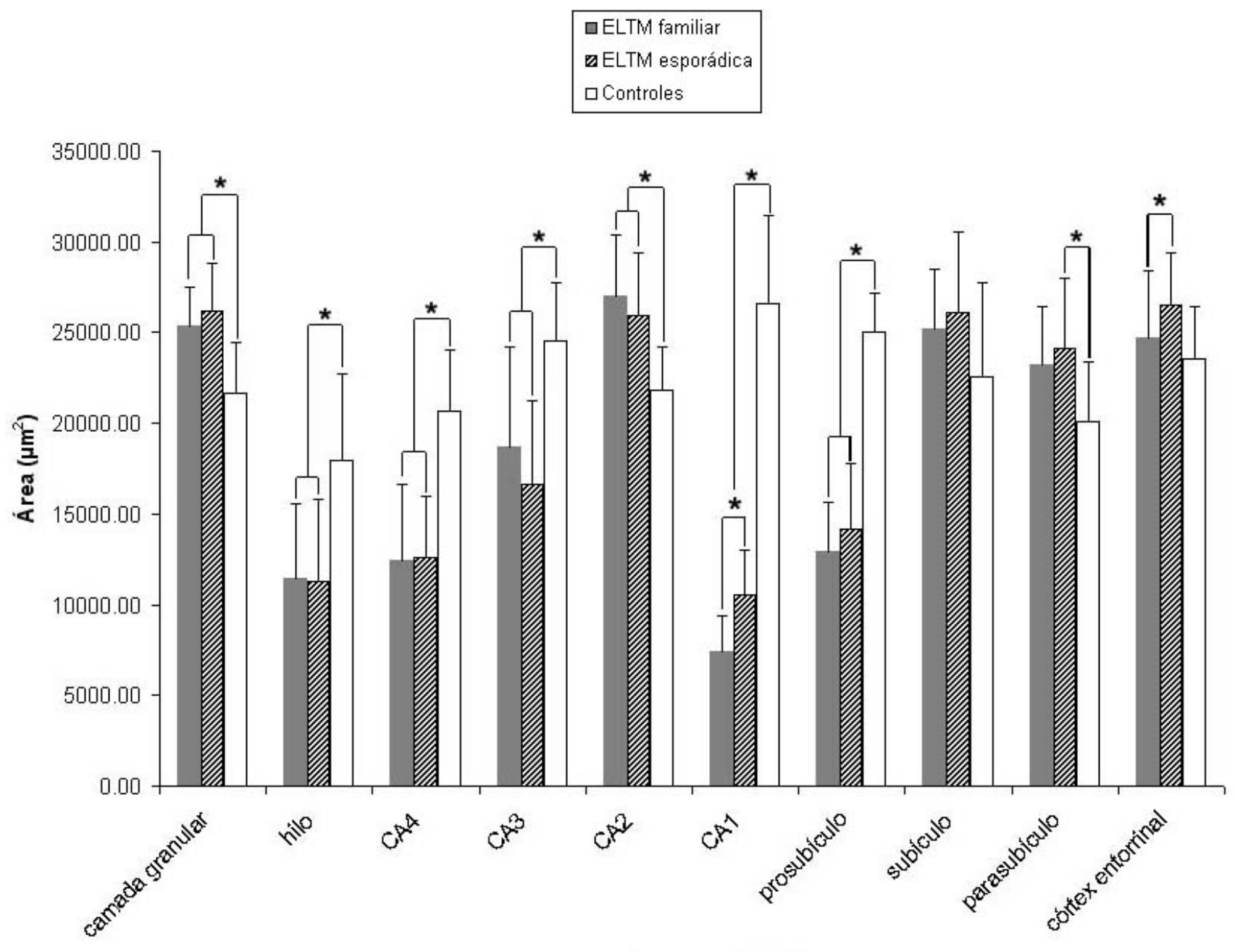

Regiões Hipocampais

Figura 15: Expressão de MAP2 nas diferentes subregiões do hipocampo entre os grupos com

ELTM familiar, esporádica e controle. Os grupos familiar e esporádico apresentaram maior expressão de MAP2 que o grupo controle nas regiões da camada granular ( ${ }^{*}$, ANOVA, p<0,001) e em CA2 (*, ANOVA, $p=0,005)$. Entretanto, os grupos familiar e esporádico apresentaram menor expressão de MAP2 que o grupo controle nas regiões do hilo $\left({ }^{*}\right.$, ANOVA, $\left.p=0,011\right)$, CA4 $\left({ }^{*}\right.$, ANOVA, $\left.p<0,01\right)$, CA3 $\left({ }^{*}\right.$, ANOVA, $p=0,008), C A 1\left({ }^{*}, A N O V A, p<0,001\right)$ e prosubículo $\left({ }^{*}\right.$, ANOVA, $\left.p<0,001\right)$. O grupo esporádico apresentou maior expressão de MAP2 que o grupo controle no parasubículo ( ${ }^{*}$, ANOVA, $\left.p=0,042\right)$. O grupo ELTM esporádica apresentou maior expressão de MAP2 que o grupo ELTM familiar nas regiões de CA1 ( ${ }^{*}$, teste $t, p=0,002)$ e córtex entorrinal $\left({ }^{*}\right.$, teste $\left.t, p=0,042\right)$. Valores apresentados como média $\pm D P$. 
Tabela 11: Descrição dos valores de expressão de MAP2 entre os grupos ELTM familiar e esporádica. Os valores estão representados como média \pm DP. Regiões que apresentaram diferença estatística significativa estão em negrito.

\begin{tabular}{|l|l|l|l|}
\hline Regiões & ELTM familiar & ELTM esporádica & valor de $p$ \\
\hline CG & $25402,45 \mu \mathrm{m}^{2}( \pm 2097,48)$ & $26187,63 \mu \mathrm{m}^{2}( \pm 2670,65)$ & $\mathrm{p}=0,40$ \\
\hline Hilo & $11482,62 \mu \mathrm{m}^{2}( \pm 4068,21)$ & $11314,00 \mu \mathrm{m}^{2}( \pm 4468,93)$ & $\mathrm{p}=0,678$ \\
\hline CA4 & $12432,84 \mu \mathrm{m}^{2}( \pm 4238,31)$ & $12617,80 \mu \mathrm{m}^{2}( \pm 3369,17)$ & $\mathrm{p}=0,911$ \\
\hline CA3 & $18665,97 \mu \mathrm{m}^{2}( \pm 5585,13)$ & $16605,13 \mu \mathrm{m}^{2}( \pm 4630,07)$ & $\mathrm{p}=0,463$ \\
\hline CA2 & $26993,20 \mu \mathrm{m}^{2}( \pm 3416,86)$ & $25916,33 \mu \mathrm{m}^{2}( \pm 3466,84)$ & $\mathrm{p}=0,410$ \\
\hline CA1 & $7443,90 \mu \mathrm{m}^{2}( \pm 1979,95)$ & $10543,63 \mu \mathrm{m}^{2}( \pm 2440,14)$ & $\mathrm{p}=\mathbf{0 , 0 0 2}$ \\
\hline Prosubículo & $12906,52 \mu \mathrm{m}^{2}( \pm 2777)$ & $14154,12 \mu \mathrm{m}^{2}( \pm 3673,25)$ & $\mathrm{p}=0,313$ \\
\hline Subículo & $25164,71 \mu \mathrm{m}^{2}( \pm 3351,48)$ & $26074,45 \mu \mathrm{m}^{2}( \pm 4495,67)$ & $\mathrm{p}=0,486$ \\
\hline Parasubículo & & $24106,57 \mu \mathrm{m}^{2}( \pm 3867,29)$ & $\mathrm{p}=0,397$ \\
\hline $\begin{array}{l}\text { Córtex } \\
\text { entorrinal }\end{array}$ & $24687,13 \mu \mathrm{m}^{2}( \pm 3723,75)$ & $26543,82 \mu \mathrm{m}^{2}( \pm 2825,03)$ & $\mathrm{p}=\mathbf{0 , 0 4 2}$ \\
\hline
\end{tabular}

\subsubsection{Tau}

A proteína tau é bastante conhecida na formação dos emaranhados neurofibrilares, vistos na doença de Alzheimer, porém sua expressão aparece alterada também na ELTM (figura 16). Nesta imagem, podemos observar que o grupo ELTM apresentou maior expressão de tau no neurópilo de todas as subregiões hipocampais ilustradas na figura que o grupo controle.

Nossos resultados indicaram que o grupo com ELTM apresentou maior expressão da proteína tau que o grupo controle nas regiões da camada granular $(p<0,001$, teste $t)$, hilo $(p=0,005$, teste $t)$, CA3 $(p=0,006$, teste $t)$, CA2 $(p=0,006$, teste $t)$ e córtex entorrinal $(p=0,038$, teste $\mathrm{t}$ ), figura 17 . 

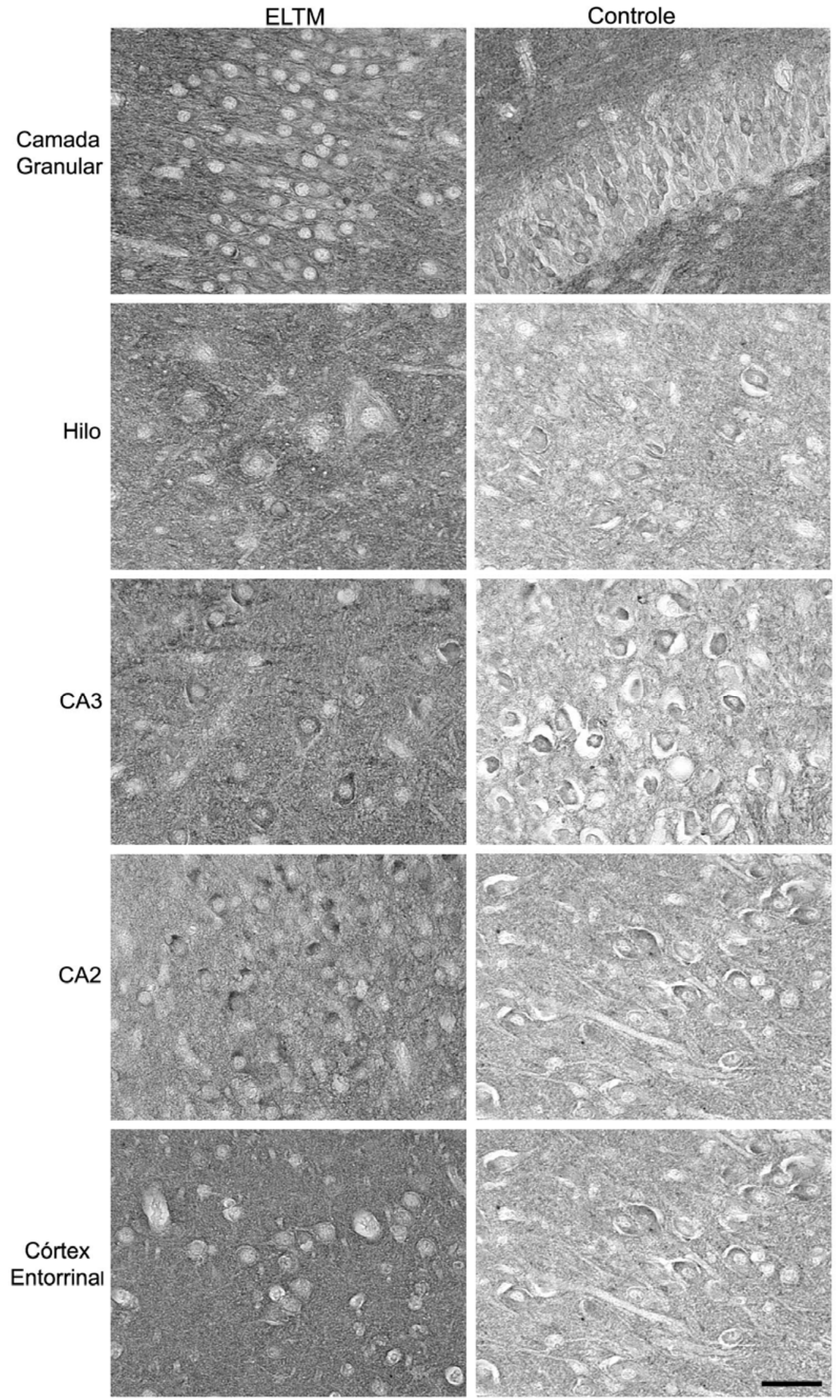

Figura 16: Imagem ilustrativa da expressão da proteína tau em secções hipocampais provenientes de casos ELTM e controle. O grupo ELTM apresentou maior expressão de tau que 0 
grupo controle em todas estas regiões apresentadas na figura. A barra no canto inferior direito equivale a $50 \mu \mathrm{m}$.

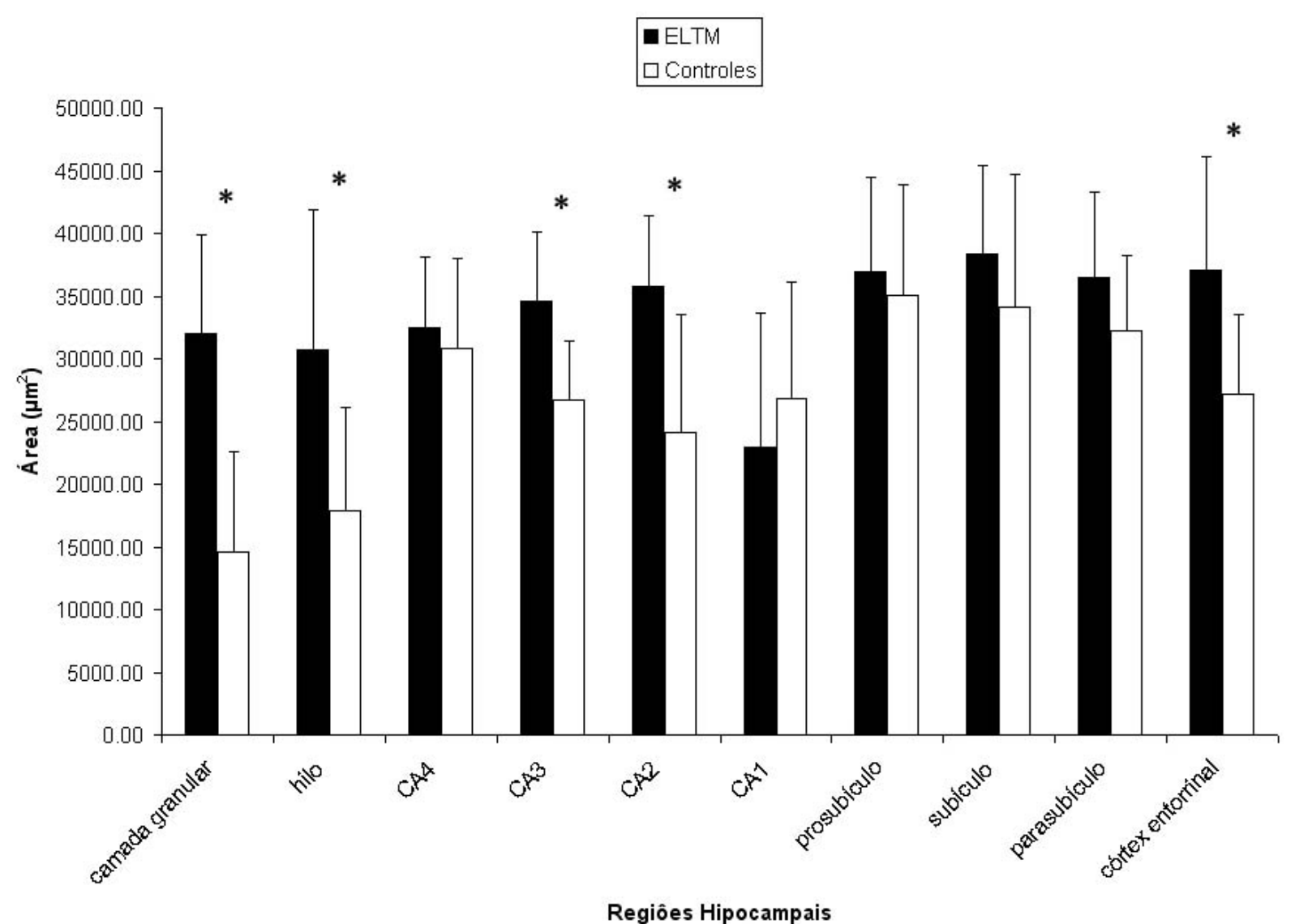

Figura 17: Expressão de tau nas subregiões do hipocampo entre os grupos ELTM e controle. $O$ grupo ELTM apresentou maior expressão de proteína tau que o grupo controle nas regiões da camada granular $(p<0,001$, teste $t)$, hilo $(p=0,005)$, CA3 $(p=0,006), C A 2(p=0,006)$ e córtex entorrinal $(p=0,038)$, como indicado pelos asteriscos. Valores apresentados como média \pm DP.

Tabela 12: Descrição dos valores de expressão de tau entre os grupos ELTM e controle. Os valores estão representados como média \pm DP. Regiões que apresentaram diferença estatística significativa estão em negrito.

\begin{tabular}{|l|l|l|l|}
\hline Regiões & ELTM & Controles & valor de $\mathbf{p}$ \\
\hline CG & $31963,03 \mu \mathrm{m}^{2}( \pm 7930,35)$ & $14612,52 \mu \mathrm{m}^{2}( \pm 7959,39)$ & $\mathbf{p}<\mathbf{0 , 0 0 1}$ \\
\hline Hilo & $30661,85 \mu \mathrm{m}^{2}( \pm 11249,59)$ & $17910,84 \mu \mathrm{m}^{2}( \pm 8202,22)$ & $\mathbf{p}=\mathbf{0 , 0 0 5}$ \\
\hline CA4 & $32479,71 \mu \mathrm{m}^{2}( \pm 5651,41)$ & $30810,20 \mu \mathrm{m}^{2}( \pm 7152,52)$ & $\mathrm{p}=0,541$ \\
\hline CA3 & $34560,28 \mu \mathrm{m}^{2}( \pm 5608,13)$ & $26742,64 \mu \mathrm{m}^{2}( \pm 4647,67)$ & $\mathbf{p}=\mathbf{0 , 0 0 6}$ \\
\hline CA2 & $35730,87 \mu \mathrm{m}^{2}( \pm 5657,17)$ & $24100,72 \mu \mathrm{m}^{2}( \pm 9434,07)$ & $\mathbf{p}=\mathbf{0 , 0 0 6}$ \\
\hline CA1 & $22979,88 \mu \mathrm{m}^{2}( \pm 10618,65)$ & $26837,85 \mu \mathrm{m}^{2}( \pm 9262,72)$ & $\mathrm{p}=0,353$ \\
\hline Prosubículo & $36894,47 \mu \mathrm{m}^{2}( \pm 7632,46)$ & $35028,58 \mu \mathrm{m}^{2}( \pm 8799,15)$ & $\mathrm{p}=0,569$ \\
\hline Subículo & $38302,50 \mu \mathrm{m}^{2}( \pm 7120,11)$ & $34112,19 \mu \mathrm{m}^{2}( \pm 10595,98)$ & $\mathrm{p}=0,230$ \\
\hline Parasubículo & $36456,04 \mu \mathrm{m}^{2}( \pm 6805,14)$ & $32239,34 \mu \mathrm{m}^{2}( \pm 6003,78)$ & $\mathrm{p}=0,236$ \\
\hline Córtex entorrinal & $37007,01 \mu \mathrm{m}^{2}( \pm 9141,53)$ & $27150,06 \mu \mathrm{m}^{2}( \pm 6373,89)$ & $\mathbf{p}=\mathbf{0 , 0 3 8}$ \\
\hline
\end{tabular}


Quando comparamos os grupos ELTM familiar, esporádica e controle encontramos que os grupos familiar e esporádico têm maior expressão de tau que o grupo controle nas regiões da camada granular ( $p<0,001$, ANOVA) e hilo ( $p=0,018$, ANOVA), figura 18.

O grupo ELTM familiar apresentou maior expressão de tau que o grupo controle nas regiões de CA3 ( $p=0,013$, ANOVA) e córtex entorrinal ( $p=0,010$, ANOVA), figura 18.

O grupo ELTM esporádica apresentou maior expressão de tau que o grupo controle na região de CA2 ( $p=0,016, A N O V A)$, figura 18.

Quando comparamos apenas os grupos ELTM familiar e esporádica, encontramos que o grupo familiar tem maior expressão de tau que o grupo esporádico na região do córtex entorrinal $(p=0,034$, teste $t)$, figura 18 .

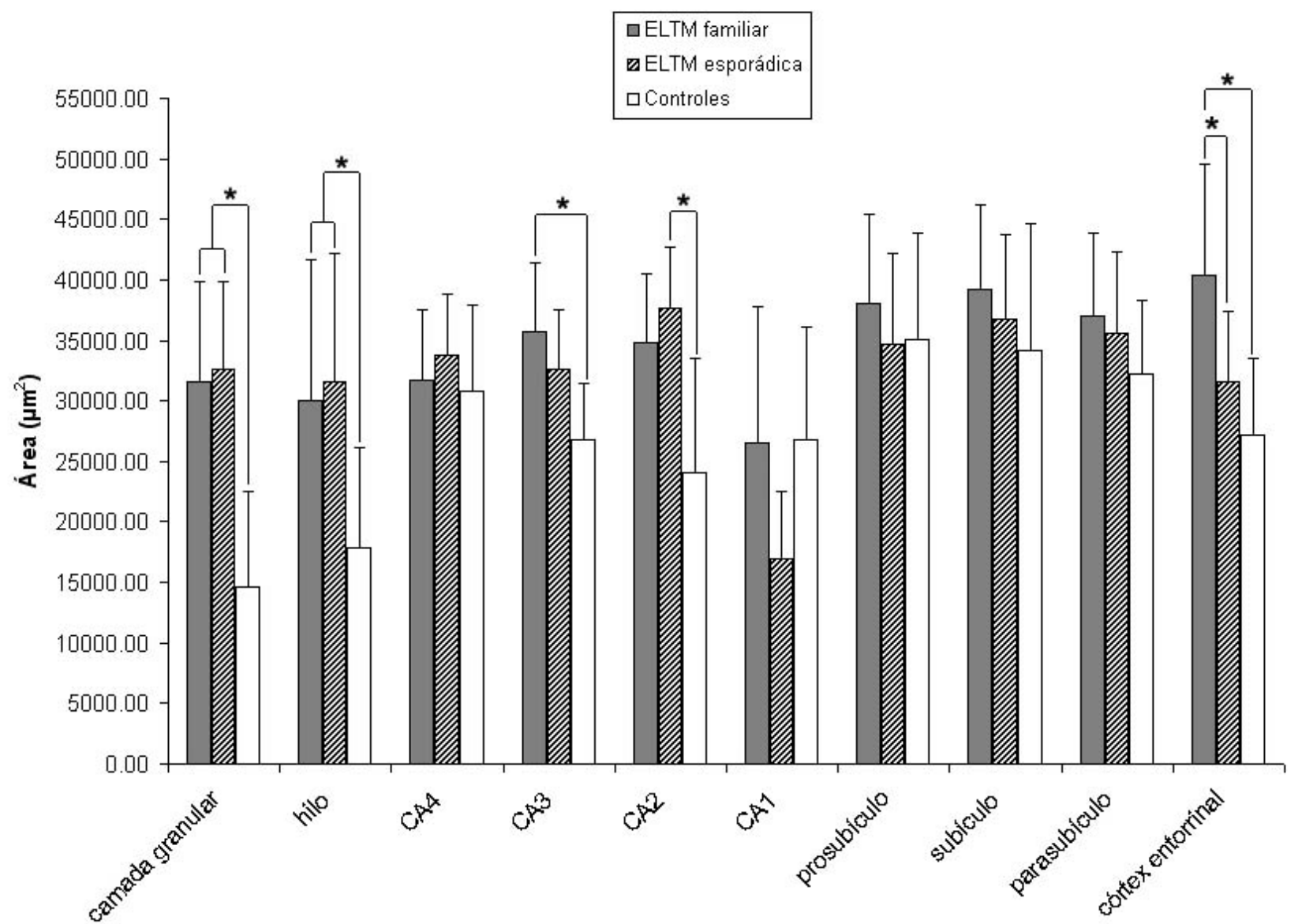

Regiões Hipocampais

Figura 18: Expressão de tau nas diferentes subregiões do hipocampo entre os casos de ELTM familiar, esporádica e controle. Os grupos familiar e esporádico apresentaram menor expressão de tau que o grupo controle nas regiões da camada granular ( ${ }^{*}$, ANOVA, $\left.p<0,001\right)$ e hilo ( ${ }^{*}$, ANOVA, $\left.p=0,018\right) .0$ grupo com ELTM familiar apresentou maior expressão de tau que o grupo controle nas regiões de CA3 $\left(^{*}\right.$, 
ANOVA, $p=0,013)$ e córtex entorrinal $(*$, ANOVA, $p=0,010)$. O grupo com ELTM esporádica apresentou maior expressão de tau que o grupo controle na região de CA2 $\left({ }^{*}\right.$, ANOVA, $\left.p=0,016\right)$. O grupo ELTM familiar apresentou maior expressão de tau que o grupo esporádico na região do córtex entorrinal ${ }^{*}$, teste $\mathrm{t}, \mathrm{p}=0$,034). Barras cinza representam o grupo ELTM familiar, barras hachuradas o grupo ELTM esporádica e barras claras o grupo controle. Valores apresentados como média \pm DP.

Tabela 13: Descrição dos valores de expressão de tau entre os grupos ELTM familiar e esporádica. Os valores estão representados como média \pm DP. Região que apresentou diferença estatística significativa está em negrito.

\begin{tabular}{|l|l|l|l|}
\hline Regiões & ELTM familiar & ELTM esporádica & valor de $\mathbf{p}$ \\
\hline CG & $31573,61 \mu \mathrm{m}^{2}( \pm 8323,97)$ & $32564,92 \mu \mathrm{m}^{2}( \pm 7239,20)$ & $\mathrm{p}=0,758$ \\
\hline Hilo & $30063,84 \mu \mathrm{m}^{2}( \pm 11641,76)$ & $31618,68 \mu \mathrm{m}^{2}( \pm 10521,50)$ & $\mathrm{p}=0,744$ \\
\hline CA4 & $31642,91 \mu \mathrm{m}^{2}( \pm 5875,08)$ & $33781,40 \mu \mathrm{m}^{2}( \pm 5014,41)$ & $\mathrm{p}=0,399$ \\
\hline CA3 & $35750,32 \mu \mathrm{m}^{2}( \pm 5659,32)$ & $32576,89 \mu \mathrm{m}^{2}( \pm 4918,90)$ & $\mathrm{p}=0,305$ \\
\hline CA2 & $34761,01 \mu \mathrm{m}^{2}( \pm 5714,98)$ & $37670,60 \mu \mathrm{m}^{2}( \pm 5004,47)$ & $\mathrm{p}=0,374$ \\
\hline CA1 & $26513,08 \mu \mathrm{m}^{2}( \pm 11225,19)$ & $16922,96 \mu \mathrm{m}^{2}( \pm 5653,00)$ & $\mathrm{p}=0,062$ \\
\hline Prosubículo & $38059,81 \mu \mathrm{m}^{2}( \pm 7422,15)$ & $34680,33 \mu \mathrm{m}^{2}( \pm 7535,73)$ & $\mathrm{p}=0,273$ \\
\hline Subículo & $39251,29 \mu \mathrm{m}^{2}( \pm 7008,81)$ & $36749,94 \mu \mathrm{m}^{2}( \pm 7027,1)$ & $\mathrm{p}=0,377$ \\
\hline Parasubículo & $37068,01 \mu \mathrm{m}^{2}( \pm 6751,80)$ & $35538,08 \mu \mathrm{m}^{2}( \pm 6781,60)$ & $\mathrm{p}=0,644$ \\
\hline Córtex entorrinal & $40331,86 \mathrm{~m}^{2}( \pm 9213,96)$ & $31604,13 \mu \mathrm{m}^{2}( \pm 5852,56)$ & $\mathrm{p}=\mathbf{0 , 0 3 4}$ \\
\hline
\end{tabular}

\subsubsection{Correlações}

\subsubsection{Variáveis Clínicas}

Encontramos as seguintes correlações positivas em pacientes ELTM:

- Frequência de crises e a espessura da camada molecular interna $(R=0,57 ; p=0,02)$

- Início das crises recorrentes (anos) e a expressão de MAP2 no prosubículo $(R=0,59$; $p=0,001$ )

- $Q$ l e escolaridade $(R=0,70 ; p=0,000001)$

- $Q \mathrm{l}$ e expressão de tau em CA1 $(R=0,55 ; p=0,017)$

4.1.5.2 Expressão das proteínas do citoesqueleto, densidade neuronal e Timm 
Tabela 14: Comparação entre os resultados de correlação encontrados entre os pacientes ELTM e os casos controles. CG: camada granula; CMi: camada molecular interna; CMe: camada molecular externa. Apenas as correlações significativas e com possível significado biológico foram descritas.

\begin{tabular}{|c|c|c|c|c|c|}
\hline ELTM & & & Controle & & \\
\hline Variável & $\begin{array}{l}\text { valor } \\
\text { de R }\end{array}$ & \begin{tabular}{|l} 
valor \\
de p
\end{tabular} & Variável & $\begin{array}{l}\text { valor } \\
\text { de } \mathbf{R}\end{array}$ & $\begin{array}{l}\text { valor } \\
\text { de p }\end{array}$ \\
\hline NeuN no hilo $x$ tau no hilo & 0,51 & 0,01 & $\begin{array}{l}\text { NeuN na CG x NeuN no córtex } \\
\text { entorrinal }\end{array}$ & 1 & 0,02 \\
\hline $\begin{array}{l}\text { Valor de cinza da CG } \times \text { valor } \\
\text { de cinza da CMi }\end{array}$ & 0,81 & $\begin{array}{l}0,0000 \\
8\end{array}$ & $\begin{array}{l}\text { Valor de cinza da CG } \times \text { valor de } \\
\text { cinza da CMi }\end{array}$ & 0,81 & 0,003 \\
\hline $\begin{array}{l}\text { Valor de cinza da CG } \times \text { valor } \\
\text { de cinza da CMe }\end{array}$ & 0,67 & 0,003 & $\begin{array}{l}\text { Valor de cinza da CG } \times \text { valor de } \\
\text { cinza da CMe }\end{array}$ & 0,75 & 0,009 \\
\hline $\begin{array}{l}\text { Valor de cinza da CG } x \text { tau na } \\
\text { CG }\end{array}$ & 0,65 & 0,02 & $\begin{array}{l}\text { Valor de cinza da CMi x valor de } \\
\text { cinza da CMe }\end{array}$ & 0,80 & 0,003 \\
\hline $\begin{array}{l}\text { Valor de cinza da CMi } x \text { tau na } \\
\text { CG }\end{array}$ & 0,63 & 0,03 & $\begin{array}{l}\text { MAP2 no hilo x MAP2 no córtex } \\
\text { entorrinal }\end{array}$ & 0,67 & 0,04 \\
\hline $\begin{array}{l}\text { Espessura da CG } x \text { espessura } \\
\text { da CMi }\end{array}$ & 0,71 & 0,001 & MAP2 no hilo $x$ MAP2 em CA3 & 0,77 & 0,01 \\
\hline MAP2 no hilo $x$ MAP2 em CA4 & 0,52 & 0,009 & MAP2 no hilo x MAP2 em CA4 & 0,66 & 0,03 \\
\hline MAP2 em CA4 x MAP2 em CA3 & 0,67 & 0,003 & $\begin{array}{l}\text { tau em CA1 } x \text { tau no cortex } \\
\text { entorrinal }\end{array}$ & 1 & 0,02 \\
\hline $\begin{array}{l}\text { MAP2 no córtex entorrinal } x \\
\text { tau na CG }\end{array}$ & 0,63 & 0,002 & $\begin{array}{l}\text { Valor de cinza da CMe } x \text { tau em } \\
\text { CA3 }\end{array}$ & $-0,93$ & $\begin{array}{l}0,0000 \\
002 \\
\end{array}$ \\
\hline $\begin{array}{l}\text { tau em CA1 } x \text { tau no cortex } \\
\text { entorrinal }\end{array}$ & 0,65 & 0,02 & $\begin{array}{l}\text { Valor de cinza da CMe } x \text { tau na } \\
\text { CG }\end{array}$ & $-0,67$ & 0,04 \\
\hline $\begin{array}{l}\text { NeuN no hilo } x \text { espessura da } \\
\text { CMi }\end{array}$ & $-0,84$ & 0,0006 & $\begin{array}{l}\text { Valor de cinza da CMi } x \text { tau em } \\
\text { CA3 }\end{array}$ & $-0,82$ & 0,01 \\
\hline $\begin{array}{l}\text { NeuN em CA4 } x \text { espessura da } \\
\text { CMi }\end{array}$ & $-0,71$ & 0,015 & $\begin{array}{l}\text { Valor de cinza da CG } x \text { tau em } \\
\text { CA3 }\end{array}$ & $-0,82$ & 0,01 \\
\hline $\begin{array}{l}\text { NeuN no prosubículo } x \text { valor } \\
\text { de cinza da CG }\end{array}$ & $-0,79$ & 0,002 & $\begin{array}{l}\text { Valor de cinza do hilo x MAP2 no } \\
\text { hilo }\end{array}$ & $-0,64$ & 0,04 \\
\hline $\begin{array}{l}\text { NeuN no prosubículo } x \text { valor } \\
\text { de cinza da CMi }\end{array}$ & $-0,53$ & 0,08 & & & \\
\hline NeuN em CA3 x NeuN no hilo & 0,52 & 0,05 & & & \\
\hline $\begin{array}{l}\text { Espessura da CMi } x \text { tau no } \\
\text { hilo }\end{array}$ & $-0,85$ & 0,0005 & & & \\
\hline
\end{tabular}

\subsection{Animais}

No modelo animal de lítio-pilocarpina, comparamos 5 grupos diferentes, sendo 4 de animais submetidos a SE e 1 injetado com salina (controle). O grupo de animais que sofreram SE foi divido em 4 grupos de acordo com a data de sacrifício (anestesia seguida de perfusão) após a indução do SE. Os tempos foram: 1, 7, 15 e 60 dias e os grupos foram denominados respectivamente SE1, SE7, SE15 e SE60. 
Inicialmente, 120 animais foram submetidos a SE, sendo que 62 animais não entraram em SE e 25 morreram. Dos animais submetidos ao SE, 33 foram utilizados. A data de sacrifício e perfusão corresponde a categorização em grupos descrita abaixo (tabela 15):

Tabela 15: Descrição dos dados comportamentais de animais submetidos a SE (SE1, 7, 15 e 60 dias) e animais controle (salina). Os valores das variáveis latência para SE, severidade SE, latência para CERs e severidade CERs estão representados como média \pm desvio-padrão. CERs: crises espontâneas e recorrentes; n.a.: não se aplica.

\begin{tabular}{|c|c|c|c|c|c|}
\hline & SE 1 & SE 7 & SE 15 & SE 60 & Salina \\
\hline$n^{\circ}$ total de animais & 23 & 34 & 38 & 25 & 16 \\
\hline $\begin{array}{l}\mathrm{n}^{\circ} \text { animais que } \\
\text { não entraram em SE }\end{array}$ & 11 & 21 & 15 & 15 & n.a. \\
\hline$n^{\circ}$ mortes & 4 & 6 & 13 & 2 & n.a. \\
\hline $\begin{array}{l}n^{\circ} \text { final de animais no } \\
\text { grupo }\end{array}$ & 8 & 7 & 10 & 8 & 16 \\
\hline $\begin{array}{lcc}\text { latência para } & \text { SE } \\
\text { (minutos, média } \pm \text { DP) }\end{array}$ & $39.57 \pm 6.37$ & $45 \pm 10.97$ & $41.67 \pm 11.35$ & $22.57 \pm 2.26$ & n.a \\
\hline $\begin{array}{l}\text { severidade SE (escala } \\
\text { Racine, média } \pm \text { DP) }\end{array}$ & $4 \pm 0$ & $4.17 \pm 0.37$ & $3.78 \pm 0.42$ & $4.29 \pm 0.45$ & n.a. \\
\hline $\begin{array}{l}\text { latência para } \\
\text { (dias, média } \pm \text { DP) }\end{array}$ & n.a & n.a & n.a & $11.14 \pm 8.71$ & n.a. \\
\hline $\begin{array}{l}\text { severidade CERs (escala } \\
\text { Racine, média } \pm \text { DP) }\end{array}$ & n.a & n.a & n.a & $3.43 \pm 1.05$ & n.a. \\
\hline
\end{tabular}

\subsubsection{Densidade Neuronal}

A figura 19 ilustra a imunorreatividade para NeuN na formação hipocampal de todos os grupos analisados. Podemos observar que o grupo SE60 dias tem maior perda neuronal que os demais grupos.

Comparamos a densidade neuronal entre os 4 grupos submetidos a SE e o grupo controle. Encontramos diferença estatística significativa na região da camada granular $(p<0,001, A N O V A)$, onde os grupos SE15 e SE60 apresentaram menor densidade neuronal 
que o grupo salina; no hilo ( $p<0,001$, ANOVA), entre os grupos SE, o grupo SE1 apresentou maior densidade neuronal que os grupos SE7, SE15 e SE60, e o grupo salina apresentou maior densidade neuronal que os grupos SE 7, SE15 e SE60.

Na região de CA4 ( $p<0,001$, ANOVA), entre os grupos SE, o grupo SE1 apresentou maior densidade que o grupo SE60, já em comparação ao grupo salina, o grupo SE60 apresentou menor densidade neuronal. Em CA3 ( $p<0,001$, ANOVA), o grupo salina apresentou maior número de células neuronais que os grupos SE15 e SE60, já entre os grupos SE, o grupo SE1 apresentou maior densidade neuronal que o grupo SE60.

Em CA2 ( $p=0,015$, ANOVA), entre os grupos SE, o grupo SE1 apresentou maior densidade neuronal que o grupo SE7, e ainda, o grupo SE7 apresentou menor densidade que o grupo salina.

Para finalizar, em CA1 ( $p<0,001$, ANOVA), o grupo salina apresentou maior densidade neuronal que os grupos SE7, SE15 e SE60 (figura 20). 

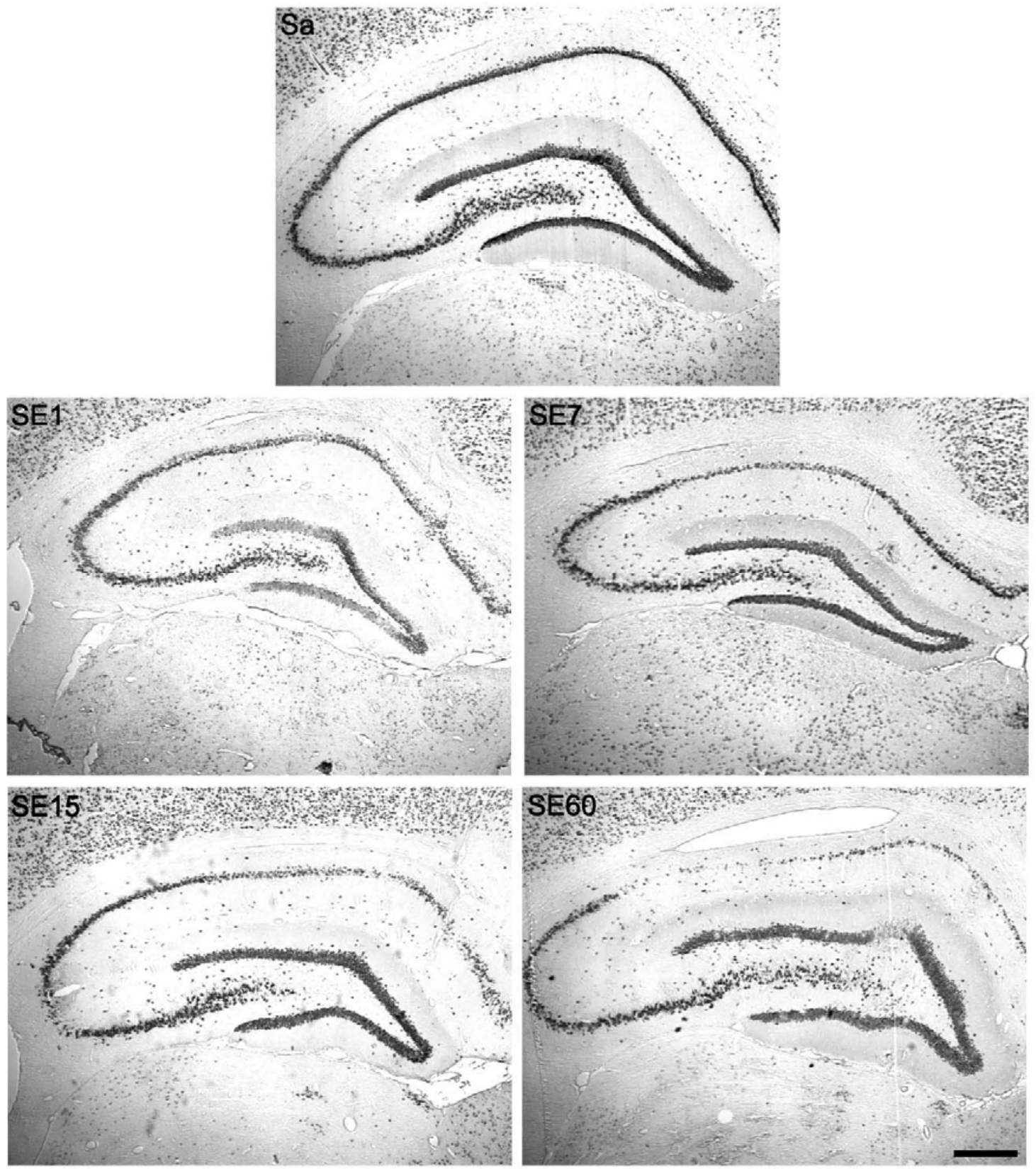

Figura 19: Imagem ilustrativa da imunohistoquímica para NeuN em hipocampo de ratos. $O$ grupo SE60 e o grupo SE15 apresentaram maior perda neuronal que os demais grupos analisados. A barra no canto inferior direito equivale a $400 \mu \mathrm{m}$. 


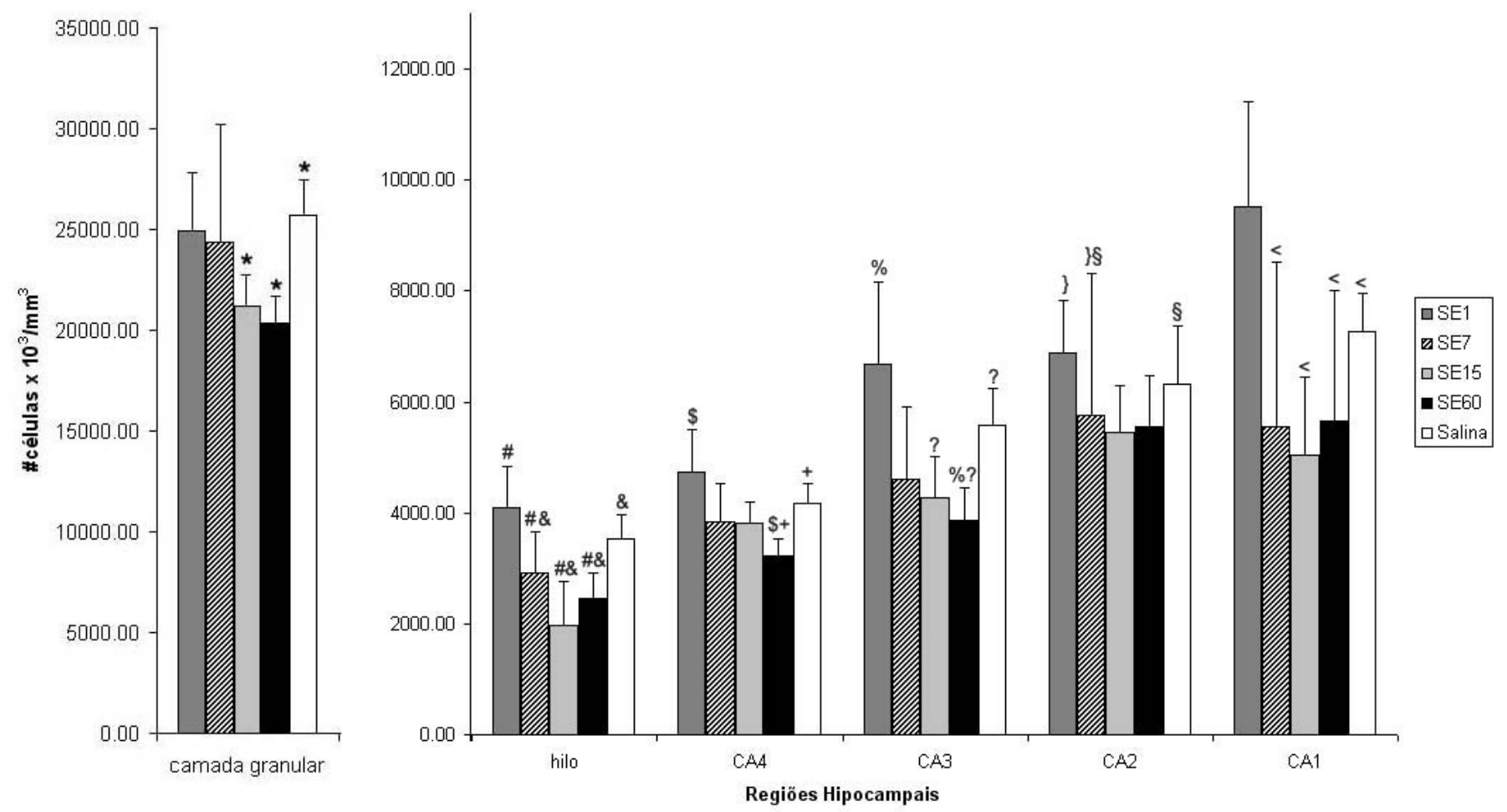

Figura 20: Densidade neuronal entre as diferentes regiões do hipocampo de ratos. $\mathrm{Na}$ camada granular ( $p<0,001$, ANOVA), os grupos SE15 e SE60 apresentaram menor densidade neuronal que 0 grupo salina $\left(^{*}\right)$; no hilo $(p<0,001$, ANOVA), o grupo SE1 apresentou maior densidade neuronal que os grupos SE7, SE15 e SE60 (\#), o grupo salina apresentou maior densidade neuronal que os grupos SE7, SE15 e SE60 (\&). Em CA4 ( $<<0,001$, ANOVA), o grupo SE1 apresentou maior densidade neuronal que o grupo SE60 (\$) e o grupo salina apresentou maior densidade que o grupo SE60 (+). Em CA3 ( $p<0,001$, ANOVA), o grupo salina apresentou maior densidade neuronal que os grupos SE15 e SE60 (?) e o grupo SE1 apresentou maior densidade neuronal que o grupo SE60 (\%). Em CA2 ( $p=0,015$, ANOVA), o grupo SE1 apresentou maior densidade neuronal que o grupo SE7 (\{) e o grupo salina apresentou maior densidade neuronal que o grupo SE7 (§). Em CA1 ( $p<0,001$, ANOVA), o grupo salina apresentou maior densidade neuronal que os grupos SE7, SE15 e SE60 (<), como indicado pelos símbolos. Valores apresentados como média \pm DP. 
Tabela 16: Descrição dos valores de densidade neuronal entre os grupos animais em todas as regiões do hipocampo. Os valores estão representados como média \pm DP. Regiões que apresentaram diferença estatística significativa estão em negrito.

\begin{tabular}{|l|l|l|l|}
\hline Regiões & SE 1 & SE 7 & SE 15 \\
\hline CG & $24939,65 \times 10^{3} / \mathrm{mm}^{3}( \pm 2876,81)$ & $24366,44 \times 10^{3} / \mathrm{mm}^{3}( \pm 5865,28)$ & $21167,11 \times 10^{3} / \mathrm{mm}^{3}( \pm 1511,62)$ \\
\hline Hilo & $3988,75 \times 10^{3} / \mathrm{mm}^{3}( \pm 537,00)$ & $2916,93 \times 10^{3} / \mathrm{mm}^{3}( \pm 749,60)$ & $2408,66 \times 10^{3} / \mathrm{mm}^{3}( \pm 613,97)$ \\
\hline CA4 & $4319,31 \times 10^{3} / \mathrm{mm}^{3}( \pm 477,08)$ & $3833,61 \times 10^{3} / \mathrm{mm}^{3}( \pm 692,89)$ & $3804,56 \times 10^{3} / \mathrm{mm}^{3}( \pm 393,52)$ \\
\hline CA3 & $5614,69 \times 10^{3} / \mathrm{mm}^{3}( \pm 914,60)$ & $4613,96 \times 10^{3} / \mathrm{mm}^{3}( \pm 1289,67)$ & $4263,65 \times 10^{3} / \mathrm{mm}^{3}( \pm 752,74)$ \\
\hline CA2 & $6679,85 \times 10^{3} / \mathrm{mm}^{3}( \pm 761,14)$ & $5414,57 \times 10^{3} / \mathrm{mm}^{3}( \pm 1706,42)$ & $5446,95 \times 10^{3} / \mathrm{mm}^{3}( \pm 843,07)$ \\
\hline CA1 & $7819,92 \times 10^{3} / \mathrm{mm}^{3}( \pm 1219,51)$ & $5549,99 \times 10^{3} / \mathrm{mm}^{3}( \pm 2959,85)$ & $4993,37 \times 10^{3} / \mathrm{mm}^{3}( \pm 1534,60)$ \\
\hline
\end{tabular}

\begin{tabular}{|l|l|l|}
\hline SE 60 & Salina & $\begin{array}{l}\text { valor } \\
\text { de } p\end{array}$ \\
\hline $20351,79 \times 10^{3} / \mathrm{mm}^{3}( \pm 1290,88)$ & $25589,26 \times 10^{3} / \mathrm{mm}^{3}( \pm 1661,20)$ & $\mathbf{p}<\mathbf{0 , 0 0 1}$ \\
\hline $2456,77 \times 10^{3} / \mathrm{mm}^{3}( \pm 450,95)$ & $3807,57 \times 10^{3} / \mathrm{mm}^{3}( \pm 410,06)$ & $\mathbf{p}<\mathbf{0 , 0 0 1}$ \\
\hline $3234,84 \times 10^{3} / \mathrm{mm}^{3}( \pm 308,33)$ & $4301,10 \times 10^{3} / \mathrm{mm}^{3}( \pm 323,62)$ & $\mathbf{p}<\mathbf{0 , 0 0 1}$ \\
\hline $3871,69 \times 10^{3} / \mathrm{mm}^{3}( \pm 574,97)$ & $5616,70 \times 10^{3} / \mathrm{mm}^{3}( \pm 630,17)$ & $\mathbf{p}<\mathbf{0 , 0 0 1}$ \\
\hline $5421,60 \times 10^{3} / \mathrm{mm}^{3}( \pm 804,73)$ & $6404,76 \times 10^{3} / \mathrm{mm}^{3}( \pm 950,06)$ & $\mathbf{p}=\mathbf{0 , 0 1 5}$ \\
\hline $4987,32 \times 10^{3} / \mathrm{mm}^{3}( \pm 1802,61)$ & $7908,88 \times 10^{3} / \mathrm{mm}^{3}( \pm 637,66)$ & $\mathbf{p}<\mathbf{0 , 0 0 1}$ \\
\hline
\end{tabular}

\subsubsection{Neo-Timm}

Analisamos o valor de cinza entre os 5 grupos estudados e encontramos diferença estatística significativa nas regiões da camada granular $(p=0,005$, ANOVA), onde o grupo SE60 apresentou maior valor de cinza que os grupos SE1 e SE7 e que o grupo salina; no hilo $(p=0,001, A N O V A)$, o grupo SE60 apresentou maior valor de cinza que os grupos SE1 e salina e os grupos SE7 e SE15 apresentaram maior valor de cinza que o grupo salina; na camada molecular interna ( $p<0,001$, ANOVA), o grupo SE60 apresentou maior valor de cinza que os grupos SE1 e salina (figura 22).

A figura 21 mostra a impregnação por zinco no tecido animal dos grupos analisados neste trabalho. Animais SE15 e SE60 possuem maior valor de cinza que os demais grupos. Isso ocorre porque o neobrotamento anormal das fibras musgosas em animais experimentais se forma em média a partir do $12^{\circ}$ dia pós SE. 

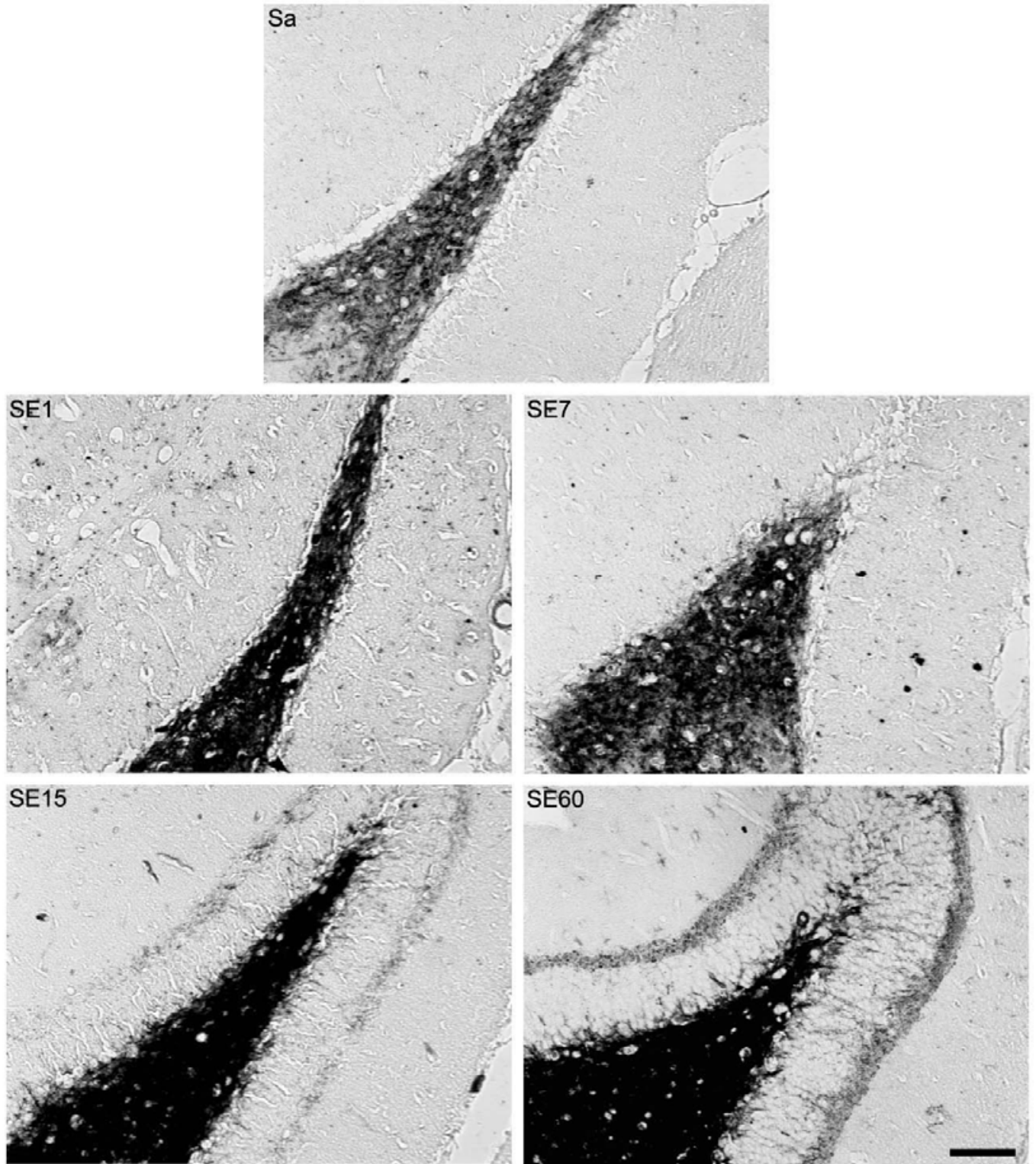

Figura 21: Imagens ilustrativas da histoquímica de neo-timm no tecido animal. Apenas os animais SE60 e SE15 demonstram formação do neobrotamento anormal das fibras musgosas. A barra no canto inferior direito equivale a $200 \mu \mathrm{m}$. 


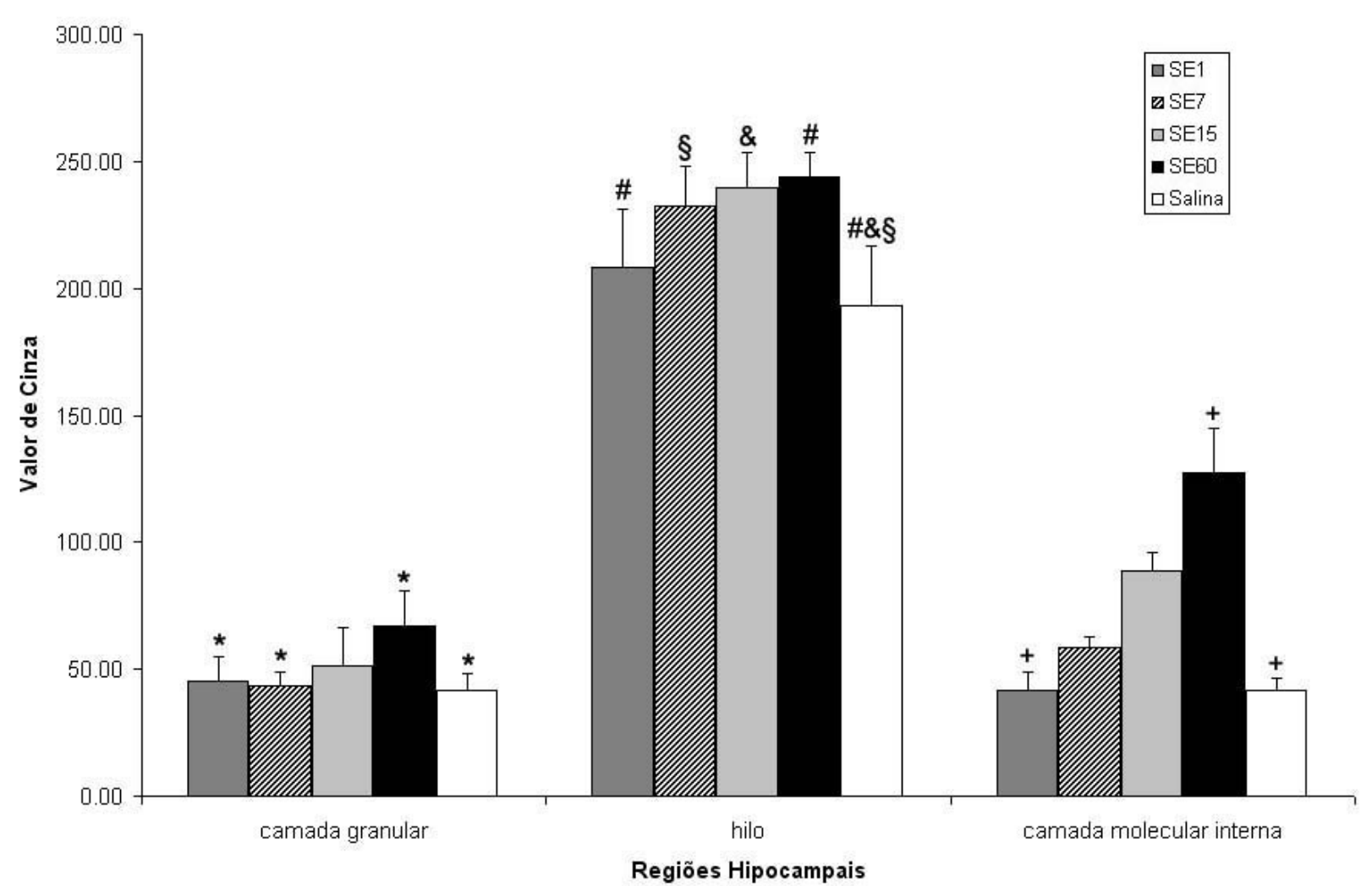

Figura 22: Medidas de valor de cinza nas diferentes subregiões do hipocampo de ratos. Na camada granular ( $p=0,005$, ANOVA), o grupo SE60 apresentou maior valor de cinza que os grupos SE1, SE7 e salina ( $\left.{ }^{*}\right)$; no hilo ( $\left.p=0,001, A N O V A\right)$, o grupo SE60 apresentou maior valor de cinza que os grupos SE1 e salina (\#) e os grupos SE7 (§) e SE15 (\&) apresentaram maior valor de cinza que o grupo salina; na camada molecular interna ( $p<0,001$, ANOVA), o grupo SE60 apresentou maior valor de cinza que os grupos SE1 e salina (+), como indicado pelos símbolos. Barras cinza escuro representam animais SE1, barras hachuradas animais SE7, barras cinza claro animais SE15, barras escuras animais SE60 e barras claras animais controle. Valores apresentados como média \pm DP.

Tabela 17: Descrição dos valores de cinza da marcação de Neo-Timm entre os grupos animais. Os valores estão representados como média \pm DP. Regiões que apresentaram diferença estatística significativa estão em negrito.

\begin{tabular}{|l|l|l|l|}
\hline Regiões & SE 1 & SE 7 & SE 15 \\
\hline CG & 45,34 valor de cinza $( \pm 9,29)$ & 43,58 valor de cinza $( \pm 5,08)$ & 51,40 valor de cinza $( \pm 14,72)$ \\
\hline Hilo & 208,08 valor de cinza $( \pm$ & $\begin{array}{l}232,23 \text { valor de cinza }( \pm \\
15,58)\end{array}$ & $\begin{array}{l}239,36 \text { valor de cinza }( \pm \\
14,18)\end{array}$ \\
\hline $\begin{array}{l}\text { Camada } \\
\text { molecular interna }\end{array}$ & 41,66 valor de cinza $( \pm 7,08)$ & 58,39 valor de cinza $( \pm 4,50)$ & 88,66 valor de cinza $( \pm 7,60)$ \\
\hline
\end{tabular}

\begin{tabular}{|c|c|c|}
\hline SE 60 & Salina & valor de $p$ \\
\hline 67,13 valor de cinza $( \pm 13,93)$ & 41,75 valor de cinza $( \pm 6,68)$ & $p=0,005$ \\
\hline 243,92 valor de cinza $( \pm 9,84)$ & $\begin{array}{l}193,35 \\
23,37)\end{array}$ valor de cinza $( \pm$ & $p=0,001$ \\
\hline $\begin{array}{llll}127,14 & \text { valor de cinza } & ( \pm \\
17,53) & & & \\
\end{array}$ & 41,57 valor de cinza $( \pm 5,06)$ & $p<0,001$ \\
\hline
\end{tabular}




\subsubsection{MAP2}

$\mathrm{Na}$ análise da expressão de MAP2 no modelo animal de lítio-pilocarpina, encontramos diferenças significativas entre os grupos estudados na região da camada granular $(p<0,001$, ANOVA), sendo que os grupos epilépticos SE60 e SE15 apresentaram maior expressão de MAP2 que o grupo salina. No hilo ( $p=0,003$, ANOVA) encontramos que o grupo SE60 apresentou maior expressão de MAP2 que o grupo SE15. Em CA4 ( $p=0,004$, ANOVA), o grupo SE15 apresentou maior expressão de MAP2 que o grupo salina. O mesmo ocorreu em CA2 $(p=0,008, A N O V A)$, o grupo SE15 também apresentou maior expressão de MAP2 que o grupo salina (figura 24).

A figura 23 ilustra a imunorreatividade para MAP2 nas regiões da camada granular (A e B) e em CA2 ( $C$ e $D$ ) entre animais injetados com lítio-pilocarpina ( $A$ e $C$ ) e salina (B e $D)$. Diferente do que ocorreu em humanos, os grupos animais SE15 e SE60 apresentaram maior expressão de MAP2 que os demais grupos submetidos a SE e grupo salina em toda formação hipocampal (figura 24).

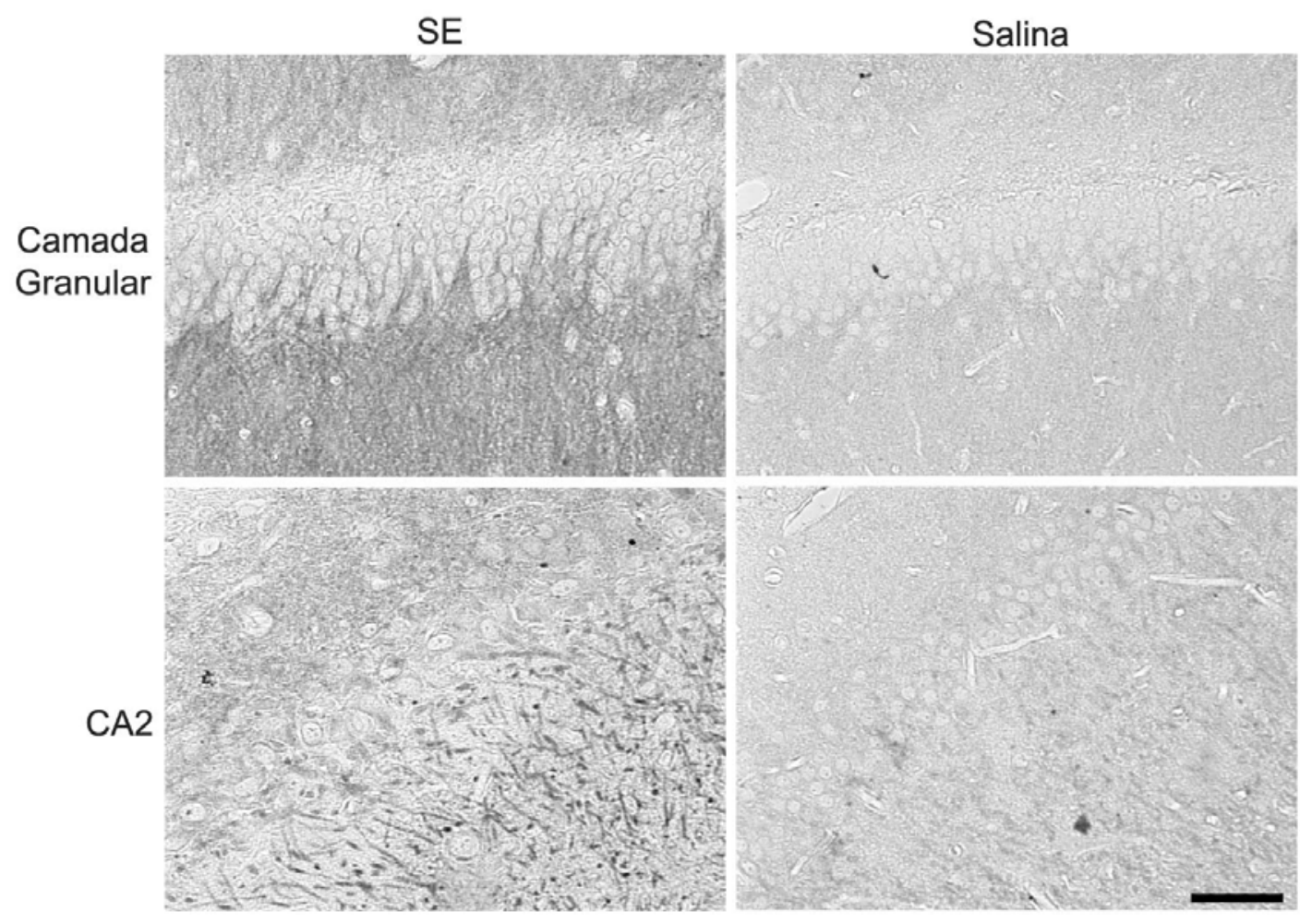

Figura 23: Imunorreatividade para MAP2 na camada granular e CA2 de ratos. O grupo SE apresentou maior imunorreatividade para MAP2 que o grupo salina em várias regiões do 
hipocampo. Na figura, em destaque, as regiões da camada granular e CA2. A barra no canto inferior direito equivale a $50 \mu \mathrm{m}$.

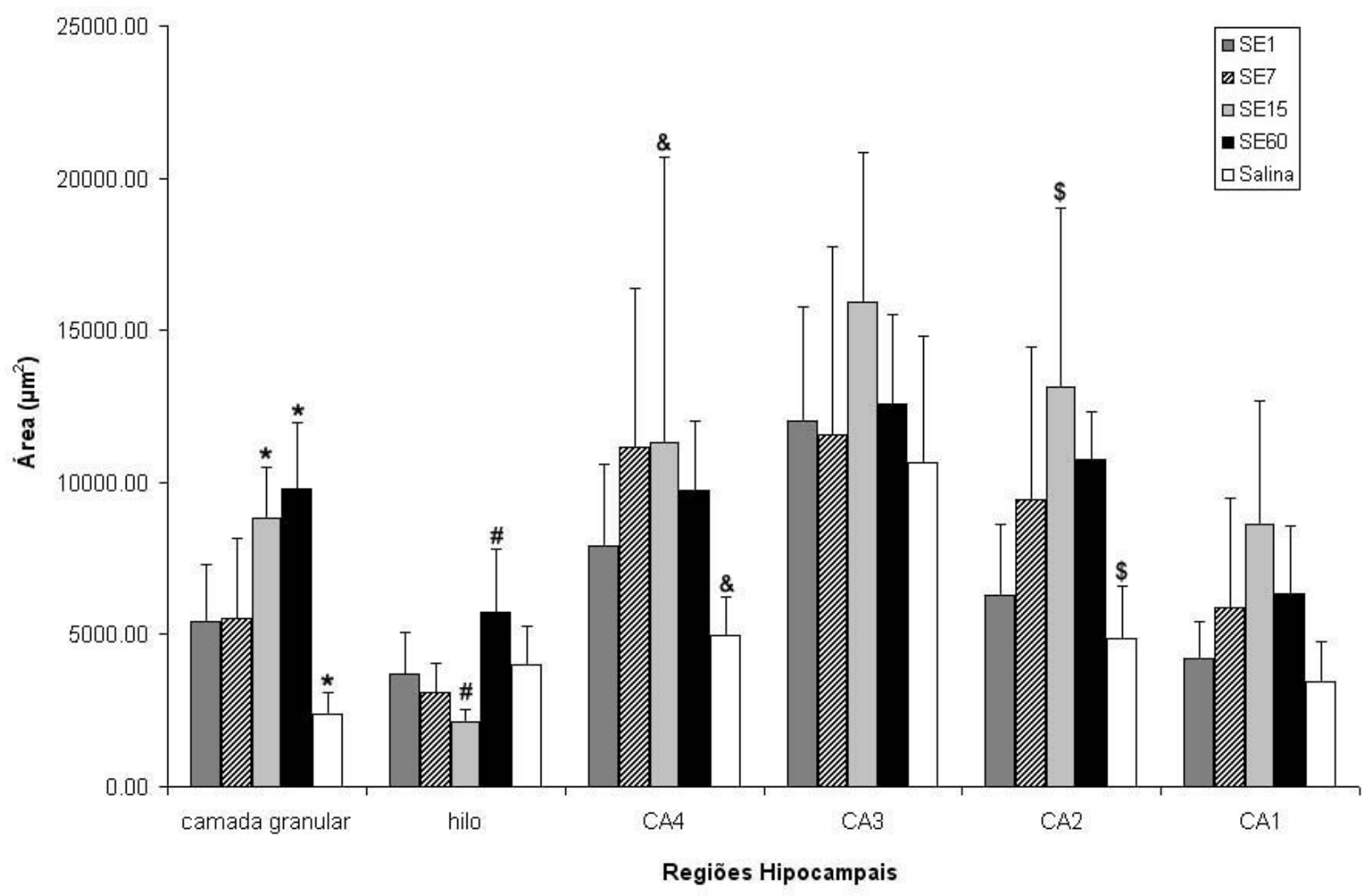

Figura 24: Expressão de MAP2 nas subregiões do hipocampo de animais experimentais. Na camada granular ( $p<0,001$, ANOVA) os grupos SE60 e SE15 apresentaram maior expressão de MAP2 que o grupo salina $\left(^{*}\right)$. No hilo ( $p=0,003$, ANOVA) o grupo SE60 apresentou maior expressão de MAP2 que o grupo SE15 (\#). Em CA4 ( $p=0,004$, ANOVA), o grupo SE15 apresentou maior expressão de MAP2 que o grupo salina (\&). Em CA2 ( $p=0,008$, ANOVA), o grupo SE15 também apresentou maior expressão de MAP2 que o grupo salina (\$), como indicado pelos diferentes símbolos. Barras cinza escuro representam animais SE1, barras hachuradas animais SE7, barras cinza claro animais SE15, barras escuras animais SE60 e barras claras animais controle. Valores apresentados como média \pm DP. 
Tabela 18: Descrição dos valores de expressão de MAP2 entre os grupos animais nas regiões hipocampais. Os valores estão representados como média \pm DP. Regiões que apresentaram diferença estatística significativa estão em negrito.

\begin{tabular}{|c|c|c|c|}
\hline Regiões & SE 1 & SE 7 & SE 15 \\
\hline CG & $5412,30 \mu \mathrm{m}^{2}( \pm 1867,95)$ & $5536,93 \mu \mathrm{m}^{2}( \pm 2647,82)$ & $8848,40 \mu \mathrm{m}^{2}( \pm 1637,34)$ \\
\hline Hilo & $3687,08 \mu \mathrm{m}^{2}( \pm 1382,68)$ & $3068,51 \mu \mathrm{m}^{2}( \pm 976,88)$ & $2136,00 \mu m^{2}( \pm 402,20)$ \\
\hline CA4 & $7914,49 \mu \mathrm{m}^{2}( \pm 2706,60)$ & $\begin{array}{ll}11159,21 & \mu m^{2} \\
5235,74)\end{array}$ & $\begin{array}{l}14886,57 \\
6910,67)\end{array} \quad \mu m^{2}$ \\
\hline CA3 & $\begin{array}{lll}12024,73 & \mu m^{2} & ( \pm \\
3730,37) & & \\
\end{array}$ & $\begin{array}{lll}11558,85 & \mu m^{2} & ( \pm \\
6172,91)\end{array}$ & $\begin{array}{l}15943,10 \\
4904,10)\end{array}$ \\
\hline CA2 & $6291,44 \mu \mathrm{m}^{2}( \pm 2865,79)$ & $9417,15 \mu \mathrm{m}^{2}( \pm 5794,15)$ & $\begin{array}{lll}12632,38 & \mu m^{2} & ( \pm \\
5762,84) & & \\
\end{array}$ \\
\hline CA1 & $4213,04 \mu \mathrm{m}^{2}( \pm 1194,55)$ & $5889,47 \mu \mathrm{m}^{2}( \pm 3612,63)$ & $8627,31 \mu \mathrm{m}^{2}( \pm 4051,06)$ \\
\hline
\end{tabular}

\begin{tabular}{|c|c|c|}
\hline SE 60 & Salina & valor de $p$ \\
\hline $9792,77 \mu \mathrm{m}^{2}( \pm 2171,49)$ & $2406,94 \mu \mathrm{m}^{2}( \pm 697,21)$ & $p<0,001$ \\
\hline $5709,16 \mu \mathrm{m}^{2}( \pm 2074,95)$ & $4030,47 \mu \mathrm{m}^{2}( \pm 1223,24)$ & $p=0,003$ \\
\hline $9747,73 \mu \mathrm{m}^{2}( \pm 2290,84)$ & $4986,93 \mu \mathrm{m}^{2}( \pm 1244,40)$ & $p=0,004$ \\
\hline $\begin{array}{lll}12574,63 & \mu m^{2} & ( \pm \\
2936,59)\end{array}$ & \begin{tabular}{|lll}
10667,39 & $\mu \mathrm{m}^{2}$ & $( \pm$ \\
$4162,79)$ & & \\
\end{tabular} & $p=0,347$ \\
\hline $\begin{array}{lll}10760,13 & \mu m^{2} & ( \pm \\
1714,59)\end{array} \quad{ }^{1}$ & $4731,63 \mu \mathrm{m}^{2}( \pm 1884,67)$ & $p=0,008$ \\
\hline $6348,17 \mu \mathrm{m}^{2}( \pm 2197,96)$ & $3457,91 \mu \mathrm{m}^{2}( \pm 1307,41)$ & $p=0,076$ \\
\hline
\end{tabular}

\subsubsection{Tau}

A imunorreatividade para a proteína tau em ratos foi bem diferente da observada em humanos. Observamos uma intensa marcação na região de CA3 (figura 25), único subcampo considerado para fins quantitativos. Não encontramos diferença estatística significativa na área imunorreativa marcada para tau em CA3 entre os grupos animais analisados (figura 26). 

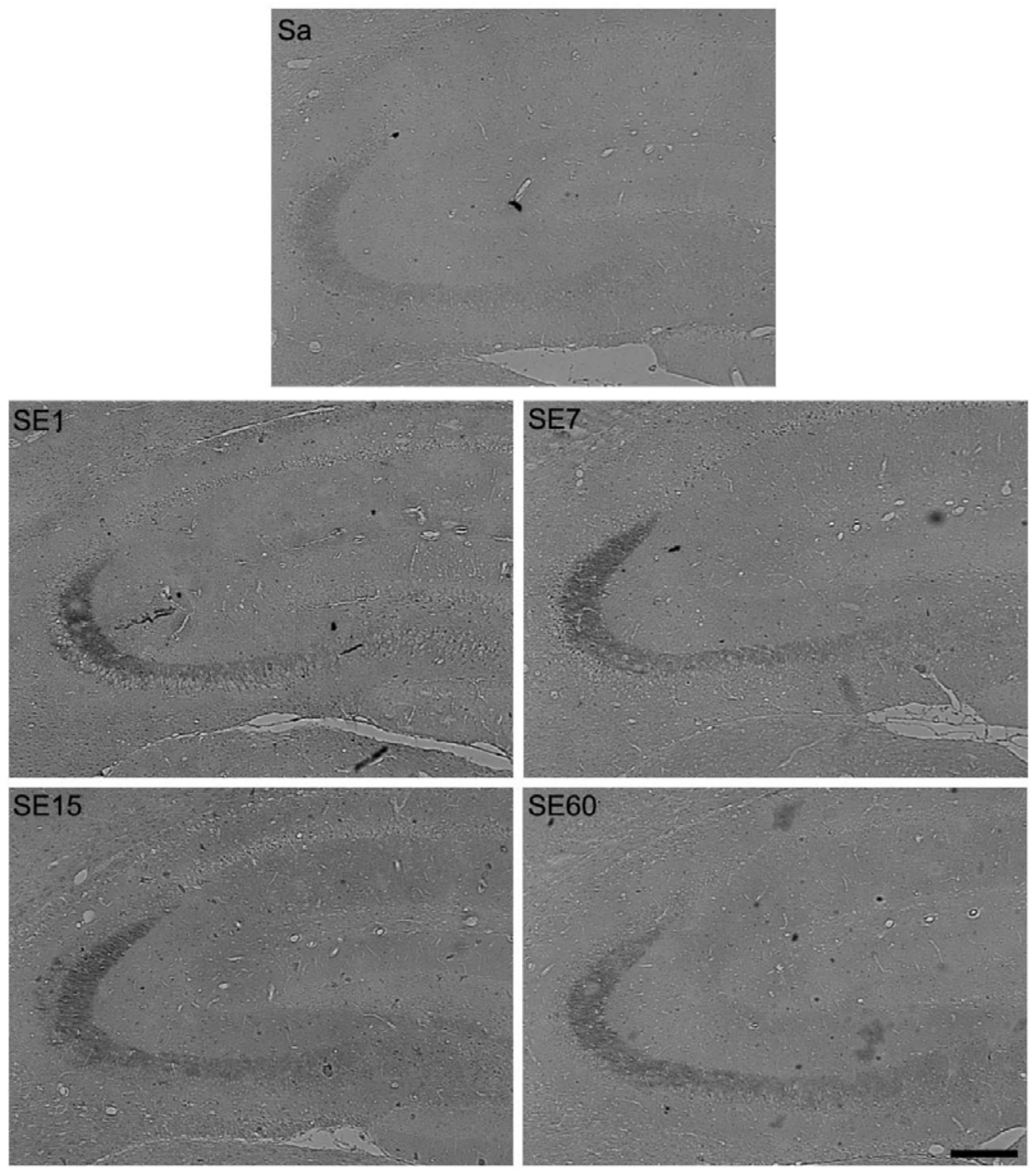

Figura 25: Figura ilustrativa da expressão de tau na região de CA3 do hipocampo animal. A imunorreatividade da proteína tau em hipocampo de ratos concentrou-se apenas na região de CA3 em todos os grupos analisados, enquanto que as demais regiões do hipocampo praticamente não apresentaram marcação. A barra no canto inferior direito equivale a $200 \mu \mathrm{m}$. 


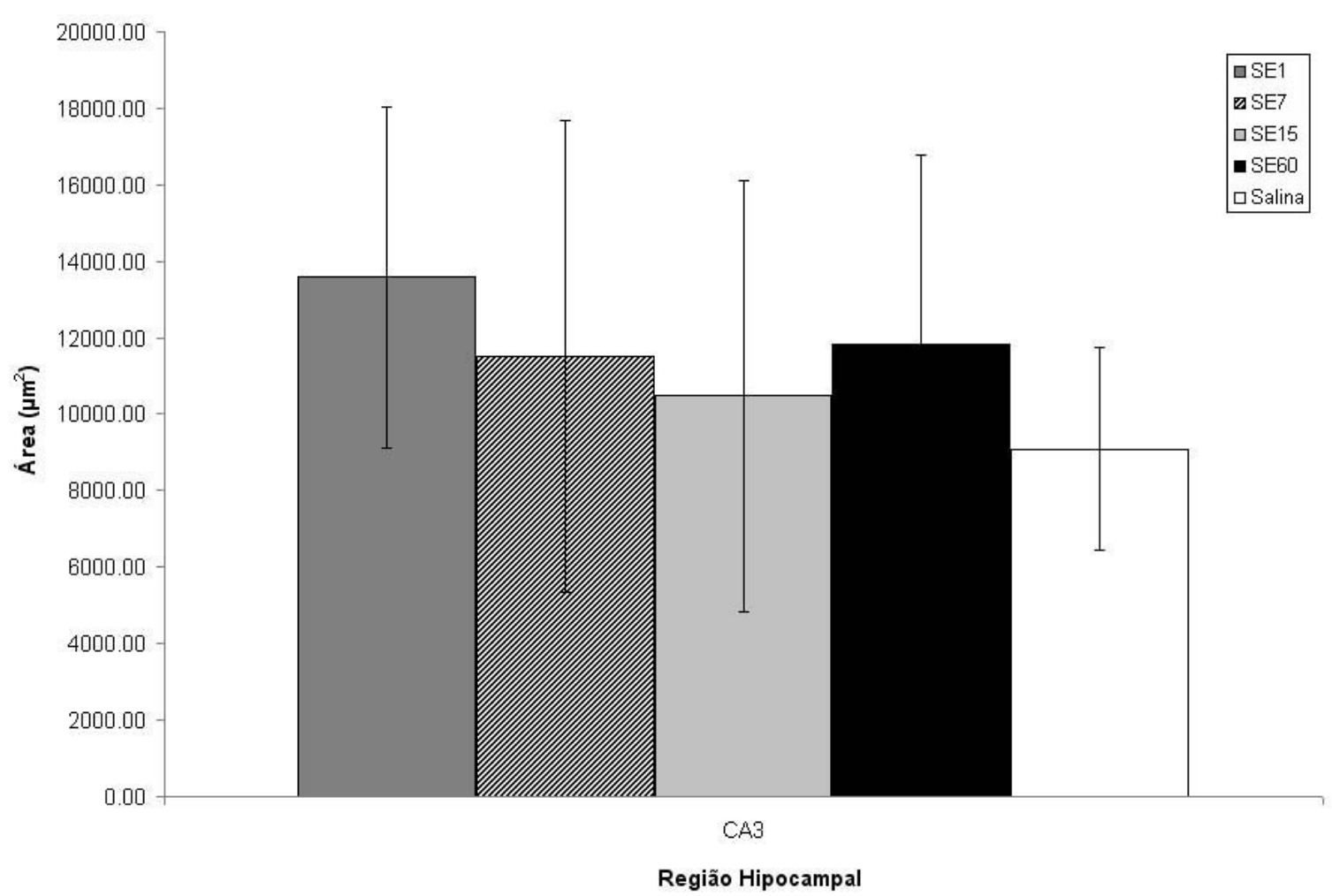

Figura 26: Expressão de tau na região de CA3 de animais. Não encontramos diferença estatística significativa entre os grupos analisados. Barra cinza escuro representa animais SE1, barra hachurada animais SE7, barra cinza claro animais SE15, barra escura animais SE60 e barra clara animais controle. Valores apresentados como média \pm DP.

Tabela 19: Descrição dos valores de expressão da proteína tau na região de CA3 de ratos. Os valores estão representados como média $\pm \mathrm{DP}$.

\begin{tabular}{|l|l|l|l|}
\hline Regiões & SE 1 & SE 7 & SE 15 \\
\hline CA3 & $13588,30 \mu \mathrm{m}^{2}( \pm 4459,79)$ & $11510,96 \mu \mathrm{m}^{2}( \pm 6183,60)$ & $10477,59 \mu \mathrm{m}^{2}( \pm 5637,00)$ \\
\hline
\end{tabular}

\subsubsection{Correlações}

Entre os grupos animais SE1, SE7, SE15 e SE60 encontramos correlações positivas entre a densidade neuronal do hilo e a severidade do SE ( $p=0,01$ e $r=0,51)$; entre a expressão 
de MAP2 na camada granular e a latência das CERs ( $p=0,03$ e $r=0,92)$; e entre a expressão de MAP2 no hilo e a média da duração das CERs ( $p=0,03, r=0,92)$.

Encontramos correlações negativas entre a densidade neuronal em CA2 e a expressão de MAP2 em CA2 $(p=0,04, r=-0,51)$ e entre a densidade neuronal em CA4 e a média da severidade das CERs $(p=0,01, r=-0,90)$. 


\section{DISCUSSÃO}

\subsection{Pacientes}

\subsubsection{Densidade Neuronal}

Pacientes com ELTM apresentam perda neuronal em subcampos específicos da formação hipocampal, caracterizando um quadro de EH (Babb et al 1984; Leite et al 2002; Mathern et al 1996; Thom et al 2002). Em nossa casuística, o grupo ELTM apresentou menor densidade neuronal que o grupo controle em várias regiões hipocampais. As regiões onde encontramos perda neuronal significativa no grupo ELTM foram camada granular, hilo, CA4, CA3, CA1 e prosubículo.

Não encontramos diferença significativa na densidade neuronal entre os grupos ELTM e controle nas regiões de CA2 e subículo, consideradas relativamente resistentes às crises quando comparadas às demais regiões hipocampais. No caso de CA2, um dos motivos principais que levaria à neuroproteção é a grande quantidade de proteínas ligantes de cálcio nas células piramidais e interneurônios locais, como calbindina e parvalbumina (Leranth \& Ribak 1991). Proteínas ligantes de cálcio poderiam atuar como quelantes endógenos de cálcio, contribuindo assim para diminuição da hiperexcitabilidade local (Scharfman \& Schwartzkroin 1989; Wittner et al 2009). Dessa forma, a maior expressão das proteínas ligantes de cálcio na região de CA2 está intimamente relacionada à resistência dos neurônios desta região aos danos causados pelas crises epilépticas.

O subículo é uma região relativamente preservada da formação hipocampal de pacientes epilépticos (Cavazos et al 2004; Stafstrom 2005). Entretanto, a perda neuronal pode ocorrer no subículo de pacientes com ELT (Dam 1980). A diminuição de uma grande porcentagem de interneurônios pode estar relacionada à geração de descargas interictais no subículo de pacientes com ELT (He de et al 2009; Tang \& Loke 2010).

As regiões do parasubículo e córtex entorrinal analisadas neste estudo também não apresentaram perda neuronal significativa. Nossos resultados de densidade neuronal no córtex entorrinal discordam do trabalho de Du e colaboradores (1993). Neste trabalho, os autores demonstraram uma perda neuronal pronunciada na camada III do córtex entorrinal de 
pacientes com ELTM submetidos à cirurgia para controle das crises. O mesmo padrão de perda neuronal na camada III do córtex entorrinal foi observado em três modelos animais diferentes de epilepsia: por abrasamento, pilocarpina e ácido caínico (Du et al 1995). Segundo estes autores, os mecanismos de perda neuronal preferencial na camada III do córtex entorrinal não estão claramente elucidados. Estes autores acreditam que os receptores de aminoácidos excitatórios, particularmente o N-metil-D-aspartato (NMDA), estão envolvidos com o processo de epileptogênese e com os danos cerebrais associados às crises epilépticas, como a perda neuronal. Porém, há a necessidade de um estudo detalhado destes receptores de aminoácidos no córtex entorrinal humano.

A perda de células neuronais na ELTM é específica de determinadas regiões do hipocampo, como giro denteado, CA4, CA3, CA1 e prosubículo. Segundo Babb e colaboradores (1984), a especificidade de algumas regiões à perda de células neuronais tem relação com o processo de epileptogênese que ocorre nestes pacientes. Os autores sugerem que regiões com perda neuronal significativa estão relacionadas a regiões geradoras de crises.

\subsubsection{Neobrotamento das Fibras Musgosas}

O neobrotamento anormal das fibras musgosas em direção à camada molecular interna do giro denteado é uma característica histopatológica comumente associada à ELTM (Babb et al 1991; Cavazos \& Cross 2006; Mathern et al 1996). Em nossa casuística, o grupo ELTM apresentou maior valor de cinza em secções coradas com Neo-Timm na camada granular, camada molecular interna e camada molecular externa. Além disso, o grupo ELTM apresentou maior espessura do neobrotamento axonal na camada molecular interna.

Fisiologicamente, os axônios das células granulares (fibras musgosas) emitem prolongamentos para as células hilares e piramidais de CA3 e CA4, bem como para as próprias células granulares (Amaral \& Insausti 1990). Porém, diante de uma perda celular intensa nas regiões do hilo, CA3 e CA4, como a que ocorre em pacientes epilépticos, as fibras musgosas sofrem alterações. Essas alterações resultam em reorganização sináptica das fibras musgosas, com formação de neobrotamento aberrante em direção a camada molecular interna. Este processo é responsável pela formação de novos terminais sinápticos com os dendritos dos 
interneurônios e com os dendritos das próprias granulares (Cavazos \& Cross 2006). A reorganização das fibras musgosas pode gerar uma hiperexcitabilidade do circuito hipocampal, contribuindo para a patogênese da epilepsia (Cavazos \& Cross 2006; Dudek et al 1994; Mathern et al 1996).

\subsubsection{MAP2}

Em nosso estudo, o grupo ELTM apresentou menor expressão de MAP2 nas regiões do hilo, CA4, CA3, CA1 e prosubículo em comparação ao grupo controle. Por outro lado, nas regiões da camada granular, CA2 e parasubículo, o grupo ELTM apresentou maior expressão de MAP2 que o grupo controle.

A maioria das regiões do hipocampo nas quais encontramos diminuição na expressão de MAP2 em pacientes epilépticos são conhecidas por apresentarem acentuada perda neuronal. Como a expressão de MAP2 é específica de dendritos e corpos celulares (Garner et al 1988), a menor expressão de MAP2 poderia estar relacionada à perda de células neuronais. Porém, encontramos correlação positiva entre densidade neuronal e expressão de MAP2 apenas na região de CA3. Em concordância com nossos resultados, Pollard e colaboradores (1994) observaram que no período entre 4 a 12 dias após injeção de ácido caínico em ratos houve perda neuronal em CA3 acompanhada por uma queda na imunoreatividade para MAP2 nesta região.

A maior expressão de MAP2 na camada de células granulares do grupo ELTM pode sugerir a ocorrência de hipertrofia dendrítica (von Campe et al 1997). Por outro lado, o aumento na expressão de MAP2 pode indicar um aumento na densidade das espículas dos dendritos proximais das células granulares em pacientes epilépticos (Isokawa 1997). Quanto à maior imunoreatividade para MAP2 na região de CA2, este aumento parece estar relacionado às modificações decorrentes do processo epileptogênico. Algumas regiões do hipocampo, como a região de $\mathrm{CA} 2$, apresentam resistência à perda de células neuronais em resposta às crises epilépticas. Esta resistência parece estar relacionada ao mecanismo de homeostase do cálcio. Além disso, outro fator que poderia explicar a resistência dos neurônios da região de CA2 às crises está relacionado à baixa quantidade de aferências excitatórias para esta região. Por 
exemplo, as fibras musgosas glutamatérgicas das células granulares fazem conexões com CA3 mas não com CA2 (Amaral \& Lavenex 2006).

As fibras musgosas fisiológicas fazem contato sináptico com os dendritos dos neurônios piramidais de CA3. Em nossa casuística, observamos perda neuronal e provável atrofia dendrítica na região CA3 de specimens ELTM. Poderia este cenário representar uma desaferentação parcial da conexão fisiológica das fibras musgosas-CA3 resultando no reforço das novas conexões estabelecidas pelo neobrotamento anormal das fibras musgosas? Em concordância com esta hipótese, observamos correlação negativa entre a expressão de MAP2 em CA3 e a espessura do neobrotamento aberrante das fibras musgosas. Embora o neobrotamento não seja indispensável para a ocorrência de crises espontâneas (Longo \& Mello 1997), nossos resultados sugerem que alterações dendríticas e axonais são componentes neuropatológicos importantes em quadros crônicos de ELTM.

\subsubsection{Tau}

As alterações na expressão da proteína tau são encontradas na maioria das desordens que afetam os mecanismos de memória e aprendizagem, como na doença de Alzheimer, Pakinson e demências frontotemporais (Delacourte \& Buee 2000; Delacourte et al 2002a). O hipocampo é uma das principais estruturas responsáveis pelos processos de aprendizagem e memória (Neves et al 2008). Danos hipocampais e déficits cognitivos associados são encontrados com frequência em pacientes com ELTM (Black et al 2010) e em modelos animais de ELTM (Chauviere et al 2009). Delacourte e Buee (2000) demonstraram que as disfunções da proteína tau estão presentes em desordens que apresentam deficits cognitivos. Em concordância com Delacourte e Buee (2000), encontramos maior expressão da proteína tau no hipocampo de pacientes com ELTM. Em nosso estudo, o grupo ELTM apresentou maior expressão de tau que o grupo controle nas regiões da camada granular, hilo, CA3, CA2 e córtex entorrinal.

As alterações na expressão da proteína tau observadas em algumas síndromes, podem ocorrer devido a inúmeras disfunções nas vias de síntese e manutenção desta proteína. 
Essas disfunções incluem: mutações, fosforilação anormal, agregação de isoformas específicas, processamento anormal e perda da proteína tau normal (Delacourte et al 2002a).

Além da maior expressão de tau em axônios de células neuronais em determinadas regiões hipocampais, encontramos ainda, maior imunorreatividade desta proteína no neurópilo de todas as regiões do hipocampo de pacientes ELTM. Na doença de Alzheimer, Kowall e Kosic (1987) observaram alterações marcantes no neurópilo de neurônios corticais, reveladas pela localização anormal da proteína tau. Esta alteração no neurópilo de pacientes com Alzheimer está presente até mesmo em regiões sem os emaranhados neurofibrilares e placas senis. Este depósito de proteína tau no neurópilo das células neuronais pode ocorrer devido à desagregação microtubular que ocorre nos axônios. Há um deslocamento da proteína tau para outros compartimentos não usuais como corpo celular, dendritos e regiões pré-sinápticas (Kowall \& Kosik 1987). Desta maneira, é provável que o depósito de tau no neurópilo contribua para as disfunções neuronais que ocorrem na doença de Alzheimer. O depósito anormal de tau no neurópilo e a consequente alteração das funções neuronais provavelmente não acontecem apenas na doença de Alzheimer, mas também na epilepsia como observado em nossa casuística.

A fosforilação anormal da proteína tau é uma disfunção importante que está relacionada às alterações patológicas observadas na doença de Alzheimer e provavelmente na epilepsia. A fosforilação anormal da proteína tau na doença de Alzheimer parece estar relacionada a um aumento na atividade das proteínas cinases ou na diminuição da atividade de proteínas fosfatases (Delacourte et al 2003). Na doença de Alzheimer, a fosforilação anormal da proteína tau resulta na deposição desta proteína nos filamentos em forma de hélice pareados, que se acumulam nas ramificações axonais e corpos celulares neuronais. Esse acúmulo de proteína tau resulta em lesões que são responsáveis pelo processo de neurodegeneração que ocorre nesta doença (Kosik 1990; Wood et al 1986). Dessa forma, a fosforilação da proteína tau em seus sítios específicos de ligação é o que garante seu funcionamento normal. Da mesma maneira, a fosforilação inapropriada resulta em disfunção e menor viabilidade celular desta proteína. De fato, as doenças neurodegenerativas envolvidas com a proteína tau apresentam esta proteína anormalmente fosforilada (Gartner et al 1998; Kosik 1990; Lee et al 1993), o que provavelmente ocorre na epilepsia. 
Alterações no estado de fosforilação da tau afetam a estabilidade dos microtúbulos, contribuindo para o prejuízo do transporte axonal, uma vez que a proteína tau é específica de axônios (Kosik 1990). Franck e colaboradores (1995) demonstraram que alterações na expressão de tau prejudicam a circuitaria axonal em células hipocampais humanas in vitro. Os autores sugeriram que as mudanças nos mecanismos de excitação/inibição que ocorre nos pacientes epilépticos são consistentes com as evidências anatômicas de reorganização axonal. Assim, nossos resultados de maior expressão da proteína tau em pacientes epilépticos indicam que estes pacientes apresentam modificações na circuitaria axonal (Pollard et al 1994).

Nossos resultados de correlação sugerem o envolvimento da proteína tau no neobrotamento anormal das fibras musgosas. Encontramos correlação positiva entre a expressão de tau na camada granular e os valores de cinza da camada granular e da camada molecular interna apenas nos pacientes epilépticos. Além disso, encontramos correlação negativa entre a expressão de tau em CA3 e os valores de cinza da camada granular, camada molecular interna e molecular externa nos pacientes ELTM. Como a proteína tau é expressa em axônios e corpos celulares, esta correlação indica que provavelmente houve perda de células neuronais em CA3. A perda de células neuronais em CA3 é um mecanismo que realmente ocorre anteriormente à reorganização das fibras musgosas em pacientes epilépticos (Amaral \& Insausti 1990; Cavazos \& Cross 2006). Outra correlação positiva importante que encontramos foi entre a expressão de tau no córtex entorrinal e a expressão de tau em CA1 nos grupos ELTM e controle. A maioria dos axônios do córtex entorrinal faz contato sináptico com CA1 através da via alvear (Deng et al 2007). Como encontramos esta correlação em ambos grupos, ELTM e controle, provavelmente ela indica a preservação das conexões da via alvear em pacientes epilépticos (Deller et al 1996; Deng et al 2007).

Alguns trabalhos demonstraram que a fosforilação incorreta da proteína tau resulta em anormalidades patológicas como a doença de Alzheimer (Gartner et al 1998; Kosik 1990; Wood et al 1986). Assim, as modificações no estado de fosforilação da proteína tau provavelmente ocorrem na epilepsia devido às modificações plásticas que acontecem no decorrer do processo epileptogênico. 


\subsection{ELTM familiar e ELTM esporádica}

Muitos trabalhos têm demonstrado a predisposição genética de certos indivíduos à epilepsia (Andermann 1982; Cavalleri et al 2005; Coan et al 2004; Kobayashi et al 2003; Kobayashi et al 2001). O estudo da forma familiar da ELTM é recente na literatura, com suas características clínicas bem definidas, englobando aproximadamente $7 \%$ dos casos de ELT (Cendes et al 1998; Kobayashi et al 2001). Alguns trabalhos demonstraram diferenças clínicas (Cendes et al 1998; Kobayashi et al 2003) e nas características histopatológicas de densidade neuronal e formação do neobrotamento das fibras musgosas (Andrade-Valenca et al 2008) entre os grupos familiar e esporádico. Porém Kobayashi e colaboradores (2001) não observaram diferenças na intensidade do sinal em T2 pela análise de ressonância magnética e nos padrões de anormalidades histopatológicas entre os grupos ELTM familiar e esporádica.

Em nosso trabalho, encontramos diferenças na expressão de todas as proteínas analisadas neste estudo em relação aos grupos ELTM familiar e esporádica. Além da maior frequência de crises, o grupo ELTM esporádica apresentou tendência à maior perda de células neuronais que o grupo ELTM familiar na região do parasubículo. Porém não encontramos qualquer correlação entre a densidade neuronal e a frequência de crises nestes pacientes.

O grupo ELTM esporádica apresentou maior valor de cinza e tendência à maior espessura da camada molecular interna que o grupo ELTM familiar. Os resultados de maior reorganização sináptica entre os pacientes esporádicos são coincidentes com o estudo de Andrade-valença e colaboradores (2008). Apesar de ambos grupos apresentarem manifestações clínicas semelhantes, os maiores valores de neobrotamento das fibras musgosas, frequência de crises e tendência à maior perda celular no parasubículo foram encontrados no grupo esporádico.

Em relação à expressão das proteínas estruturais, o grupo ELTM esporádica teve maior expressão de MAP2 que o grupo ELTM familiar nas regiões de CA1 e no córtex entorrinal e maior expressão de MAP2 que o grupo controle na região do parasubículo. As alterações na expressão de MAP2 observadas em pacientes epilépticos parecem refletir as modificações na excitabilidade das redes neuronais que ocorrem nestes pacientes (Johnson \& Jope 1992; Thom et al 2002). Dessa forma, acreditamos que o grupo esporádico seja mais 
afetado que o grupo familiar pelas modificações na excitabilidade neuronal que ocorrem como resultado das crises epilépticas.

Em nossos resultados de expressão da proteína tau entre os casos ELTM familiar e esporádica, encontramos que o grupo ELTM esporádica apresentou menor expressão de tau que o grupo familiar na região do córtex entorrinal. Agora na comparação entre estes grupos e o grupo controle, observamos que o grupo familiar demonstrou maior expressão de tau que o grupo controle nas regiões de CA3 e córtex entorrinal e o grupo ELTM esporádica teve maior expressão que os controles na região de CA2. A reorganização axonal é maior em pacientes epilépticos que em pacientes sem alterações neurológicas, um conceito bastante conhecido na literatura. Assim, nossos resultados de expressão da proteína tau entre pacientes epilépticos e controles concordam com a literatura. Em adição, dentre os grupos epiléticos de nosso estudo, a reorganização axonal parece ser maior no grupo familiar, pelo menos na região do córtex entorrinal.

Pacientes ELTM familiar e ELTM esporádica respondem de maneira diferente às modificações plásticas induzidas pela perda e diferenciação neuronais e crises recorrentes (Andrade-Valenca et al 2008). Estas diferentes respostas frente a estímulos similares provavelmente resultam da influência genética que atua de forma distinta entre os grupos. Segundo Yasuda e colaboradores (2010), pacientes ELTM familiar apresentam forte influência de fatores genéticos, enquanto pacientes ELTM esporádica apresentam influência de fatores ambientes, como infecções cerebrais, traumas. Além disso, a progressão dos danos induzidos pelas crises epilépticas ao longo dos anos é mais lenta nos pacientes com ELTM familiar que nos pacientes com ELTM esporádica (Conz et al 2011).

\subsection{Variáveis clínicas}

Dentre as variáveis clínicas consideradas no presente estudo (vide tabela 1), apenas a variável frequência de crises teve distribuição diferente entre os grupos ELTM familiar e esporádico. Não encontramos correlação entre a densidade neuronal ou expressão de MAP2 e as variáveis clínicas analisadas neste estudo. 
O grupo ELTM esporádica apresentou maior frequência de crises por mês que o grupo ELTM familiar. A frequência de crises parece ter influência sobre a evolução da doença como demonstrado por estudos clínicos, experimentais, neuropsicológicos e de neuroimagem (Bernhardt et al 2009; Bonilha et al 2006; Cendes 2005; Coan et al 2009; Fuerst et al 2003; Kalviainen et al 1998; Pitkanen et al 2002). Além disso, encontramos correlação positiva entre a frequência de crises e a espessura da camada molecular interna. Lemos e Cavalheiro (1995) demonstraram essa correlação em um modelo de epilepsia induzida por pilocarpina. Porém, em um trabalho posterior, Longo e Mello (1997) demonstraram, através de um modelo animal de pilocarpina, que o neobrotamento anormal das fibras musgosas parece não ser imprescindível para o aparecimento de crises espontâneas recorrentes. Outros autores não conseguiram demonstrar a associação entre a frequência de crises e a formação do neobrotamento axonal nos modelos experimentais de epilepsia induzida por ácido caínico (Buckmaster \& Dudek 1997) ou por abrasamento (Pitkanen et al 2000a).

\subsection{Modelo Animal}

\subsubsection{Variáveis comportamentais}

Obtivemos resultados semelhantes a estudos anteriores que descreveram alterações histopatológicas associadas ao modelo de ELTM induzido por lítio-pilocarpina (Clifford et al 1987; Jope et al 1986) (Mello et al 1993; Turski et al 1983). O pré-tratamento com cloreto de lítio potencializa o efeito da pilocarpina, sendo necessária uma quantidade por volta de 10 vezes menor da droga para a indução do SE. Assim, o pré-tratamento com lítio impede a grande mortalidade que geralmente ocorre nos modelos de pilocarpina (Clifford et al 1987; Jope et al 1986). De fato, encontramos uma mortalidade menor que $40 \%$ em todos os nossos grupos experimentais.

Em nosso estudo, o tempo de início para o SE variou entre 22 e 45 minutos, semelhante à outros trabalhos que mencionaram uma variação de 22 a 43 minutos (Clifford et al 1987; Glien et al 2001). Além disso, os animais que entraram em SE, apresentaram a primeira CER em uma média de 11,14 dias. Este intervalo de tempo está dentro do descrito em 
alguns trabalhos, onde este intervalo variou entre 5 a 40 dias (Cavalheiro 1995; Goffin et al 2007; Scorza et al 2009).

\subsubsection{Densidade Neuronal}

Animais injetados com lítio-pilocarpina apresentaram resultados semelhantes aos encontrados em pacientes com ELTM. Animais SE15 e SE60 apresentaram maior perda neuronal que os demais grupos nas regiões da camada granular, hilo, CA4 e CA3. Estes resultados indicam que o SE e as crises epilépticas comprometem a sobrevivência neuronal. Porém, Pitkanen e colaboradores (2000b) sugeriram que o tempo de duração da doença parece agravar a perda neuronal em ratos. Neste trabalho, os autores concluíram que a perda de células hilares correlacionava-se de forma positiva com o tempo entre o SE e o sacrifício dos animais e não com o número de crises espontâneas que eles apresentavam após o SE.

\subsubsection{Neobrotamento das Fibras Musgosas}

Apenas os grupos SE15 e SE60 desenvolveram o neobrotamento anormal das fibras musgosas (Cavalheiro 1995; Cavazos \& Cross 2006; Scorza et al 2009). Em modelos animais de epilepsia induzida por pilocarpina, o neobrotamento anormal das fibras musgosas aumenta em decorrência do tempo após o insulto epileptogênico, manifestando-se a partir do início das CERs (Cavalheiro 1995). Por este motivo, não encontramos formação de neobrotamento anormal das fibras musgosas no grupo agudo pós-SE (SE1) ou na fase latente (SE7).

A perda de células neuronais, principalmente na região do hilo, pode desencadear os eventos que culminam na reorganização sináptica das fibras musgosas. Essas mudanças, por sua vez, podem gerar a excitação das células granulares e CERs em modelos animais de epilepsia (Cavalheiro 1995; Cavazos \& Cross 2006). De fato, encontramos maior perda de células hilares e formação do neobrotamento anormal das fibras musgosa em nossos grupos SE15 e SE60 em comparação aos demais grupos estudados. 


\subsubsection{MAP2}

Obtivemos resultados semelhantes aos encontrados em humanos na expressão de MAP2 nas regiões da camada granular e em CA2. Os grupos SE60 e SE15 tiveram maior expressão de MAP2 que o grupo salina nestas regiões. O aumento na expressão de MAP2 na camada granular concorda com os resultados de Pollard e colaboradores (1994). Estes autores observaram um aumento nos níveis do RNAm da proteína MAP2 nos corpos celulares e dendritos das células granulares. Neste trabalho, o aumento na expressão de MAP2 ocorreu entre o terceiro dia até a segunda semana após o tratamento com ácido caínico. Em nosso estudo, apenas animais SE15 e SE60 demonstraram aumento nos níveis de MAP2.

Na região do hilo, o grupo SE60 teve maior expressão de MAP2 que o grupo SE15. Na região de CA4 o grupo SE15 apresentou maior expressão de MAP2 que o grupo salina. Estes resultados foram diferentes dos encontrados em humanos, onde o grupo controle teve maior expressão de MAP2 que o grupo ELTM nestas regiões.

\subsubsection{Tau}

Não encontramos diferença estatística significativa na expressão da proteína tau na região de CA3 entre os grupos analisados no modelo animal de lítio-pilocarpina. Esta densa banda imunorreativa para tau na região de CA3 também foi observada no trabalho de Pollard e colaboradores (1994). Segundo estes autores, a faixa onde existe a intensa marcação de proteína tau coincide com a região dos terminais das fibras musgosas. Colaterais das fibras musgosas na camada polimórfica e outras vias aferentes axonais foram imunorreativas para este anticorpo.

\subsection{ELTM em humanos e em modelos experimentais}

Existem muitas formas de epilepsia, com diferentes substratos patofisiológicos e cujos mecanismos de origem e manutenção de crises recorrentes ainda não foram completamente compreendidos (Berg et al 2010). O estudo controlado de tais mecanismos depende em grande parte da geração e utilização de modelos experimentais. A capacidade de reproduzir doenças humanas em modelos animais representa uma grande vantagem para a medicina moderna 
(Curia et al 2008). Nestes modelos, é possível controlar a maioria das variáveis que podem influenciar o resultado final. Quando estudamos pacientes epilépticos, podemos observar que cada indivíduo tem uma idade, um tempo de epilepsia, um padrão genético, são de sexos diferentes entre outras características. Por outro lado, quando estudamos modelos animais, todos têm a mesma idade, o mesmo peso, o mesmo tempo de epilepsia, em sua grande maioria são do mesmo sexo, geralmente machos já que fêmeas podem sofrer influência hormonal. Como exemplo, podemos citar o trabalho de Juraska e colaboradores (1989). Estes autores demonstraram que neurônios do giro denteado de fêmeas tinham mais ramificações dendríticas proximais e nos machos havia uma prevalência de ramificações dendríticas distais. Segundo os autores, estes resultados sugerem a presença de dimorfismo sexual.

Em nosso trabalho, estudamos as alterações histopatológicas que ocorrem na ELTM como perda neuronal e formação do neobrotamento axonal das fibras musgosas, bem como a expressão de proteínas estruturais MAP2 e tau. Em paralelo, decidimos acompanhar se existiam alterações na expressão destas proteínas estruturais ao longo da epileptogênese. Para isso, utilizamo-nos do modelo animal de lítio-pilocarpina. Observamos que a maioria das alterações são coincidentes entre pacientes com ELTM e animais na fase crônica do modelo. O modelo animal de epilepsia induzida por lítio-pilocarpina que utilizamos neste estudo é um modelo dito isomórfico, ou seja, que consegue reproduzir a doença mas não a causa principal da doença (Curia et al 2008). Mesmo com um modelo altamente isomórfico com a ELTM humana, encontramos diferenças no padrão de expressão das proteínas MAP2 e tau entre humanos e animais.

Existe um consenso de que muitos dos modelos animais de epilepsia não representam a condição humana em toda sua complexidade (Avanzini 1995; Engel 1992; 1995; Gordon 2010). Porém, estes modelos servem como ferramentas para testar hipóteses na tentativa de entendermos os mecanismos envolvidos nas doenças humanas. Como foi observado em nosso trabalho, o modelo animal reproduziu as principais características fisiopatológicas observadas na ELTM humana. Estas características são o surgimento das CERs, perda neuronal e formação do neobrotamento anormal das fibras musgosas. 


\section{CONCLUSÕES}

Nossos resultados indicam que além da perda neuronal e reorganização sináptica, hipocampos de pacientes com ELTM exibem alterações dendríticas relacionadas à expressão de MAP2. O aumento na expressão de tau em hipocampos epileptogênicos indica que esta proteína está alterada na fase crônica da ELTM e parece ter envolvimento no neobrotamento das fibras musgosas. Dentre os casos ELTM, encontramos diferenças no neobrotamento de fibras musgosas e na expressão de MAP2 e tau entre os grupos com ELTM familiar e esporádica. Estas diferenças neuroquímicas sugerem que exista um diferente substrato neuropatológico entre estes subgrupos, apesar de a evolução clínica da ELTM ser bastante semelhante em ambos. Embora os resultados de perda neuronal e neobrotamento de fibras musgosas terem sido semelhantes entre a fase crônica do modelo de lítio-pilocarpina e a ELTM humana, encontramos disparidade nos resultados de expressão de MAP2 e tau. Vários estudos sugerem a possibilidade de falhas nos modelos induzidos com quimio-convulsivantes como pilocarpina e ácido caínico, uma vez que a variabilidade de resultados intra-grupos é extremamente alta e a fonte de descargas e espalhamento das crises é em sua maioria extrahipocampal. Assim, embora o modelo animal de pilocarpina permaneça como um modelo relevante para o estudo da epilepsia do lobo temporal, outros modelos e novos protocolos de indução de SE, com concentrações de droga e tempos de SE diferentes poderão representar com mais verossimilhança o que vemos na fase crônica em humanos. 


\section{Referências Bibliográficas}

Abercrombie M. 1946. Estimation of nuclear population from microtome sections. Anat. Rec. 94:239-47

Amaral A, Lavenex P. 2006. Historical Perspective: Proposed Functions, Biological Characteristics, and Neurobiological Models of the Hippocampus. In The Hippocampus Book, ed. P Andersen, R Morris, D Amaral, T Bliss, J O'Keefe, pp. 9-36. 872: Oxford University Press

Amaral DG, Insausti R. 1990. Hippocampal Formation. In The Human Nervous System, pp. 711-54: Academic Press

Andrade-Valenca LP, Valenca MM, Velasco TR, Carlotti CG, Jr., Assirati JA, et al. 2008. Mesial temporal lobe epilepsy: clinical and neuropathologic findings of familial and sporadic forms. Epilepsia 49:1046-54

Avanzini G. 1995. Animal models relevant to human epilepsies. Ital J Neurol Sci 16:5-8

Avila-Costa MR, Colin-Barenque L, Fortoul TI, Machado-Salas P, Espinosa-Villanueva J, et al. 1999. Memory deterioration in an oxidative stress model and its correlation with cytological changes on rat hippocampus CA1. Neurosci Lett 270:107-9

Baas PW. 2002. Neuronal polarity: microtubules strike back. Nat Cell Biol 4:E194-5

Babb TL, Brown WJ, Pretorius J, Davenport C, Lieb JP, Crandall PH. 1984. Temporal lobe volumetric cell densities in temporal lobe epilepsy. Epilepsia 25:729-40

Babb TL, Kupfer WR, Pretorius JK, Crandall PH, Levesque MF. 1991. Synaptic reorganization by mossy fibers in human epileptic fascia dentata. Neuroscience 42:351-63

Benitez-King G, Ramirez-Rodriguez G, Ortiz L, Meza I. 2004. The neuronal cytoskeleton as a potential therapeutical target in neurodegenerative diseases and schizophrenia. Curr Drug Targets CNS Neurol Disord 3:515-33

Bensimon G, Chermat R. 1991. Microtubule disruption and cognitive defects: effect of colchicine on learning behavior in rats. Pharmacol Biochem Behav 38:141-5

Berg AT, Berkovic SF, Brodie MJ, Buchhalter J, Cross JH, et al. 2010. Revised terminology and concepts for organization of seizures and epilepsies: report of the ILAE Commission on Classification and Terminology, 2005-2009. Epilepsia 51:676-85

Berkovic SF, Howell RA, Hay DA, Hopper JL. 1998. Epilepsies in twins: genetics of the major epilepsy syndromes. Ann Neurol 43:435-45

Berkovic SF, Scheffer IE. 1999. Genetics of the epilepsies. Curr Opin Neurol 12:17782

Bernhardt R, Matus A. 1984. Light and electron microscopic studies of the distribution of microtubule-associated protein 2 in rat brain: a difference between dendritic and axonal cytoskeletons. J Comp Neurol 226:203-21

Black LC, Schefft BK, Howe SR, Szaflarski JP, Yeh HS, Privitera MD. 2010. The effect of seizures on working memory and executive functioning performance. Epilepsy Behav 17:412-9

Brady S, Colman D, Brophy P. 2003. Subcellular organization of the nervous system: organelles and their functions. In Fundamental neuroscience, pp. 79-114. San Diego: Academic Press

Bray D, Gilbert D. 1981. Cytoskeletal elements in neurons. Annu Rev Neurosci 4:50523 
Brusco J, Dall'Oglio A, Rocha LB, Rossi MA, Moreira JE, Rasia-Filho AA. 2010. Descriptive findings on the morphology of dendritic spines in the rat medial amygdala. Neurosci Lett 483:152-6

Bulinski JC, Ohm T, Roder H, Spruston N, Turner DA, Wheal HV. 1998. Changes in dendritic structure and function following hippocampal lesions: correlations with developmental events? Prog Neurobiol 55:641-50

Caceres A, Banker GA, Binder L. 1986. Immunocytochemical localization of tubulin and microtubule-associated protein 2 during the development of hippocampal neurons in culture. $J$ Neurosci 6:714-22

Caceres A, Mautino J, Kosik KS. 1992. Suppression of MAP2 in cultured cerebellar macroneurons inhibits minor neurite formation. Neuron 9:607-18

Caceres A, Potrebic S, Kosik KS. 1991. The effect of tau antisense oligonucleotides on neurite formation of cultured cerebellar macroneurons. J Neurosci 11:1515-23

Camfield P, Camfield C, Gordon K, Dooley J. 1994. What types of epilepsy are preceded by febrile seizures? A population-based study of children. Dev Med Child Neurol 36:887-92

Cavalheiro EA. 1995. The pilocarpine model of epilepsy. Ital J Neurol Sci 16:33-7

Cavalheiro EA, Leite JP, Bortolotto ZA, Turski WA, Ikonomidou C, Turski L. 1991. Long-term effects of pilocarpine in rats: structural damage of the brain triggers kindling and spontaneous recurrent seizures. Epilepsia 32:778-82

Cavalheiro EA, Sanabria ER. 2000. Epileptogênese: contribuíção dos modelos experimentais. In Epileptogênese: contribuição dos modelos experimentais, pp. 29-57. São Paulo: Epilepsia

Cavalheiro EA, Santos NF, Priel MR. 1996. The pilocarpine model of epilepsy in mice. Epilepsia 37:1015-9

Cavazos JE, Cross DJ. 2006. The role of synaptic reorganization in mesial temporal lobe epilepsy. Epilepsy \& Behavior 8:483-93

Cendes F, Lopes-Cendes I, Andermann E, Andermann F. 1998. Familial temporal lobe epilepsy: a clinically heterogeneous syndrome. Neurology 50:554-7

Chauviere L, Rafrafi N, Thinus-Blanc C, Bartolomei F, Esclapez M, Bernard C. 2009. Early deficits in spatial memory and theta rhythm in experimental temporal lobe epilepsy. J Neurosci 29:5402-10

Chung WJ, Kindler S, Seidenbecher C, Garner CC. 1996. MAP2a, an alternatively spliced variant of microtubule-associated protein 2. J Neurochem 66:1273-81

Clifford DB, Olney JW, Maniotis A, Collins RC, Zorumski CF. 1987. The functional anatomy and pathology of lithium-pilocarpine and high-dose pilocarpine seizures. Neuroscience 23:953-68

Conz L, Morita ME, Coan AC, Kobayashi E, Yasuda CL, et al. 2011. Longitudinal MRI volumetric evaluation in patients with familial mesial temporal lobe epilepsy. Front Neurol 2:5

Curia G, Longo D, Biagini G, Jones RS, Avoli M. 2008. The pilocarpine model of temporal lobe epilepsy. J Neurosci Methods 172:143-57

Dam AM. 1980. Epilepsy and neuron loss in the hippocampus. Epilepsia 21:617-29

de Lanerolle NC, Kim JH, Robbins RJ, Spencer DD. 1989. Hippocampal interneuron loss and plasticity in human temporal lobe epilepsy. Brain Res 495:387-95

Delacourte A, Buee L. 2000. Tau pathology: a marker of neurodegenerative disorders. Curr Opin Neurol 13:371-6

Delacourte A, Sergeant N, Buee L. 2003. In vitro models of age-related neurodegenerative disorders. Exp Gerontol 38:1309-17 
Delacourte A, Sergeant N, Wattez A, Maurage CA, Lebert F, et al. 2002a. Tau aggregation in the hippocampal formation: an ageing or a pathological process? Exp Gerontol 37:1291-6

Deng JB, Yu DM, Wu P, Li MS. 2007. The tracing study of developing entorhinohippocampal pathway. Int J Dev Neurosci 25:251-8

Drewes G, Ebneth A, Mandelkow EM. 1998. MAPs, MARKs and microtubule dynamics. Trends Biochem Sci 23:307-11

Du F, Eid T, Lothman EW, Kohler C, Schwarcz R. 1995. Preferential neuronal loss in layer III of the medial entorhinal cortex in rat models of temporal lobe epilepsy. $J$ Neurosci 15:6301-13

Du F, Whetsell WO, Jr., Abou-Khalil B, Blumenkopf B, Lothman EW, Schwarcz R. 1993. Preferential neuronal loss in layer III of the entorhinal cortex in patients with temporal lobe epilepsy. Epilepsy Res 16:223-33

Dudek FE, Obenaus A, Schweitzer JS, Wuarin JP. 1994. Functional significance of hippocampal plasticity in epileptic brain: electrophysiological changes of the dentate granule cells associated with mossy fiber sprouting. Hippocampus 4:259-65

Eitzen G. 2003. Actin remodeling to facilitate membrane fusion. Biochim Biophys Acta 1641:175-81

Engel J, Jr. 1992. Experimental animal models of epilepsy: classification and relevance to human epileptic phenomena. Epilepsy Res Suppl 8:9-20

Engel J, Jr. 1995. Critical evaluation of animal models for localization-related epilepsies. Ital J Neurol Sci 16:9-16

Ferreira A, Busciglio J, Caceres A. 1987. An immunocytochemical analysis of the ontogeny of the microtubule-associated proteins MAP-2 and Tau in the nervous system of the rat. Brain Res 431:9-31

Franck JE, Pokorny J, Kunkel DD, Schwartzkroin PA. 1995. Physiologic and morphologic characteristics of granule cell circuitry in human epileptic hippocampus. Epilepsia 36:543-58

Gama Sosa MA, Friedrich VL, Jr., DeGasperi R, Kelley K, Wen PH, et al. 2003. Human midsized neurofilament subunit induces motor neuron disease in transgenic mice. Exp Neurol 184:408-19

Gardiner J, Marc J. 2010. Disruption of normal cytoskeletal dynamics may play a key role in the pathogenesis of epilepsy. Neuroscientist 16:28-39

Garner CC, Tucker RP, Matus A. 1988. Selective localization of messenger RNA for cytoskeletal protein MAP2 in dendrites. Nature 336:674-7

Gartner U, Janke C, Holzer M, Vanmechelen E, Arendt T. 1998. Postmortem changes in the phosphorylation state of tau-protein in the rat brain. Neurobiol Aging 19:535-43

Glien M, Brandt C, Potschka H, Voigt H, Ebert U, Loscher W. 2001. Repeated lowdose treatment of rats with pilocarpine: low mortality but high proportion of rats developing epilepsy. Epilepsy Res 46:111-9

Gordon JA. 2010. Testing the glutamate hypothesis of schizophrenia. Nat Neurosci $13: 2-4$

Guerreiro C, Guerreiro M, Cendes F, Cendes I. 2000. Epilepsia. p. 419. São Paulo: Editorial Lemos

Hadfield JA, Ducki S, Hirst N, McGown AT. 2003. Tubulin and microtubules as targets for anticancer drugs. Prog Cell Cycle Res 5:309-25 
Harada A, Oguchi K, Okabe S, Kuno J, Terada S, et al. 1994. Altered microtubule organization in small-calibre axons of mice lacking tau protein. Nature 369:48891

Harvey BD, Sloviter RS. 2005. Hippocampal granule cell activity and c-Fos expression during spontaneous seizures in awake, chronically epileptic, pilocarpine-treated rats: implications for hippocampal epileptogenesis. J Comp Neurol 488:442-63

He de F, Ma DL, Tang YC, Engel J, Jr., Bragin A, Tang FR. 2009. Morpho-physiologic characteristics of dorsal subicular network in mice after pilocarpine-induced status epilepticus. Brain Pathol 20:80-95

Houser CR. 1990. Granule cell dispersion in the dentate gyrus of humans with temporal lobe epilepsy. Brain Res 535:195-204

Houser CR. 1999. Neuronal loss and synaptic reorganization in temporal lobe epilepsy. Adv Neurol 79:743-61

Isokawa M. 1997. Preservation of dendrites with the presence of reorganized mossy fiber collaterals in hippocampal dentate granule cells in patients with temporal lobe epilepsy. Brain Res 744:339-43

Johnson GV, Jope RS. 1992. The role of microtubule-associated protein 2 (MAP-2) in neuronal growth, plasticity, and degeneration. J Neurosci Res 33:505-12

Johnson GV, Stoothoff WH. 2004. Tau phosphorylation in neuronal cell function and dysfunction. J Cell Sci 117:5721-9

Jope RS, Morrisett RA, Snead OC. 1986. Characterization of lithium potentiation of pilocarpine-induced status epilepticus in rats. Exp Neurol 91:471-80

Juraska JM, Fitch JM, Washburne DL. 1989. The dendritic morphology of pyramidal neurons in the rat hippocampal CA3 area. II. Effects of gender and the environment. Brain Res 479:115-9

Kalcheva N, Weidenheim KM, Kress Y, Shafit-Zagardo B. 1997. Expression of microtubule-associated protein-2a and other novel microtubule-associated protein-2 transcripts in human fetal spinal cord. $J$ Neurochem 68:383-91

Kandratavicius L. 2007. Caracterização neuropatológica da sintase neuronal do óxido nítrico e das proteínas de choque térmico 70 e 90 na epilepsia do lobo temporal associada ou não a comorbidades psiquiátricas USP, Ribeirão Preto. 89 pp.

Kato K, Masa T, Tawara Y, Kobayashi K, Oka T, et al. 2001. Dendritic aberrations in the hippocampal granular layer and the amygdalohippocampal area following kindled-seizures. Brain Res 901:281-95

Kinton L, Johnson MR, Smith SJ, Farrell F, Stevens J, et al. 2002. Partial epilepsy with pericentral spikes: a new familial epilepsy syndrome with evidence for linkage to chromosome 4p15. Ann Neurol 51:740-9

Kitagawa K, Matsumoto M, Sobue K, Tagaya M, Okabe T, et al. 1992. The synapsin I brain distribution in ischemia. Neuroscience 46:287-99

Kitamura O, Gotohda T, Ishigami A, Tokunaga I, Kubo S, Nakasono I. 2005. Effect of hypothermia on postmortem alterations in MAP2 immunostaining in the human hippocampus. Leg Med (Tokyo) 7:24-30

Kobayashi E, Lopes-Cendes I, Guerreiro CA, Sousa SC, Guerreiro MM, Cendes F. 2001. Seizure outcome and hippocampal atrophy in familial mesial temporal lobe epilepsy. Neurology 56:166-72

Kosik KS. 1990. Tau protein and Alzheimer's disease. Curr Opin Cell Biol 2:101-4

Kosik KS, Orecchio LD, Bakalis S, Neve RL. 1989. Developmentally regulated expression of specific tau sequences. Neuron 2:1389-97 
Kowall NW, Kosik KS. 1987. Axonal disruption and aberrant localization of tau protein characterize the neuropil pathology of Alzheimer's disease. Ann Neurol 22:63943

Lee MK, Xu Z, Wong PC, Cleveland DW. 1993. Neurofilaments are obligate heteropolymers in vivo. $J$ Cell Biol 122:1337-50

Lee VM, Goedert M, Trojanowski JQ. 2001. Neurodegenerative tauopathies. Annu Rev Neurosci 24:1121-59

Leite JP, Bortolotto ZA, Cavalheiro EA. 1990. Spontaneous recurrent seizures in rats: an experimental model of partial epilepsy. Neurosci Biobehav Rev 14:511-7

Leite JP, Garcia-Cairasco N, Cavalheiro EA. 2002. New insights from the use of pilocarpine and kainate models. Epilepsy Res 50:93-103

Lemos T, Cavalheiro EA. 1995. Suppression of pilocarpine-induced status epilepticus and the late development of epilepsy in rats. Exp Brain Res 102:423-8

Leranth C, Ribak CE. 1991. Calcium-binding proteins are concentrated in the CA2 field of the monkey hippocampus: a possible key to this region's resistance to epileptic damage. Exp Brain Res 85:129-36

Lewis SA, Wang DH, Cowan NJ. 1988. Microtubule-associated protein MAP2 shares a microtubule binding motif with tau protein. Science 242:936-9

Longo BM, Mello LE. 1997. Blockade of pilocarpine- or kainate-induced mossy fiber sprouting by cycloheximide does not prevent subsequent epileptogenesis in rats. Neurosci Lett 226:163-6

Lorente de Nó R. 1934. Studies on the structure of the cerebral cortex:

II. Continuation of study of the Ammonic System. J Psychol Neurol 46:113-7

Ludin B, Matus A. 1993. The neuronal cytoskeleton and its role in axonal and dendritic plasticity. Hippocampus 3 Spec No:61-71

Matesic DF, Lin RC. 1994. Microtubule-associated protein 2 as an early indicator of ischemia-induced neurodegeneration in the gerbil forebrain. $J$ Neurochem 63:1012-20

Mathern GW, Adelson PD, Cahan LD, Leite JP. 2002. Hippocampal neuron damage in human epilepsy: Meyer's hypothesis revisited. Prog Brain Res 135:237-51

Mathern GW, Babb TL, Leite JP, Pretorius K, Yeoman KM, Kuhlman PA. 1996. The pathogenic and progressive features of chronic human hippocampal epilepsy. Epilepsy Res 26:151-61

Mathern GW, Pretorius JK, Babb TL. 1995. Influence of the type of initial precipitating injury and at what age it occurs on course and outcome in patients with temporal lobe seizures. J Neurosurg 82:220-7

McNamara JO. 1994. Cellular and molecular basis of epilepsy. J Neurosci 14:3413-25

Mello LE, Cavalheiro EA, Tan AM, Kupfer WR, Pretorius JK, et al. 1993. Circuit mechanisms of seizures in the pilocarpine model of chronic epilepsy: cell loss and mossy fiber sprouting. Epilepsia 34:985-95

Meng Y, Zhang Y, Tregoubov V, Falls DL, Jia Z. 2003. Regulation of spine morphology and synaptic function by LIMK and the actin cytoskeleton. Rev Neurosci 14:233-40

Meyer A, Falconer MA, Beck E. 1954. Pathological findings in temporal lobe epilepsy. J Neurol Neurosurg Psychiatry 17:276-85

Mikuni N, Babb TL, Chakravarty DN, Chung CK. 1998. Postnatal expressions of nonphosphorylated and phosphorylated neurofilament proteins in the rat hippocampus and the Timm-stained mossy fiber pathway. Brain Res 811:1-9

Mitchison T, Kirschner M. 1988. Cytoskeletal dynamics and nerve growth. Neuron $1: 761-72$ 
Mizoguchi M, Iwaki T, Morioka T, Fukui M, Tateishi J. 1998. Abnormal cytoarchitecture of cortical dysplasia verified by immunohistochemistry. Clin Neuropathol 17:100-9

Monteiro M, Kandratavicius L, Leite J. 2011. Proteínas do citoesqueleto e neuropatologias do sistema nervoso central

Journal of Epilepsy and Clinical Neurophysiology

Moreno H, Choi S, Yu E, Brusco J, Avila J, et al. 2011. Blocking Effects of Human Tau on Squid Giant Synapse Transmission and Its Prevention by T-817 MA. Front Synaptic Neurosci 3:3

Neves G, Cooke SF, Bliss TV. 2008. Synaptic plasticity, memory and the hippocampus: a neural network approach to causality. Nat Rev Neurosci 9:65-75

Ottman R, Lee JH, Risch N, Hauser WA, Susser M. 1996. Clinical indicators of genetic susceptibility to epilepsy. Epilepsia 37:353-61

Palmini A, Gambardella A, Andermann F, Dubeau F, da Costa JC, et al. 1994. Operative strategies for patients with cortical dysplastic lesions and intractable epilepsy. Epilepsia 35 Suppl 6:S57-71

Paxinos G, Watson C. 1986. The rat brain in stereotaxic coordinates. Califórnia

Pitkanen A, Nissinen J, Lukasiuk K, Jutila L, Paljarvi L, et al. 2000a. Association between the density of mossy fiber sprouting and seizure frequency in experimental and human temporal lobe epilepsy. Epilepsia 41 Suppl 6:S24-9

Pitkanen A, Nissinen J, Nairismägi J, Lukasiuk K, Gröhn OH, et al. 2000b. Progression of neuronal damage after status epilepticus and during spontaneous seizures in a rat model of temporal lobe epilepsy. Prog Brain Res 135:67-83

Pollard H, Khrestchatisky M, Moreau J, Ben-Ari Y, Represa A. 1994. Correlation between reactive sprouting and microtubule protein expression in epileptic hippocampus. Neuroscience 61:773-87

Poulain FE, Sobel A. 2010. The microtubule network and neuronal morphogenesis: Dynamic and coordinated orchestration through multiple players. Mol Cell Neurosci 43:15-32

Priel MR, Albuquerque EX. 2002. Short-term effects of pilocarpine on rat hippocampal neurons in culture. Epilepsia 43 Suppl 5:40-6

Quinlan EM, Halpain S. 1996. Emergence of activity-dependent, bidirectional control of microtubule-associated protein MAP2 phosphorylation during postnatal development. J Neurosci 16:7627-37

Racine RJ. 1972. Modification of seizure activity by electrical stimulation. II. Motor seizure. Electroencephalogr Clin Neurophysiol 32:281-94

Sanchez C, Diaz-Nido J, Avila J. 2000. Phosphorylation of microtubule-associated protein 2 (MAP2) and its relevance for the regulation of the neuronal cytoskeleton function. Prog Neurobiol 61:133-68

Sharma N, Kress Y, Shafit-Zagardo B. 1994. Antisense MAP-2 oligonucleotides induce changes in microtubule assembly and neuritic elongation in pre-existing neurites of rat cortical neurons. Cell Motil Cytoskeleton 27:234-47

Sloviter RS, Zappone CA, Harvey BD, Bumanglag AV, Bender RA, Frotscher M. 2003. "Dormant basket cell" hypothesis revisited: relative vulnerabilities of dentate gyrus mossy cells and inhibitory interneurons after hippocampal status epilepticus in the rat. J Comp Neurol 459:44-76

Sutula T, Cascino G, Cavazos J, Parada I, Ramirez L. 1989. Mossy fiber synaptic reorganization in the epileptic human temporal lobe. Ann Neurol 26:321-30 
Tang FR, Loke WK. 2010. Cyto-, axo- and dendro-architectonic changes of neurons in the limbic system in the mouse pilocarpine model of temporal lobe epilepsy. Epilepsy Res 89:43-51

Thom M, Sisodiya SM, Beckett A, Martinian L, Lin WR, et al. 2002. Cytoarchitectural abnormalities in hippocampal sclerosis. J Neuropathol Exp Neurol 61:510-9

Tucker RP. 1990. The roles of microtubule-associated proteins in brain morphogenesis: a review. Brain Res Brain Res Rev 15:101-20

Turski L, Ikonomidou C, Turski WA, Bortolotto ZA, Cavalheiro EA. 1989. Review: cholinergic mechanisms and epileptogenesis. The seizures induced by pilocarpine: a novel experimental model of intractable epilepsy. Synapse 3:15471

Turski WA, Cavalheiro EA, Schwarz M, Czuczwar SJ, Kleinrok Z, Turski L. 1983. Limbic seizures produced by pilocarpine in rats: behavioural, electroencephalographic and neuropathological study. Behav Brain Res 9:31535

Vaidya VA, Terwilliger RZ, Duman RS. 2000. Alterations in heavy and light neurofilament proteins in hippocampus following chronic ECS administration. Synapse 35:137-43

von Campe G, Spencer DD, de Lanerolle NC. 1997. Morphology of dentate granule cells in the human epileptogenic hippocampus. Hippocampus 7:472-88

Watanabe A, Hasegawa M, Suzuki M, Takio K, Morishima-Kawashima M, et al. 1993. In vivo phosphorylation sites in fetal and adult rat tau. $J$ Biol Chem 268:25712-7

Wood JG, Mirra SS, Pollock NJ, Binder LI. 1986. Neurofibrillary tangles of Alzheimer disease share antigenic determinants with the axonal microtubule-associated protein tau (tau). Proc Natl Acad Sci U S A 83:4040-3

Wuarin JP, Dudek FE. 2001. Excitatory synaptic input to granule cells increases with time after kainate treatment. J Neurophysiol 85:1067-77

Yanagihara T, Brengman JM, Mushynski WE. 1990. Differential vulnerability of microtubule components in cerebral ischemia. Acta Neuropathol 80:499-505

Yoshida H, Ihara Y. 1993. Tau in paired helical filaments is functionally distinct from fetal tau: assembly incompetence of paired helical filament-tau. $J$ Neurochem 61:1183-6 


\section{ANEXOS}

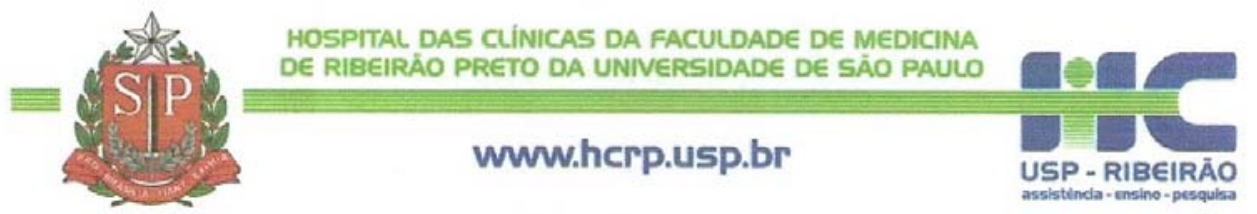

Ribeirão Preto, 06 de outubro de 2010

Oficio $n^{\circ} 3316 / 2010$

$\mathrm{CEP} / \mathrm{MGV}$

Prezados Senhores,

O trabalho intitulado "PADRÕES DE EXPRESSÃO DE PROTEINAS ESTRUTURAIS E PLASTICIDADE NA EPILEPSIA DO LOBO TEMPORAL" foi analisado pelo Comitê de Ética em Pesquisa, em sua $313^{2}$ Reuniāo Ordinária realizada em 04/10/2010 e enquadrado na categoria: APROVADO, bem como o Termo de Consentimento Livre e Esclarecido, de acordo com o Processo HCRP n ${ }^{\circ} 8730 / 2010$.

Este Comitê segue integralmente a Conferência Internacional de Harmonização de Boas Práticas Clinicas (IGH-GCP), bem como a Resoluçāo no 196/96 CNS/ MS.

Lembramos que devem ser apresentados a este CEP, o

Relatório Parcial e o Relatório Final da pesquisa. Atenciosamente.

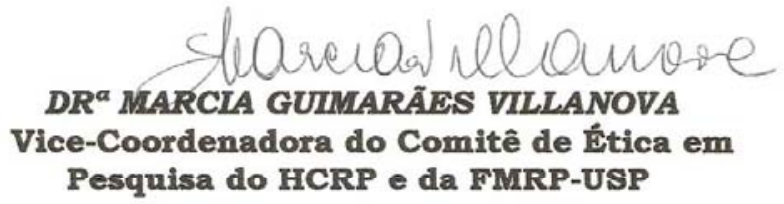

Ilustríssimos Senhores

MARIANA RAQUEL MONTEIRO

PROF. DR. JOĀO PEREIRA LEITE (Orientador)

Depto. de Neurociências e Ciências do Comportamento 


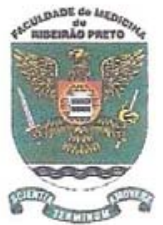

\title{
UNIVERSIDADE DE SÃO PAULO FACULDADE DE MEDICINA DE RIBEIRÃO PRETO \\ - Comissão de Ética em Experimentação Animal -
}

\section{E R T I F I C A D O}

Certificamos que o Protocolo para Uso de Animais em Experimentação $\mathrm{n}^{\circ}$ 093/2008, sobre o projeto intitulado "Padrões de expressão de proteinas estruturais e plasticidade na epilepsia do lobo temporal", sob a responsabilidade do Professor Doutor João Pereira Leite está de acordo com os Princípios Éticos na Experimentação Animal adotado pelo Colégio Brasileiro de Experimentação Animal (COBEA) e foi APROVADO pela COMISSÃO DE ÉTICA EM EXPERIMENTAÇÃO ANIMAL (CETEA) em reunião de 28 de julho de 2008.

(We certify that the protocol $n^{\circ} 093 / 2008$, about "Expression of structural proteins and plasticity in temporal lobe epilepsy", agrees with the ETHICAL PRINCIPLES IN ANIMAL RESEARCH adopted by Brazilian College of Animal Experimentation (COBEA) and was approved by the COLLEGE OF MEDICINE OF RIBEIRÃO PRETO OF THE UNIVERSITY OF SÃO PAULO - ETHICAL COMMISSION OF ETHICS IN ANIMAL RESEARCH (CETEA) in 07/28/2008 meeting).

Ribeirão Preto, 28 de julho de 2008.

\author{
Ederendo poero \\ Prof. Dr. Eduardo Melani Rocha \\ Presidente da Comissão de Ética em \\ Experimentação Animal
}


HOSPITAL DAS CLINICAS DA FACULDADE DE MEDICINA DE RIBEIRÄO PRETO DA UNIVERSIDADE DE SÃO PAULO

CAMPUS UNIVERSITÁRIO - MONTE ALEGRE
FONE: 602-1000 - FAX (016) 633-1144

CEP. $14048-900$

BRASTL

Ribeirão Preto, 19 de agosto de 2005

Oficio $n^{\circ} 2343 / 2005$

CEP/SPC

\section{PROCESSO HCRP n $^{\circ}$ 9370/2003}

Prezado Professor:

A proposta de criação do Banco de Amostras de Tecido Cerebral do Laboratório de Investigação em Epilepsia foi analisada e APROVADA "AD REFERENDUM" em $17 / 08 / 2005$.

Aproveito a oportunidade para apresentar a Vossa Senhoria protestos de estima e consideração.

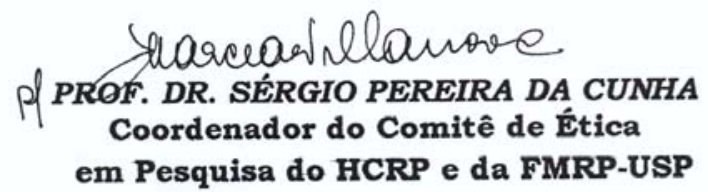

Ilustríssimo Senhor

PROF. DR. JOĀO PEREIRA LEITE

Depto. de Neurologia, Psiquiatria e Psicologia Médica

Em mãos 